
Pedro Vinícius Durães Moura

\title{
Análise do fluxo tridimensional na tubeira de um foguete híbrido durante o processo de ablação
}

\author{
Monografia submetida ao curso de graduação \\ em (Engenharia Aeroespacial) da Universi- \\ dade de Brasília, como requisito parcial para \\ obtenção do Título de Bacharel em (Enge- \\ nharia Aeroespacial).
}

Universidade de Brasília - UnB

Faculdade UnB Gama - FGA

Orientador: Prof. Dr. Domenico Simone

Coorientador: Prof. Dr. Olexiy Shynkarenko

Brasília, DF

2019 
Pedro Vinícius Durães Moura

Análise do fluxo tridimensional na tubeira de um foguete híbrido durante o processo de ablação/ Pedro Vinícius Durães Moura. - Brasília, DF, 2019-

121 p. : il. (algumas color.) ; $30 \mathrm{~cm}$.

Orientador: Prof. Dr. Domenico Simone

Trabalho de Conclusão de Curso - Universidade de Brasília - UnB

Faculdade UnB Gama - FGA , 2019.

1. Palavra-chave01. 2. Palavra-chave02. I. Prof. Dr. Domenico Simone. II. Universidade de Brasília. III. Faculdade UnB Gama. IV. Análise do fluxo tridimensional na tubeira de um foguete híbrido durante o processo de ablação 
Pedro Vinícius Durães Moura

\title{
Análise do fluxo tridimensional na tubeira de um foguete híbrido durante o processo de ablação
}

\author{
Monografia submetida ao curso de graduação \\ em (Engenharia Aeroespacial) da Universi- \\ dade de Brasília, como requisito parcial para \\ obtenção do Título de Bacharel em (Enge- \\ nharia Aeroespacial).
}

Trabalho aprovado. Brasília, DF, 05 de dezembro de 2019:

Prof. Dr. Domenico Simone

Orientador

Prof. Dr. Olexiy Shynkarenko

Coorientador

Prof. Dr. Paolo Gessini

Convidado

Brasília, DF

2019 

Este trabalho é dedicado aos meus pais, meus avós, minha tia e meus amigos

por todo carinho e apoio ao longo desta caminhada 



\section{Agradecimentos}

Agradeço aos meus pais, minha irmã e minha tia que me ajudaram na realização de um sonho. Aos meus amigos e parceiros de pesquisa por toda a ajuda e apoio durante esse período que estive na Universidade. Quero agradecer ao meu professor orientador Dr. Domenico Simone e ao professor coorientador Dr. Olexiy Shynkarenko pela ajuda e empenho dedicado ao meu trabalho e a todos os outros professores que contribuíram para a minha pesquisa. Por fim, obrigado a todos aqueles que de alguma maneira colaboraram para a minha formação acadêmica. 

"Dia a dia, por todos os meios, vou alcançando mais êxito (Napoleon Hill) 



\section{Resumo}

Em foguetes, os materiais ablativos são usados para proteger as paredes superficiais das tubeiras devido às condições térmicas e mecânicas abruptas que ocorrem. As reações químicas que ocorrem na superfície do gás resultam principalmente em reações heterogêneas que consomem o material da superfície. Portanto, um dos principais problemas enfrentados por esses materiais é a erosão, que é a regressão da superfície que afeta seu desempenho e eficiência quando em operação. Sob essa perspectiva, o objetivo deste trabalho é apresentar um modelo analítico para simular o comportamento do processo de erosão por meio de um modelo termoquímico de ablação. Em seguida, o modelo será implementado em uma User Defined Function no Ansys Fluent para simular um caso tridimensional completo da tubeira do foguete SARA e comparar os resultados com os dados experimentais.

Palavras-chaves: materiais ablativos. erosão. modelo termoquímico de ablação. tridimensional. User Defined Function. SARA 



\section{Abstract}

In rockets, the ablative materials are used to protect the surface walls of the nozzles due to the abrupt thermal and mechanical conditions that occur. The chemical reactions occurring at the gas surface inteface result mainly in heterogenous reaction consuming the material of the surface. Therefore, one of the main problems faced by these materials is the erosion, that is the surface regression which affect its performance and efficiency when in operation. Through this perspective, aim of this work is to present an analytical model to simulate the behavior of the erosion process through a thermochemical model of ablation. Then, the model will be implemented in a used defined functions of Ansys Fluent to simulate a full three-dimensional case of the SARA rocket nozzle and comparing results with the experimental data.

Key-words: ablative materials. erosion. thermochemical model of ablation.three dimensional. User Defined Function. SARA 



\section{Lista de ilustrações}

Figura 1 - Modelos de tubeira (Fonte : SHYNKARENKO O.; ANDRIANOV 2015) 29

Figura 2 - Foguete híbrido (Fonte : SHAH 2016) . . . . . . . . . . . . 33

Figura 3 - Fluxo under-over expanded (Fonte : SUTTON 2001) . . . . . . . . 36

Figura 4 - Interação entre a camada limite e a superfície ablativa (Fonte : RUFFIN

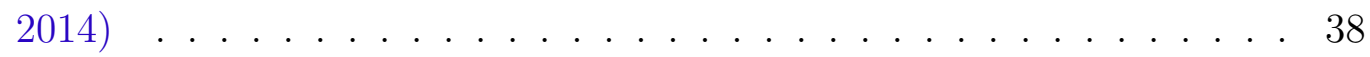

Figura 5 - Foguete SARA (Fonte : SHYNKARENKO O.; ANDRIANOV 2015) 39

Figura 6 - Fluxograma dos modelos de ablação . . . . . . . . . . . . . . 43

Figura 7 - Balanço de energia superficial (Fonte : RUFFIN 2014) . . . . . . . . 46

Figura 8 - Balanço de massa superficial (Fonte : RUFFIN 2014) . . . . . . . . . 51

Figura 9 - Fluxo de massa (Fonte : BIANCHI 2013) . . . . . . . . . . . 53

Figura 10 - Grão propelente do Sara (Fonte : SUTTON 2001) . . . . . . . . . . . . 59

Figura 11 - Tubeira divergente (Fonte : SHYNKARENKO 2015) . . . . . . . . . . 61

Figura 12 - Região da garganta (Fonte : SHYNKARENKO O.; ANDRIANOV 2015) 61

Figura 13 - Modelo da tubeira (Fonte : Elaborada pelo autor) . . . . . . . . . . . 62

Figura 14 - Taxa de erosão do SARA (Fonte : Elaborada pelo autor) . . . . . . . . 68

Figura 15 - Frações de massa das espécies (Fonte : Elaborada pelo autor) . . . . . 69

Figura 16 - Pressão e temperatura da parede (Fonte : Elaborada pelo autor) . . . . 70

Figura 17 - Distribuição de fluxo na parede (Fonte : Elaborada pelo autor) . . . . . 70

Figura 18 - Taxa de erosão para diferentes composições (Fonte : Elaborada pelo

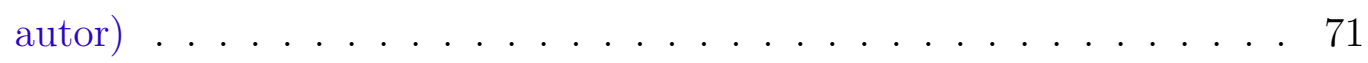

Figura 19 - Temperatura da parede para diferentes composições (Fonte :Elaborada

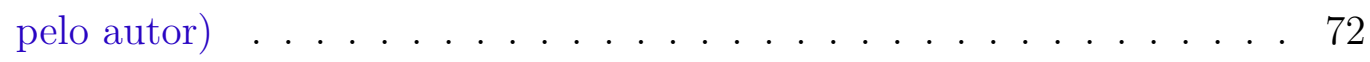

Figura 20 - Razão de equivalência e Temperatura da parede (Fonte : Elaborada pelo autor $\ldots \ldots \ldots . \ldots . \ldots . \ldots 73$

Figura 21 - Frações de massa das espécies oxidantes (Fonte : Elaborada pelo autor) 73

Figura 22 - Visão Geral da Modelagem CFD . . . . . . . . . . . . . . . . 77

Figura 23 - Geometria do SARA (Fonte :Elaborada pelo autor) . . . . . . . . . 79

Figura 24 - Malha do SARA (Fonte :Elaborada pelo autor) . . . . . . . . . . . 80

Figura 25 - Velocidade global $[\mathrm{m} / \mathrm{s}]$ (Fonte : Elaborada pelo autor) . . . . . . . . 88

Figura 26 - Pressão absoluta $[\mathrm{Pa}]$ (Fonte : Elaborada pelo autor) . . . . . . . . . . 88

Figura 27 - Temperatura estática $[\mathrm{K}]$ (Fonte : Elaborada pelo autor) . . . . . . . . 89

Figura $28-Y_{\mathrm{CO}_{2}}$ e $Y_{\mathrm{OH}}$ respectivamente . . . . . . . . . . . . . . 90

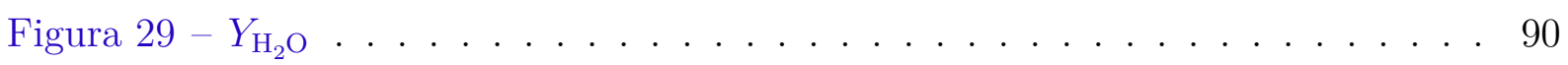


Figura 30 - Coeficiente de transferência de calor $\left[\mathrm{W} / \mathrm{m}^{2} k\right.$ ] (Fonte : Elaborada pelo

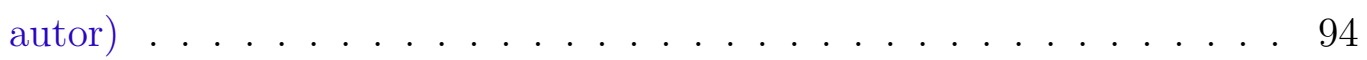

Figura 31 - Coeficiente de transferência de calor ampliado $\left[\mathrm{W} / \mathrm{m}^{2} k\right]$ (Fonte : Elaborada pelo autor $\ldots \ldots \ldots . \ldots . . \ldots 94$

Figura 32 - Gráfico do Coeficiente de transferência de calor (Fonte : Elaborada pelo

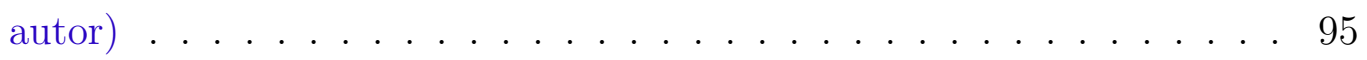

Figura 33 - Taxa de erosão $[\mathrm{m} / \mathrm{s}]$ (Fonte : Elaborada pelo autor) . . . . . . . . . . 96

Figura 34 - Taxa de erosão ampliada $[\mathrm{m} / \mathrm{s}]$ (Fonte : Elaborada pelo autor) . . . . . 97

Figura 35 - Gráfico da taxa de erosão ao longo da posição (Fonte : Elaborada pelo

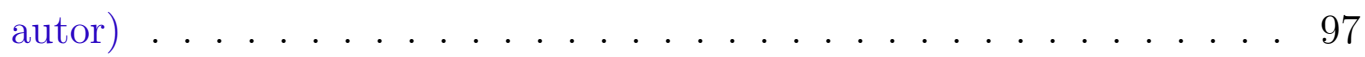

Figura 36 - Resultados calculados e obtidos pela referência (Fonte : Elaborada pelo

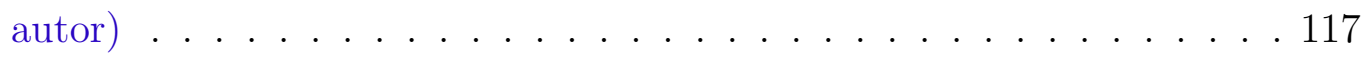

Figura 37 - Temperatura da parede $[\mathrm{K}]$. . . . . . . . . . . . . . . . . . . 119

Figura 38 - Calor específico $[\mathrm{J} / \mathrm{kg}-\mathrm{K}] \ldots \ldots$. . . . . . . . . . . . . . 119

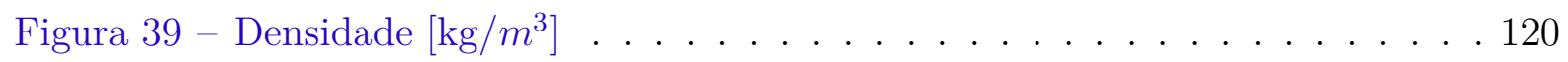

Figura 40 - Número de Pradtl . . . . . . . . . . . . . . . . . . . 120

Figura 41 - Temperatura da parede ao longo do comprimento axial . . . . . . . . . 121

Figura 42 - Número de Mach . . . . . . . . . . . . . . . . . . . . . . 121 


\section{Lista de tabelas}

Tabela 1 - Resultados experimentais . . . . . . . . . . . . 67

Tabela 2 - Frações de massa na Câmara de Combustão . . . . . . . . . . . . . . 67

Tabela 3 - Frações de massa na Câmara de Combustão . . . . . . . . . . . . . . . 81

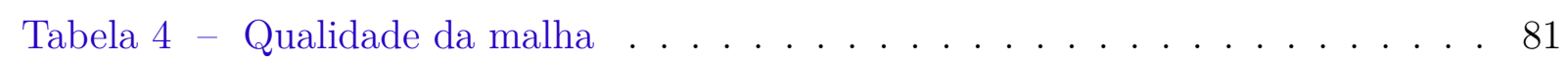

Tabela 5 - Pressure inlet e pressure outlet .............. . . 84

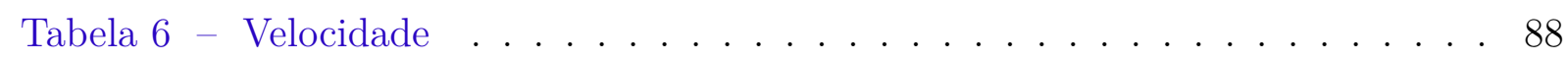

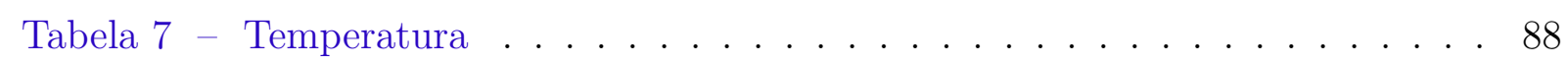

Tabela 8 - Pressão . . . . . . . . . . . . . . . 89

Tabela 9 - Frações de massa do CFD e do CEA . . . . . . . . . . . . . . 89

Tabela 10 - Comparativo entre os HTC . . . . . . . . . . . . . . . . 95

Tabela 11 - Comparativo da taxa de erosão . . . . . . . . . . . . . . . 97

Tabela 12 - Constantes heterogêneas e reações do grafite com $\mathrm{H}_{2} \mathrm{O}, \mathrm{CO}_{2}, \mathrm{OH}, \mathrm{O}$ e $\mathrm{O}_{2} 109$

Tabela 13 - BATES Motor . . . . . . . . . . . . . . 117 



\section{Lista de abreviaturas e siglas}

BATES Ballistic Test and Evaluation System

BES Balanço de energia superficial

BSM Balanço superficial de massa

CEA Chemical Equilibrium and Applications

CFD Computational Fluid Dynamics

CPL Chemical Propulsion Laboratory

HRM Hybrid Rocket Motor

HTC Coeficiente de transferência de calor (Heat Transfer Coefficient)

NASA National Aeronautics and Space Administration

NIST National Institute of Standard and Technology

O/F Razão oxidante/ combustível (Oxidizer-to-fuel mass ratio)

SARA Satélite de Reentrada Atmosférica

TPS Thermal Protection System

UDF User defined functions

UDM User defined memory 



\section{Lista de símbolos}

\section{LATINOS}

A

$C_{H}$

$C_{M}$

$D_{i m}$

$h$

$h_{g} \quad$ Coeficiente de transferência convectivo, $\left(\mathrm{W} / m^{2} \cdot K\right)$

$i$

$k \quad$ Condutividade térmica, $\mathrm{W} / \mathrm{m} \cdot \mathrm{K}$

Le $\quad$ Número de Lewis

$\dot{m}$

$\mathrm{M}$

$\mathrm{p}$

$\operatorname{Pr}$

$\dot{q}$

$\mathrm{R}$

$\dot{s}$

$\mathrm{T}$

$t$

$u$

$X$

$Y$

$y^{+}$
Área da seção transversal, $m^{2}$

Número de Stanton

Coeficiente de transferência de massa

Coeficiente de difusão efetiva, $\mathrm{m}^{2} / \mathrm{s}$

Entalpia, J/Kg

Espécie

Fluxo de massa, $\mathrm{kg} /\left(m^{2} \cdot s\right)$

Massa Molar, kg/mol

Pressão, $\mathrm{N} / m^{2}$

Número de Prandtl

Fluxo de calor, $\mathrm{W} / \mathrm{m}^{2}$

Fator de recuperação

Taxa de erosão, m/s

Temperatura, K

Tempo, s

Velocidade, $\mathrm{m} / \mathrm{s}$

Fração molar

Fração de massa

Distância da parede normalizada 


\section{GREGAS}

$\Delta H_{a b l} \quad$ Calor de ablação, $\mathrm{J} / \mathrm{kg}$

$\Phi \quad$ Razão de equivalência, (em termos de $\mathrm{O} / \mathrm{F}$ )

$\eta \quad$ Direção radial da parede

$\mu \quad$ Viscosidade cinemática, $(\mathrm{kg} / m \cdot s)$

$\rho \quad$ Densidade, $\mathrm{kg} / \mathrm{m}^{3}$

$\gamma \quad$ Coeficiente politrópico, $\left(c_{p} / c_{v}\right)$

$\dot{\omega} \quad$ Termo fonte da espécie, $\mathrm{kg} /\left(\mathrm{m}^{3} \cdot s\right)$ 


\section{Sumário}

Introdução . . . . . . . . . . . . . . . . . 27

0.1 Objetivos Gerais e Específicos . . . . . . . . . . . . . . . 29

$0.1 .1 \quad$ Objetivos Gerais . . . . . . . . . . . . . . . . . . 29

$0.1 .2 \quad$ Objetivos Específicos . . . . . . . . . . . . . . . 29

0.2 Estrutura do trabalho . . . . . . . . . . . . . . 30

0.2 .1 Módulo 1 - Revisão Bibliográfica . . . . . . . . . . . . . . . . . 30

0.2.2 Módulo 2 - Modelo Analítico . . . . . . . . . . . . . . . . . . 30

$0.2 .3 \quad$ Módulo 3 - Modelo Numérico . . . . . . . . . . . . . . . . . 30

I REVISÃO BIBLIOGRÁFICA

FOGUETE HÍBRIDO . . . . . . . . . . . . . . . . . 33

$1.1 \quad$ Conceitos básicos . . . . . . . . . . . . . . . . 33

1.2 Razão Oxidante/Combustível . . . . . . . . . . . . . . . 34

1.3 Configuração da tubeira e condições de contorno . . . . . . . . . 35

1.4 Materiais ablativos . . . . . . . . . . . . . 37

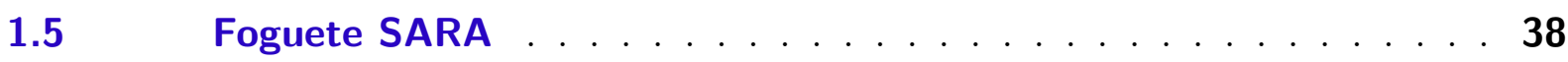

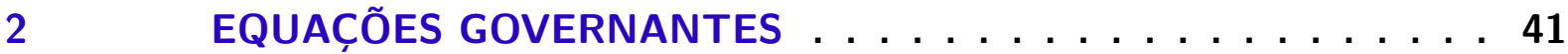

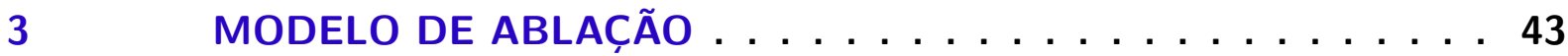

3.1 Propiedades Temoquímicas . . . . . . . . . . . . . . 44

3.1.1 Composição Química - CEA Program . . . . . . . . . . . . . . . . 44

3.1.2 Propriedades Termodinâmicas . . . . . . . . . . . . . . 45

3.2 Balanço de Energia . . . . . . . . . . . . . . 46

3.2.1 Fluxo de calor por condução . . . . . . . . . . . . . . . . . 47

3.2.2 Fluxo de calor convectivo . . . . . . . . . . . . . . 48

3.2.3 Fluxo de calor por radiação . . . . . . . . . . . . . . . . . 49

3.2.4 Fluxo de calor químico . . . . . . . . . . . . . . . . 50

3.3 Balanço de Massa . . . . . . . . . . . . . . . . 50

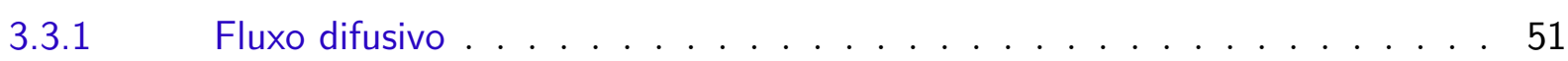

3.3.2 Fluxo devido as reações heterogêneas . . . . . . . . . . . . . . 52

3.3.2.1 Fluxo devido ao efeito de sopro (blowing effect) . . . . . . . . . . . . 54 
PARÂMETROS DO FOGUETE . . . . . . . . . . . 59

$4.1 \quad$ Condições na câmara de combustão . . . . . . . . . . . . 59

$4.1 .1 \quad$ Propelentes . . . . . . . . . . . . . . . . . . . . . 59

$4.1 .2 \quad$ Pressão . . . . . . . . . . . . . . . . . . . 60

$4.2 \quad$ Tubeira . . . . . . . . . . . . . . . . . . .60

5 MODELAGEM DO PROCESSO DE ABLAÇÃO TERMOQUÍMICA 63

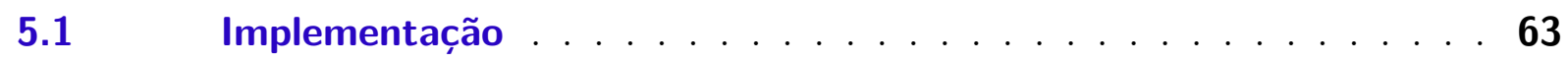

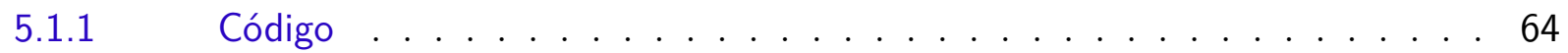

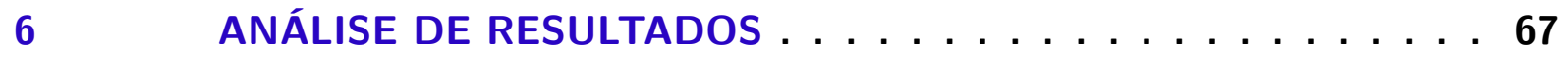

6.1 Efeito razão Oxidante/Combustível . . . . . . . . . . 71

III SIMULAÇÃO TRIDIMENSIONAL $\quad 75$

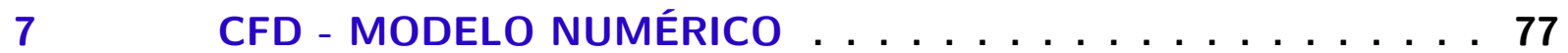

7.1 Metodologia e implementação . . . . . . . . . . . . . 79

$7.1 .1 \quad$ Geometria . . . . . . . . . . . . . . . . . . . . . . 79

$7.1 .2 \quad$ Malha . . . . . . . . . . . . . . . . . . . . . . 79

$7.2 \quad$ Configurações no Fluent . . . . . . . . . . . . . . . . . 82

7.2 .1 Setup . . . . . . . . . . . . . . . . . . 82

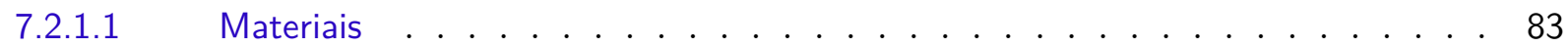

7.2.1.2 Condições de contorno . . . . . . . . . . . . . . . . 83

7.2.1.2.1 Entrada e Saída . . . . . . . . . . . . . . . . . . . . 83

7.2.1.2.2 Reações de Superfície . . . . . . . . . . . . . . . . . . . . . . 84

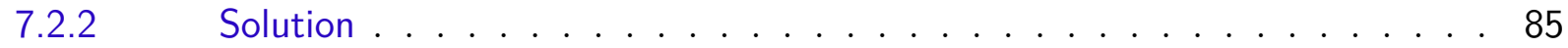

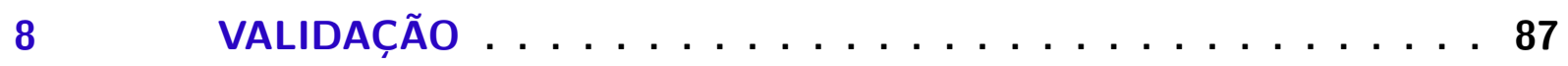

9 USER-DEFINED FUNCTION $\ldots \ldots \ldots \ldots$

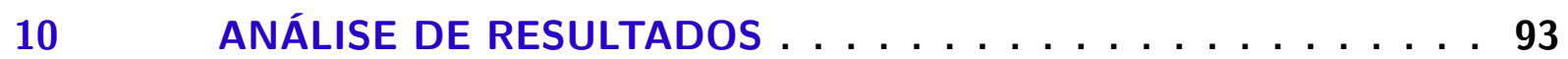

IV CONCLUSÕES $\quad 99$

10.1 Considerações Finais . . . . . . . . . . . . . . . . . 101

10.2 Trabalhos Futuros . . . . . . . . . . . . . . . . . . 101 
APÊNDICE A-PRIMEIRO APÊNDICE . . . . . . . . . 109

APÊNDICE B - SEGUNDO APÊNDICE . . . . . . . . 111

APÊNDICE C - TERCEIRO APÊNDICE . . . . . . . . 113

ANEXOS

115

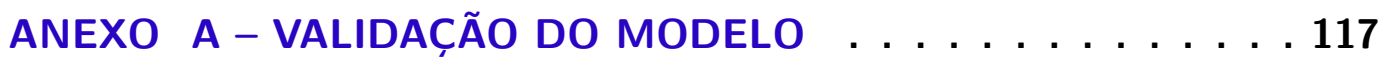

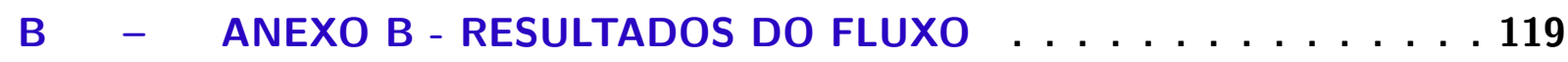





\section{Introdução}

A propulsão híbrida está recebendo cada vez mais atenção da comunidade espacial, pois é capaz de conjugar sua simplicidade operacional e, portanto, garantir a confiabilidade de sistemas de propulsão sólida e a versatilidade e desempenho dos sistemas de propulsão líquida (PANELLI, 2015).

Os foguetes de propelente híbrido apresentam algumas características com relação ao de propelente sólido como: maior flexibilidade do sistema, controle de empuxo, maior impulso específico, segurança devido à separação entre combustível/oxidante e redução dos custos de desenvolvimento e gerenciamento (BIANCHI, 2013). Todos esses parâmetros são fundamentais para avaliar o desempenho de seus componentes. Um dos mais importantes consiste na tubeira do foguete, que têm um efeito de $30 \%$ na capacidade de propulsão dos motores .

A concepção e design da tubeira é fator crucial para a performance de qualquer foguete de propulsão química. Qualquer erosão gradual na região da garganta da tubeira aumenta seu diâmetro em talvez 1 a $6 \%$ durante a operação, reduzindo o impulso e a pressão na câmara de combustão (SUTTON, 2001). De acordo com SUTTON, uma tubeira normalmente perde de 3 a $12 \%$ de sua massa inerte inicial durante a operação.

Com isso surge o termo conhecido como: ablação, bastante comum na concepção de tubeiras. A ablação é usada para proteger peças mecânicas e cargas que seriam danificadas por temperaturas extremamente altas principalmente em situações de reentrada atmosférica (SUTTON, 2001). Para avaliar o comportamento da erosão dos materiais de proteção da tubeira, é necessária uma descrição e modelagem apropriada da interação entre os gases de combustão provenientes de combustíveis híbridos e o seu material de proteção. Com isso, os materiais ablativos são comumente usados para proteger as tubeiras e fornecer o contorno interno para expandir os gases de escape em foguetes sólidos e híbridos. Por causa da interação com o gás quente, esses materiais são quimicamente erodidos durante a queima do foguete, com uma redução de seu desempenho nominal resultante (BIANCHI, 2013).

A erosão é uma consequência direta do fato de que, à medida que ocorre o processo de queima, a parede da tubeira é exposta aos gases de exaustão quentes e sua temperatura superficial aumenta. Em altas temperaturas de superfície, começam a ocorrer reações químicas heterogêneas entre o material da tubeira e as espécies oxidantes presentes nos gases de exaustão, resultando na erosão termoquímica que faz com que a superfície da tubeira retroceda. A situação se torna mais severa na garganta, devido à taxa de transferência de calor maximizada naquela região (KUO, 2012) 
As reações heterogêneas consomem as espécies oxidantes na superfície da tubeira e, assim, criam gradientes de concentração de espécies na camada limite que resultam na difusão de espécies oxidantes para a superfície. Assim, a taxa de erosão dependerá tanto da taxa de difusão de espécies oxidantes através da camada limite quanto da parede e das taxas cinéticas químicas de reação heterogênea na superfície.

De acordo com PANELLI, tanto as configurações das tubeiras de foguete sólidos quanto à de líquidos, devem limitar a taxa de regressão da garganta e a condução de calor em sua superfície, não variando tanto desempenho de empuxo e protegendo a tubeira de distribuições perigosas de temperatura.

Os motores híbridos apresentam uma maior concentração de oxigênio em relação aos demais tipos de motores, fazendo com que a taxa de erosão da garganta seja significativamente maior . Outros processos importantes que influenciam e serão analisados são as taxa de difusão das espécies através da camada limite, injeção de espécies de ablação na camada limite, condução de calor dentro do material da tubeira e propriedades termo físicas variáveis de múltiplas espécies (BIANCHI, 2013). Cada um desses processos tem um efeito importante na taxa de erosão das paredes da tubeira e necessitam de uma investigação de pesquisa.

Neste cenário de utilização de propulsores híbridos, o Chemical Propulsion Laboratory (CPL) da Universidade de Brasília desenvolveu um motor de propelente híbrido para a desaceleração da cápsula SARA operando em um par de propulsores baseado em óxido nitroso e parafina $\left(L N_{2} \mathrm{O} /\right.$ Parafina), com uma classe de empuxo em torno de 1 $\mathrm{kN}$.

O motor de bancada foi dividido em módulos de unidades de montagem. Os materiais estruturais escolhidos devem ser caracterizados pelas seguintes propriedades: resistência à corrosão, retenção de resistência a altas temperaturas, resistência à fadiga, ductilidade e manufaturabilidade (SHYNKARENKO O.; ANDRIANOV, 2015).

Quanto à composição material na parte divergente da tubeira, foram feitos testes parciais com materiais compósitos que mostraram a viabilidade de fabricação com fibra de carbono pré- impregnado e matriz epóxi pelo processo de enrolamento filamentar. O projeto e fabricação com materiais compósitos consistem principalmente no posicionamento adequado das fibras, a fim de obter o melhor aproveitamento de sua resistência à carga esperada na peça ${ }^{1}$. (SHYNKARENKO O.; ANDRIANOV, 2015).

Portanto, para avaliar o comportamento da erosão dos materiais de proteção ${ }^{2}$, é necessária uma descrição e modelagem apropriada da interação entre os gases de combustão provenientes da queima do combustível e oxidante e a parede da tubeira (TURCHI, 2013). Portanto a análise deste trabalho está voltada a caracterização geral das interações

1 A Figura 1 é mostrada o modelo utilizado em teste e que será abordado nesse trabalho

2 Comumente chamado de TPS (Thermal Protection System) 


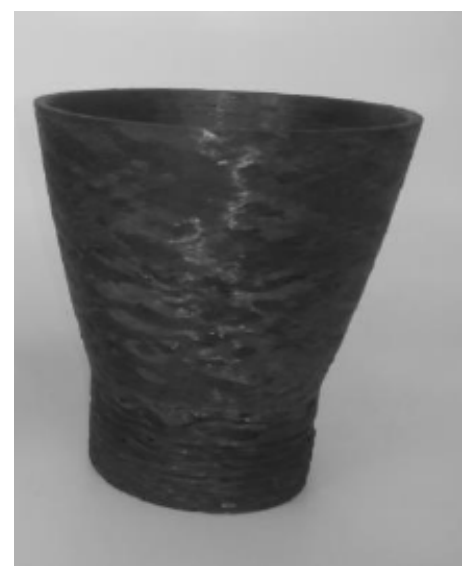

Figura 1 - Modelos de tubeira (Fonte : SHYNKARENKO O.; ANDRIANOV 2015)

que ocorrem entre o material ablativo de carbono e a composição química resultante dos processos de combustão e difusão. O modelo de ablação considerado é baseado na ablação termoquímica pois é concluído que a erosão termoquímica do grafite é a principal razão para a recessão do TPS.

\subsection{Objetivos Gerais e Específicos}

O presente trabalho tem como objetivo o estudo do comportamento erosivo da tubeira de grafite do foguete híbrido SARA em diferentes condições de operações. A seguir serão listados os objetivos gerais e específicos.

\subsubsection{Objetivos Gerais}

- Desenvolver e aplicar um modelo teórico para descrever as complexas interações fluido-superfície que resultam no processo de erosão do SARA mas que pode ser aplicado para qualquer tipo de foguete híbrido.

- Desenvolver um modelo CFD tridimensional para a estimativa da taxa de erosão.

- Analisar o impacto de vários parâmetros que afetam a taxa de erosão, variando a razão de mistura dos propelentes.

- Validar o modelo aplicado com os resultados obtidos dos testes experimentais.

\subsubsection{Objetivos Específicos}

- Revisão bibliográfica química e física do processo de erosão. 
- Desenvolver um código via UDF que levem em consideração as funções necessárias para o modelo de ablação termoquímica que pode ser aplicado para qualquer foguete híbrido ou sólido.

- Determinar as principais espécies oxidantes que contribuem para o aumento da taxa de erosão resultantes das reações de superfície.

- Determinar as distribuições dos diferentes tipos de transferência de energia ao longo da tubeira.

- Determinar se as condições do material ablativo empregadas são suficientes para o funcionamento adequado do foguete.

\subsection{Estrutura do trabalho}

O trabalho será dividido em três grandes módulos.

\subsubsection{Módulo 1 - Revisão Bibliográfica}

Neste módulo serão abordados alguns aspectos teóricos que serão desenvolvidos no decorrer do trabalho para a implementação do modelo de ablação. É apresentado o modelo de reações químicas no estabelecimento das taxas de erosão e transferência de energia na superfície da tubeira.

\subsubsection{Módulo 2 - Modelo Analítico}

Descreve o estudo da erosão do material ablativo no ambiente de operação do motor SARA realizado no teste de bancada. É apresentado o modelo de ablação termoquímica desenvolvido a partir dos conceitos do referencial teórico do Módulo 1.

Com os parâmetros conhecidos do foguete e o método de solução, os gráficos e análise de resultados são apresentados.

\subsubsection{Módulo 3 - Modelo Numérico}

A terceira parte trata da computação completa por meio de uma simulação numérica tridimensional do fluxo de gases na tubeira para prever a sua resposta ablativa. Os resultados do CFD são comparados com a abordagem experimental e analítica utilizada. 


\section{Parte I}

\section{Revisão Bibliográfica}





\section{Foguete Híbrido}

\subsection{Conceitos básicos}

Os sistemas de propulsão em que uma componente do propelente é armazenada na fase sólida, enquanto outra é armazenado na fase líquida ou gasosa são chamados de sistemas de propulsão híbrida. Tais sistemas empregam mais comumente o oxidante como propelente líquido ou gasoso e o combustível como propelente sólido (SUTTON, 2001). Como dito anteriormente, os foguetes híbridos exibem vantagens sobre os foguetes líquidos e sólidos, especialmente em termos de simplicidade, segurança e custo.

Em sua estrutura mais simples, um foguete híbrido consiste de um tanque de oxidante contendo o propelente líquido ou gasoso, válvula para a injeção do oxidante, e uma câmara de combustão contendo o propelente sólido, e uma tubeira para a expansão dos gases de mistura proveniente da câmara ${ }^{1}$.

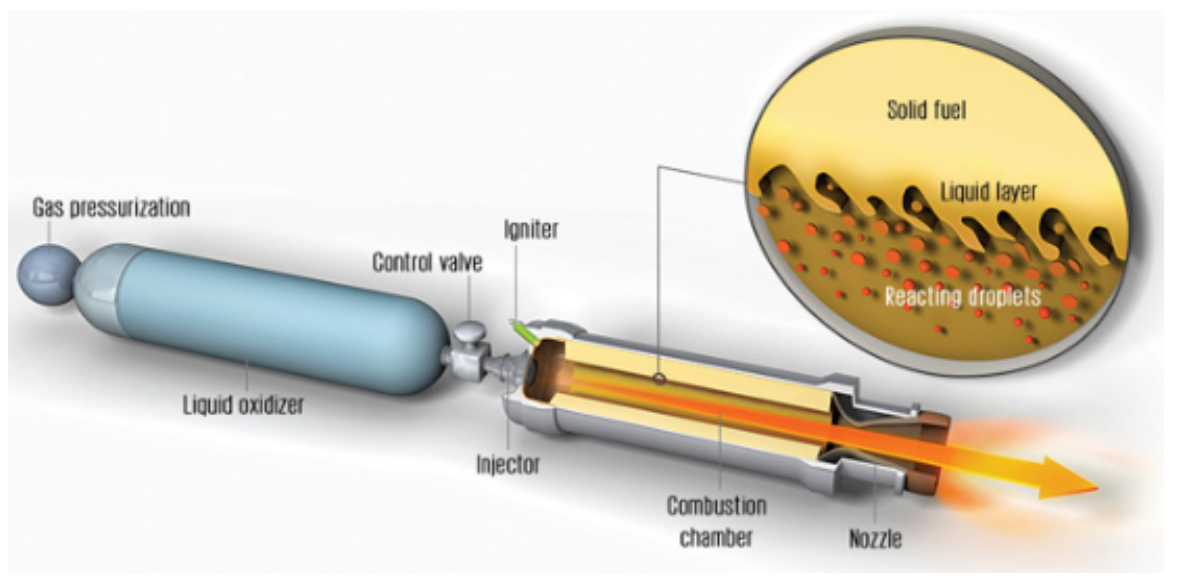

Figura 2 - Foguete híbrido (Fonte : SHAH 2016)

O grão combustível contido dentro da câmara de combustão pode assumir diferentes formas quanto a sua configuração, estando intimamente relacionadas com o tempo de queima, quantidade de gás e curva empuxo no tempo. São usados geralmente os combustíveis como o HTPB, polietileno ou a cera de parafina que permitem incorporar aditivos metálicos de alta energia que aumentam o impulso específico (HOW ..., 2019).

Quando o empuxo é desejado, uma fonte de ignição adequada é introduzida na câmara e uma chama de difusão se forma sobre a superfície adjacente do grão combustível ao longo do comprimento da porta. O mecanismo de reação de um foguete híbrido é realizado na camada limite. O grão de combustível se funde ou se decompõe sob o ca-

$1 \quad$ Na Fig 2 é dado esquemático de um HRM 
lor da chama e os gases produzidos difundem na parede de grãos até a camada limite. No lado do gás as espécies oxidantes se difundem através da camada limite em direção ao combustível. As espécies reagentes se encontram em uma região onde a relação oxidante / combustível local torna a reação possível e origina a chama (SUTTON, 2001). A combustão é sustentada pela transferência de calor da chama para o combustível sólido, causando a vaporização contínua do combustível até que o fluxo do oxidante seja desligado (CANTWELL, 2010). Deve -se atentar que o oxidante e o combustível são incapazes de se misturar rapidamente em um típico motor híbrido de foguete, o que resulta em baixas taxas de queima do propelente, causando uma redução no desempenho (JACOB, 2007).

As vantagens de se utilizar um sistema de propulsão híbrida é que eles são: mecanicamente simples, segurança durante a fabricação, armazenamento ou operação sem qualquer possibilidade de explosão, capacidade de reiniciar ou parar a operação, custo de sistema relativamente baixo, impulsos específicos mais elevados do que os motores de foguetes sólidos e impulso específico de densidade mais elevada do que os motores líquidos (SUTTON, 2001)

\subsection{Razão Oxidante/Combustível}

A seleção adequada da razão oxidante/combustível (O/F) está correlacionada com o empuxo e a mistura de fluxo. Isso é dependente para determinar a velocidade característica do propulsor. Deve-se observar que diferentemente para o que ocorre com outros foguetes, os híbridos variam $\mathrm{O} / \mathrm{F}$ ao longo da câmara de combustão e tubeira e ao longo do tempo quando em operação.

A variação de $\mathrm{O} / \mathrm{F}$ afetará obviamente o desempenho do foguete híbrido. Isso ocorre devido as mudanças na geometria na porta de combustível durante a queima. Durante a operação do foguete, a proporção de oxidante para combustível aumenta, embora a taxa de fluxo de massa do oxidante seja mantida constante, porque o diâmetro da porta aumenta com o tempo. Porém para efeitos de cálculo neste trabalho, consideraremos uma razão de mistura constante ao longo da tubeira em regime permanente (HOW. . , 2019).

Como já dito acima, as mudanças na proporção da mistura durante a queima podem envolver condições ricas em combustível e ricas em oxidante, porém como explicado em BIANCHI (2013), um aumento resultante na relação O / F total leva a um aumento na taxa de erosão da garganta da tubeira. Devido à alta erosão, a superfície da tubeira regride excessivamente, levando a uma perda adicional de impulso específico (CANTWELL, 2010).

Observaremos a frente que uma das característica de operação em híbridos é a maior concentração de produtos de combustão contendo oxigênio do que em relação aos de foguetes sólidos que resulta em uma taxa de erosão maior, pois as espécies oxidantes 
são as principais reagentes para formação de monóxido de carbono (principal causador do processo de erosão).

\subsection{Configuração da tubeira e condições de contorno}

As tubeiras são utilizadas para aumentar a velocidade de exaustão dos gases e consequentemente o empuxo. Elas estão conectadas à extremidade de saída de fluxo do grão de combustível. Estas tubeiras convergem e / ou divergem o fluxo ao longo delas a fim de acelerar o fluxo de massa na saída . Suas relações termodinâmicas dos processos dentro da tubeira e câmara de combustão fornecem as ferramentas matemáticas necessárias para calcular o desempenho e determinar vários dos principais parâmetros de projeto dos sistemas de propulsão de foguetes (SUTTON, 2001).

No processo de expansão em uma tubeira convergente-divergente, uma grande fração da energia térmica dos gases na câmara é convertida em energia cinética, o que resulta em uma queda drástica de pressão e temperatura do gás e a velocidade do gás atingem valores extremamente altos.

É importante notar que os produtos da combustão continuam reagindo quando entram na tubeira. A conversão de energia térmica em cinética causa um efeito de resfriamento dos gases, bem como a queda de pressão, que afeta as taxas de reação de alguns dos produtos de combustão. Além disso, reações químicas entre os constituintes são frequentemente consideradas em equilíbrio, uma forma simplificada para análises, dependendo assim apenas da cinética química e taxas de reação (FAROKHI, 2014).

Devido a presença de uma camada limite viscosa nas paredes, a velocidade dos gases nessa região é muito menor do que no fluxo livre. Pela condição de não deslizamento, a velocidade do fluxo na parede é nula e vai amentando gradualmente até que a condição de fluxo livre seja atingida podendo torna -se turbulento.

Quanto a temperatura, SUTTON explica que a temperatura local em parte da camada limite pode ser substancialmente maior do que a temperatura do que em fluxo livre devido à conversão da energia cinética em energia térmica à medida que a velocidade local é reduzida e como o calor é criado por fricção viscosa. A camada ao lado da parede ficará mais fria por causa da transferência de calor para a parede.

Os cálculos das propriedades físicas e termoquímicas na tubeira serão calculadas com a utilização do programa CEA feito pela NASA que será explicado na seção 3.1.1. Abaixo são considerados algumas simplificações que o software adota de acordo com GORDON; MCBRIDE (1994).

- O fluido é tratado para estar inteiramente no estado gasoso. No caso real, é recorrente que uma pequena parcela do fluido esteja na fase condensada. (SUTTON, 2001) 
enfatiza três casos que podem ocorrer: partículas sólidas do próprio propelente, da combustão que formam fuligem, e gotículas líquidas devido à queda de temperatura estática nos gases.

- O fluxo de massa do propelente é constante

- A velocidade do gás, pressão, temperatura e densidade são uniformes através de qualquer seção normal ao eixo da tubeira.

- Velocidade zero na combustão entrada da câmara, combustão completa e adiabática.

- Expansão isentrópica com mistura homogênea.

- A câmara de combustão possui uma área de seção transversal constante.

- Não há ondas de choque ou descontinuidades no fluxo da tubeira.

O último termo é bastante interessante, pois implica que a pressão ambiente seja igual a pressão de saída da tubeira. SUTTON explica que o comportamento não ideal das tubeiras é fortemente influenciado pela presença de ondas de choque dentro de sua seção divergente que são fortes descontinuidades de compressão e existem apenas no fluxo supersônico. Podem ocorrer com o fluxo de duas maneiras: under-expanded ou over expanded (Figura 3)

Uma tubeira under-expanded, o fluido na saída possui uma pressão maior que a pressão externa porque a área de saída é muito pequena para uma relação de área ideal. A expansão do fluido é, portanto, incompleta dentro da tubeira e deve ocorrer no exterior (SUTTON, 2001).

Para uma tubeira over - expanded o fluido atinge uma pressão de saída menor que a da atmosfera pois tem uma área de saída grande com relação a ideal. Para pressões externas mais altas, a separação do fluxo ocorrerá dentro da parte divergente da tubeira. (SUTTON, 2001).

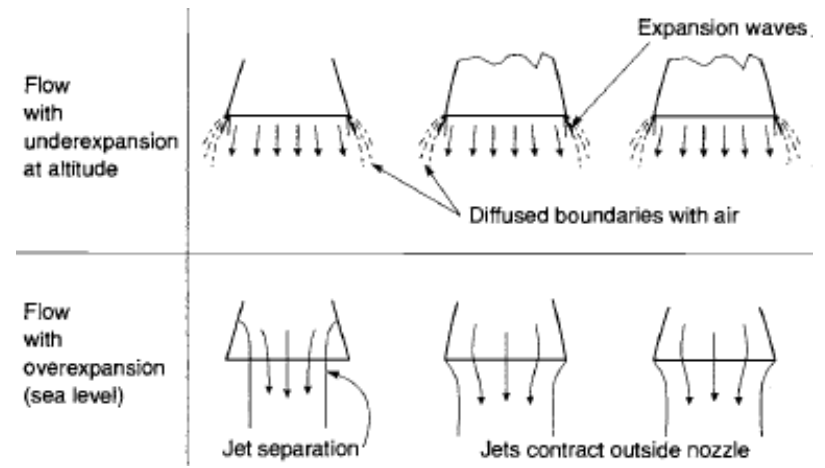

Figura 3 - Fluxo under-over expanded (Fonte : SUTTON 2001) 
Os testes realizados para o foguete SARA são realizados a temperatura atmosférica ambiente local de Brasília de aproximadamente $1 \mathrm{~atm}$, portanto trata -se de um fluxo over - expanded que ocasionará uma onda de choque no interior da tubeira. Sutton afirma que ensaios estáticos ao nível do mar são geralmente evitados devido a separação irregular do fluxo e às cargas potencialmente destrutivas. Tenta -se contornar o problema, utilizando uma tubeira com uma proporção de área muito menor. A exemplo disso temos tubeira do SARA que em condições espaciais operam a uma razão de expansão de 600 e para os testes estáticos foi utilizada uma razão de expansão de 41.75 .

\subsection{Materiais ablativos}

Materiais ablativos são comumente usados para proteger a superfície interna das tubeiras devido as severas condições térmicas e mecânicas sofridas. Ao longo dos anos, vários sistemas TPS foram estudados buscando limitar a taxa de regressão da garganta e a condução sólida. Os compostos de grafite e carbono-carbono que possuem excelentes propriedades são amplamente utilizados como TPS (THAKRE, 2008).

Existem duas categorias de materiais ablativos: carbonizados (charring) e não carbonizados (non-charring). Na carbonização ocorre um processo químico de combustão incompleta em alguns sólidos quando submetidos a altas temperaturas. Nesse processo, é removido o hidrogênio e o oxigênio do sólido de modo que o produto da reação seja um material de carbono preto residual chamado char, que queimam sem a presença de chamas. Madeira e polímero são alguns exemplos de materiais que podem ser carbonizados. (CHARRING, )

A maioria dos materiais ablativos de carbonização são feitas de plástico reforçado. Quando aquecido, estes materiais se decompõem produzindo gases de pirólise que fluem na direção do resíduo carbonáceo formado por ele que se liga ao reforço. As espécies reativas de fluxo livre se difundem através da camada limite e reagem com os gases de carbonização e de pirólise na parede da tubeira. Neste processo, a massa carbonizada é perdida devido à reação química com as espécies reativas (RUFFIN, 2014).

Já nos materiais não carbonizados, nenhuma reação de pirólise ocorre e portanto nenhum char é formado. O que caracteriza esses materiais são reações heterogêneas entre espécies químicas gasosas no propulsor e no material TPS. Os principais materiais utilizados são em geral feitos de carbono. (RUFFIN, 2014) atenta-se que caso tivéssemos uma temperatura na ordem de $4000 \mathrm{~K}$ deveríamos considerar a sublimação no processo de ablação, porém é uma temperatura extremamente alta na parede da tubeira e portanto as reações heterogêneas são a causa principal de contribuição para erosão.

Porém, por conta do ambiente termoquímico severo imposto pelos produtos de combustão que fluem ao longo da tubeira, ocasionará uma erosão indesejável desses ma- 
teriais (THAKRE, 2008). Sutton afirma que a erosão desses materiais é principalmente resultante das reações químicas de superfície heterogêneas envolvendo a reação de carbono com espécies oxidantes presentes no fluxo de gases de combustão como $\mathrm{O}_{2}, \mathrm{O}_{2} \mathrm{H}_{2} \mathrm{O}$, $\mathrm{OH}$ e $\mathrm{CO}_{2}$ para formar o $\mathrm{CO}$. Deve- se atentar que principalmente em motores híbridos, proporções de mistura rica em oxigênio e alta pressão resultará em taxas muito altas de erosão especialmente na garganta. (BIANCHI, 2013)

A figura abaixo demonstra essas interações químicas entre a superfície de ablação e a camada limite dos produtos de combustão. O fluxo de calor que entra na superfície pode ser resultante de dois tipos: convecção e radiação. Além disso, devido à presença de reações químicas na parede, há gradientes de concentração dentro da camada limite. Esses gradientes de concentração geram um fluxo de calor líquido devido à difusão de espécies. Pelo efeito de sopro, a redução do fluxo de calor por convecção é o principal meio para reduzir a energia transmitida à estrutura subjacente. As forças de atrito na parede também podem produzir uma erosão mecânica da superfície.

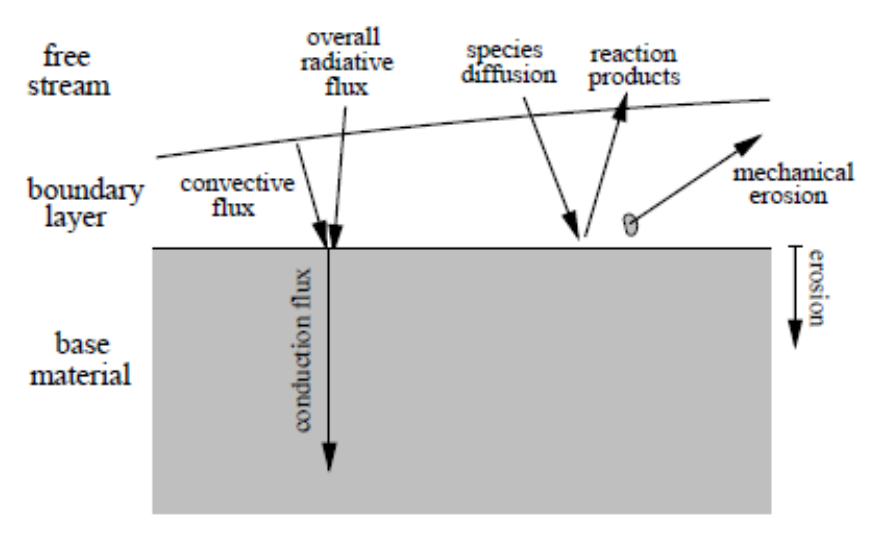

Figura 4 - Interação entre a camada limite e a superfície ablativa (Fonte : RUFFIN 2014)

\subsection{Foguete SARA}

Trata -se de um protótipo de um sistema que atenda os requisitos de indução de reentrada atmosférica da plataforma SARA utilizada para experimentos científicos de baixa gravidade. O SARA era destinado a operar em órbita baixa, circular, a $300 \mathrm{~km}$ de altitude, por um período máximo de 10 dias (IAE..., 2019).

O motor de testes é um modelo de engenharia de foguete híbrido, que opera utilizando o par de propulsores Parafina - Óxido Nitroso (N2O). Nesta fase, o protótipo consiste principalmente da interface mecânica, tanques de oxidação, propulsor, sistema de controle, subsistemas auxiliares e dispositivos de segurança (SHYNKARENKO O.; ANDRIANOV, 2015). 

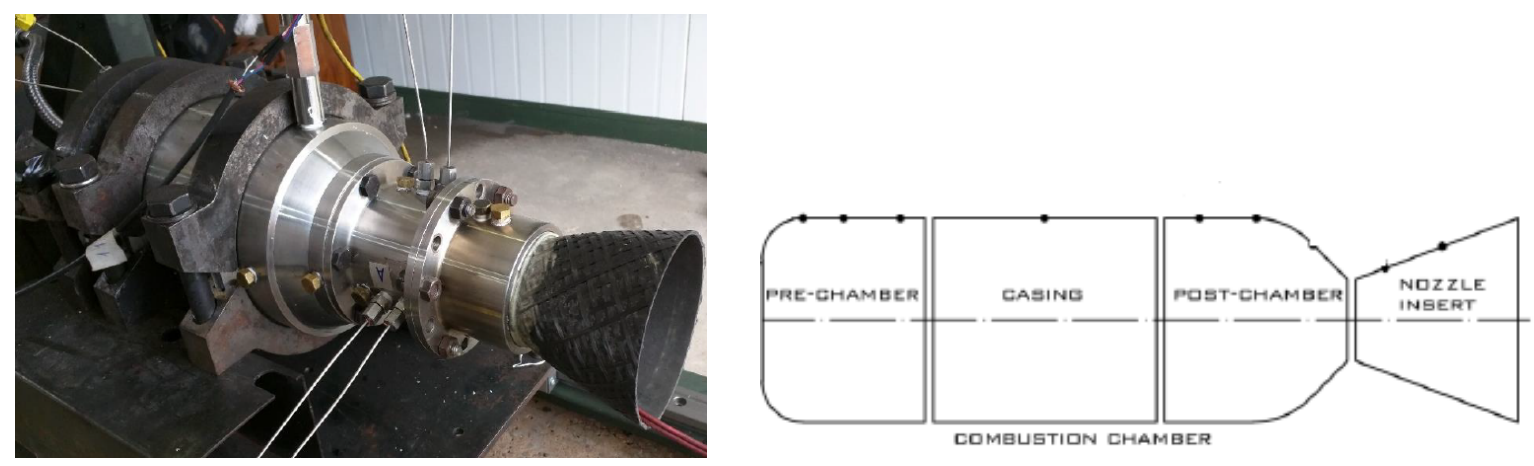

Figura 5 - Foguete SARA (Fonte : SHYNKARENKO O.; ANDRIANOV 2015)

Na figura 5 é explicitada o foguete de teste ${ }^{2}$. Também é dada uma vista simplifica da seção transversal do foguete. Abaixo explicada de forma resumida cada parte do protótipo.

- Tanque de oxidação: Local onde o oxidante é mantido para a injeção na câmara.

- Câmara de pré combustão: : Local onde a mistura da corrente oxidante precisa ser alcançado antes de ser passado sobre o grão de combustível.

- Câmara de combustão : Fornece o local para a combustão dos propelentes e também contém todo o grão de combustível.

- Câmara de pós combustão: : Usadas para permitir uma queima mais completa dos produtos de combustão antes que os produtos de combustão passem pela tubeira.

- Tubeira: Processo de expansão dos gases, onde há uma conversão de energia térmica em cinética. 



\section{Equações Governantes para Fase Gasosa}

A ablação termoquímica é o resultado da reação química entre espécies químicas gasosas no propulsor e no material TPS. A análise detalhada do desempenho de tais materiais TPS deve considerar os balanços de massa e energia de superfície e a modelagem de ablação. Para obter uma melhor avaliação do campo de fluxo de ablação, os mecanismos de troca de massa e energia devem ser modelados com precisão usando as informações das equações de Navier-Stokes.

A fase gasosa consiste nos produtos de combustão provenientes das reações ocorridas entre os combustível e o oxidante. Como já dito anteriormente, as equações governantes para a fase gasosa serão as de Navier- Stokes com média ponderada de Reynolds de acordo com (GORDON; MCBRIDE, 1994). Podemos utilizar a equação de transporte geral dada em (MARTELLI, 2006) para uma espécie qualquer que pode se especializar para dar origem à equação de continuidade, quantidade de movimento e energia.

$$
\begin{gathered}
\frac{\partial\left(\rho y_{i}\right)}{\partial t}+\nabla \cdot\left(\rho \mathbf{v} y_{i}\right)+\nabla \cdot \mathbf{j}_{\mathbf{i}}=\dot{\omega}_{i} \\
\frac{\partial \rho}{\partial t}+\nabla \cdot(\rho \mathbf{v})=0 \\
\frac{\partial(\rho \mathbf{v})}{\partial t}+\nabla \cdot(\rho \mathbf{v v})-\nabla \cdot S=0 \\
\frac{\partial\left(\rho e_{0}\right)}{\partial t}+\nabla \cdot\left(\rho e_{0} \mathbf{v}\right)=\nabla \cdot(\mathbf{v} \cdot S)-\nabla \cdot \dot{\mathbf{q}}
\end{gathered}
$$

Para descrever um estado em equilíbrio não químico, é necessário conhecer duas variáveis de estado, concentrações de espécies $\mathrm{N}$ e o campo de velocidade. As equações 2.1, 2.2, 2.3 e 2.4 formam um conjunto completo para a solução do sistema, uma vez que a velocidade de difusão, a tensão viscosa, o fluxo de calor e o termo $\dot{\omega}$ estão relacionados ao estado termodinâmico e ao vetor velocidade por relações constitutivas (MARTELLI, 2006). Consideraremos que cada mistura se comportará como gás termicamente perfeito devido as fracas interações intermoleculares.

O termo $S$ representa o tensor de tensão dividido na contribuição de forças de pressão e aquelas devidos a tensões viscosas T que é dado pela equação abaixo.

$$
S=-p \mathbf{I}+\mathbf{T}
$$


No que diz respeito ao tratamento de tensões viscosas, consideraremos que o fluxo exista uma relação linear entre o tensão e a taxa de deformação (fluido newtoniano). Portanto a tensão viscosa é dado (MARTELLI, 2006):

$$
T=-\frac{2}{3} \mu(\nabla \cdot \mathbf{v}) \mathbf{I}+\mu\left[\nabla \mathbf{v}+(\nabla \mathbf{v})^{T}\right]
$$

Para misturas de gases em equilíbrio térmico, O termo v é o vetor de fluxo de calor expresso considerando a contribuição dada pelo gradiente de temperatura, através do coeficiente de condutividade térmica $k$ (lei de Fourier) e a contribuição dada pelas velocidades de difusão das espécies.

$$
\mathbf{q}=-k \nabla T+\sum_{i=1}^{N} p_{i} h_{i} \mathbf{V}_{\mathbf{i}}
$$

O fluxo de massa difusional da iésima espécie $\mathbf{j}_{i}$ é expresso usando a aproximação da lei de Fick:

$$
\mathbf{j}_{i}=\rho_{i} \mathbf{V}_{i}=-\rho D_{i m} \nabla Y_{i}
$$

Todas essas relações serão utilizadas para desenvolver um conjunto de equações necessárias para obter uma solução de resposta de material de ablação com interações de material de camada limite na superfície de ablação (BIANCHI, 2006).

Como veremos adiante, o comportamento e equacionamento da fase gasosa estará acoplado ao CEA program ${ }^{1}$ para o calculo de composições de equilíbrio químico e propriedades de misturas complexas. 


\section{Modelo de Ablação}

Um dos principais problemas enfrentados de materiais TPS é a erosão ou regressão na tubeira do foguete. O que acontece é que na queima, a tubeira exposta aos produtos de combustão forma uma camada limite turbulenta sobre a superfície do TPS transferindo energia e aumentando a sua reatividade. Em altas temperaturas ocorrem reações químicas heterogêneas com as espécies oxidantes (principalmente $\mathrm{H}_{2} \mathrm{O}, \mathrm{CO}_{2}, \mathrm{OH}, \mathrm{O}$ e $\mathrm{O}_{2}$ ) que formam posteriormente o monóxido de carbono resultando na erosão termoquímica. De acordo com THAKRE (2008) e KUO (2012) os principais contribuintes para a erosão são a geometria, pressão e as espécies $\mathrm{H}_{2} \mathrm{O}$ e $\mathrm{CO}_{2}$.

Como dito anteriormente, devido a ablação termoquímica entre a interface gássuperfície, a tubeira regride pela perda material especialmente na região da garganta, com isso o desempenho do foguete em geral diminui. Experimentos mostram que a erosão causa uma redução da pressão na câmara, caso não houvesse erosão, a pressão da câmara seria relativamente constante o que seria benéfico para um impulso específico mais alto (KUO, 2012). Portanto prever essa redução de desempenho em teste estáticos em muitos casos é inviável financeiramente e portanto, estabelecer um modelo que possa prever com precisão as taxas de regressão ou erosão é fundamental para a construção de um foguete.

Os modelos de ablações utilizados na maioria das vezes consistem na solução de um conjunto de equações compostas por um balanço de massa para cada espécie oxidante e uma equação de balanço de energia. A implementação destes modelos requer o conhecimento das reações de superfícies, de suas taxas de reações e propriedades termodinâmicas. O modelo é simplificado nas seguintes etapas (DELENEY, 1964):

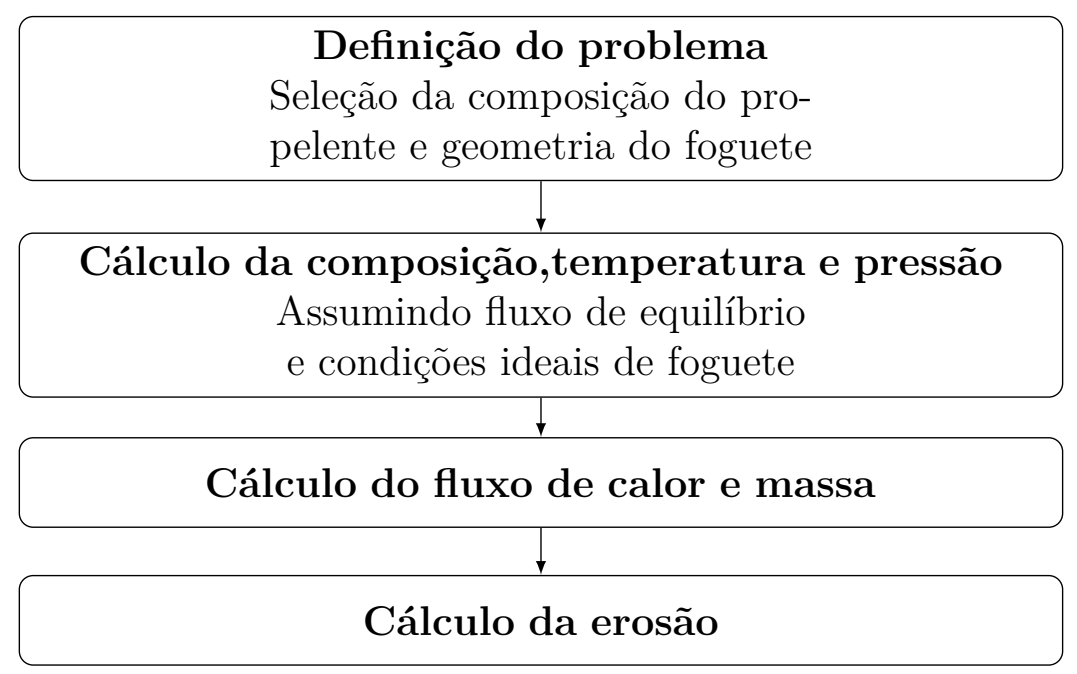

Figura 6 - Fluxograma dos modelos de ablação 
Existem dois tipos de modelo de ablação: o de equilíbrio e o de não-equilíbrio.

O modelo de ablação termoquímica de equilíbrio são os mais comuns, pois não requerem informações sobre a cinética de reações na superfície, mas apenas a sua composição de equilíbrio. Existem alguns softwares que já utilizam esse modelo (RUFFIN, 2014).

O modelo de ablação termoquímica de não equilíbrio são mais complexos e requerem informações detalhadas sobre a cinética química. Mas é um modelo que pode ser simplificado caso use materiais de superfície não carbonizados. Como a tubeira de teste do SARA é feita de compósito de carbono, é usado o modelo de ablação de não equilíbrio para materiais não carbonizados descrito de acordo com BIANCHI(2013) e RUFFIN (2014).

\subsection{Propiedades Temoquímicas}

Conhecer as composições de equilíbrio químico de um sistema permitem calcular propriedades termodinâmicas para o sistema. Essas propriedades podem ser aplicadas a uma ampla variedade de problemas de engenharia e são fundamentais no modelo de ablação termoquímica para posterior verificação do comportamento do material de proteção térmica.

\subsubsection{Composição Química - CEA Program}

Para a modelagem de ablação, os valores mais importantes são a temperatura e a composição química da câmara de combustão. Com isso, o programa CEA desenvolvido pela NASA ${ }^{1}$ foi usado para obter a temperatura da câmara de combustão e a fração molar ou de massa das espécies presentes no fluxo.

As frações de massa e molar representam uma proporção da massa da espécie oxidante com a massa total da mistura, ou o número de mol da espécie com o número de mol da mistura, respectivamente. A relação entre fração de massa $Y_{i}$ e a fração molar $X_{i}$ de uma espécie oxidante $i$ é dado por:

$$
Y_{i}=X_{i} \cdot \frac{M_{i}}{\sum_{i} X_{i} M_{i}}
$$

onde $M_{i}$ é a massa molar da espécie $i$.

Já a câmara de combustão permite a avaliação dos efeitos individuais das espécies oxidantes contidas nos produtos de combustão através da variação dos fluxo mássico dos reagentes.

$\overline{1}$ O programa é descrito em (GORDON; MCBRIDE, 1994) 
As entradas requeridas pelo programa CEA são:

- Propelentes utilizados

- Pressão da câmara de combustão

- Razão oxidante combustível $(\mathrm{O} / \mathrm{F})$ ou razão de equivalência $(\Phi)$

- Razão de expansão ou relação entre a pressão da câmara de combustão e pressão da seção de saída.

A razão $O / F$ não é constante ao longo do tempo de operação do motor, ocorrem momentos que a proporção da mistura durante a queima seja ora rica em combustível ora rica em oxidante. Os experimentos realizados por BIANCHI 2013 mostraram que a taxa de erosão na tubeira é levemente afetada por condições ricas em oxidante, enquanto é fortemente reduzida para condições ricas em combustível. O Sara por se tratar de uma operação com $\Phi$ alto, o que é caracterizado por uma taxa de mistura rica em combustível, tende a gerar taxas de erosão de baixa rotação.

O último tópico é necessário apenas se a opção de área finita para câmara de combustão for escolhida. Mas na análise do presente trabalho isso geralmente não ocorre pois será utilizada a opção de área infinita para câmara.

Com as entradas dadas, um procedimento iterativo é aplicado para obter a temperatura na qual o valor de entalpia dos gases corresponde à entalpia dos reagentes. Se o fluxo for considerado quimicamente congelado (frozen), a composição química permanecerá a mesma através da tubeira. Com o CEA, é possível considerar um fluxo de equilíbrio químico. Assim, a temperatura de equilíbrio e a composição química são calculadas automaticamente nas seções de garganta e saída (GORDON; MCBRIDE, 1994).

\subsubsection{Propriedades Termodinâmicas}

Os produtos de combustão gerado pelos propelentes podem ser considerados em situação de equilíbrio químico composto de $\mathrm{CO}, \mathrm{CO}_{2}, \mathrm{H}, \mathrm{H}_{2}, \mathrm{H}_{2} \mathrm{O}, \mathrm{NO}, \mathrm{N}_{2}, \mathrm{O}, \mathrm{OH}$ e $\mathrm{O}_{2}$ que constituem cerca de $99.8 \%$ da massa total dos gases de exaustão.

O programa CEA oferece uma opção para calcular viscosidades de mistura e calor específico. O calor específico é uma propriedade importante que expressa o comportamento de uma substância quando exposta a uma fonte de calor. O calor específico do propelente pode ser dado:

$$
c_{p}=\sum_{i} Y_{i} c_{p, i}
$$


Onde é o produto Y da fração de massa da espécie considerada pelo calor específico da espécie. O calor específico da espécie $c_{p, i}$ é obtido através de uma função de interpolação (Eq.3.3) descrita na referência (NIST..., 2011).

$$
c_{p, i}=A+B \cdot t+C \cdot t^{2} / 2+D \cdot t^{3} / 3+E / t^{2} \quad \text { onde } \mathrm{t}=\mathrm{T} / 1000
$$

Encontrar os termos $c_{p, i}$ serão extremamente importante para o cálculo de fluxo de calor químico dos gases com a superfície de ablação. A viscosidade também pode ser dada para cada molécula, porém para efeito de cálculo apenas a viscosidade da mistura é necessária e portanto usa -se o que é fornecido no CEA.

\subsection{Balanço de Energia}

O balanço de energia para o problema de ablação é considerado o fluxo de calor entrando e saindo de uma superfície de controle fixada à superfície de ablação. A taxa de variação de energia com o tempo em um volume de controle, é igual a diferença do fluxo de calor que entra com o que sai $\left(E_{\text {in }}-E_{\text {out }}=\frac{d E}{d t}\right)$ (ÇENGEL, 2013). A figura 7 mostra o equilíbrio entre o fluxos de calor no volume de controle.

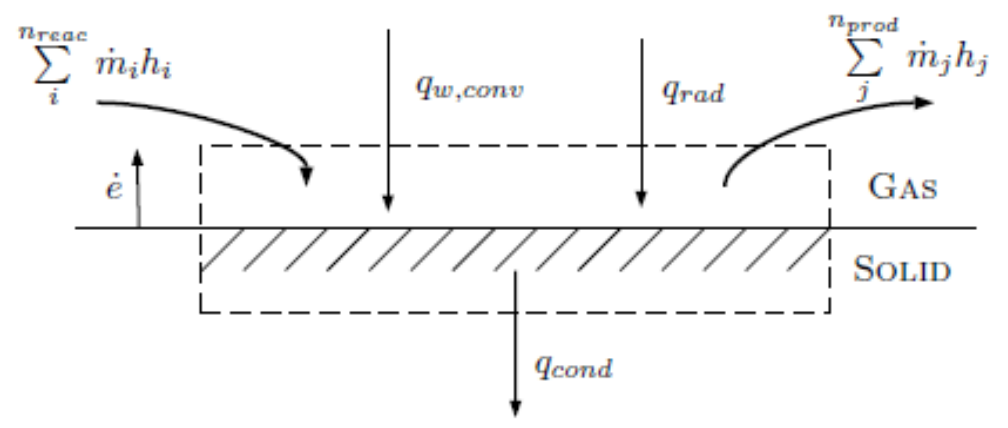

Figura 7 - Balanço de energia superficial (Fonte : RUFFIN 2014)

Consideramos o problema em regime permanente e a taxa de transferência de calor positiva quando adicionada ao sistema. Com isso o balanço de energia resulta em:

$$
q_{w, \text { conv }}+q_{\text {rad }}=q_{\text {cond }}+q_{q u i m}
$$

A equação 3.4 é o balanço de energia superficial (BES) que compreendem interações de energia que atravessam um volume de controle em um sistema e representam a energia ganha ou perdida de um sistema durante o processo (ÇENGEL, 2013). Aqui consideraremos um volume de controle móvel na parede da tubeira que se desloca a medida em que ela é regredida. Os termos do lado esquerdo representam o fluxo de calor 
convectivo na parede e a radiação que é a soma do calor dos gases de combustão e o fluxo emitido da parede. Os termos do lado direito são o fluxo de calor que entram na superfície devido à condução dos gases e o fluxo de energia que entra na superfície devido à erosão na parede respectivamente.

\subsubsection{Fluxo de calor por condução}

A análise do processo de transferência de calor por condução é um fator importante na análise de regressão da superfície da tubeira. Consideraremos a condução de calor como sendo unidimensional (1D) e estável na direção radial da tubeira. Segundo BIANCHI 2013, embora gradientes de temperatura existam ao longo da direção axial da parede da tubeira, eles são geralmente de uma ordem de grandeza menor quando comparados na direção normal a parede. Portanto para os cálculos de transferência de calor foi considerada apenas a condução na direção radial.

Em um sistema de coordenadas local móvel ligado à superfície que sofre regressão, a distribuição de temperatura a uma dada distância $r$ da superfície é governada pela seguinte equação:

$$
\rho_{s} \frac{\partial h_{s}}{\partial t}=\frac{1}{A} \frac{\partial}{\partial \eta}\left(k_{s} A \frac{\partial T_{s}}{\partial \eta}\right)-\rho_{s} \dot{s} \frac{\partial h_{s}}{\partial \eta}
$$

Os termos da equação representam, da esquerda para a direita, o acúmulo de energia sensível, a condução líquida e a energia líquida convectadas como consequência do movimento coordenado. O calor específico e a condutividade térmica dos materiais podem apresentar variação significativa na faixa de temperatura em que eles normalmente operam e, portanto, na Eq. 3.5, eles podem variar com a temperatura (BIANCHI, 2013).

Assumindo uma condição adiabática para o último termo, condição de estado estacionário $\left(\frac{\partial}{\partial t}=0\right)$ e seção transversal constante pois a transferência de calor ocorre de maneira rápida especialmente na garganta, podemos obter uma solução fechada para o fluxo de calor por condução integrando a Eq. 3.5 entre a interface superfície da tubeira - gás e parede externa da tubeira. temos que o fluxo de calor por condução na parede resulta em (RUFFIN, 2014):

$$
q_{\text {con }}=-k \frac{\partial T}{\partial \eta}=\rho c_{p} \dot{s}\left(T_{w}-T_{o}\right)=\dot{m} c_{p s}\left(T_{w}-T_{o}\right)
$$

Onde $T_{0}$ é a temperatura inicial antes da ignição. Portanto o fluxo de condução é simplesmente o fluxo de massa do material ablativo dado pela soma dos fluxos de massa de cada espécie, multiplicado pela mudança de entalpia na parede.

É importante notar que as propriedades do material na tubeira são avaliadas como funções da temperatura local. Assim, a temperatura instantânea da superfície e a taxa 
de erosão são determinadas pelo acoplamento da equação transiente de condução de calor para a tubeira de grafite com as equações de Navier-Stokes para a vazão de gás de combustão na tubeira.

\subsubsection{Fluxo de calor convectivo}

Os principais modos de transferência de calor para as paredes da tubeira são por convecção e a radiação. Esses fluxos podem atingir valores extremamente altos para o material de superfície especialmente na região da garganta, daí a importância de prever esses parâmetros afim de dimensionar o sistema de proteção térmica.

Dentre os dois tipos de fluxo citado acima (conveccção e radiação), o fluxo por convecção é dominante e a radiação tende a ser importante apenas para fluxos carregados de partículas de foguetes propelentes sólidos. No fluxo de calor por convecção, a energia é transferida por um fluido em movimento e é geralmente dominante em líquidos e gases. O calor sempre fluirá do corpo quente para o corpo frio até que o equilíbrio térmico seja atingido.

Os parâmetros que influenciam o fluxo por convecção são (TRANSFERÊNCIA. . , )$:$

- Propriedades do fluido: massa específica, viscosidade, condutividade térmica e calor específico.

- Propriedades do escoamento: velocidade (laminar, turbulento) e temperatura

- Escoamento externo, interno e rugosidade da superfície

As equações da camada limite 2D compressível sobre a transferência de calor da parede a partir de semelhanças da camada limite turbulenta é dada na figura abaixo. $\mathrm{O}$ perfil de temperatura é semelhante ao perfil de velocidade.

O fluxo de calor por convecção na parede é dado pelo pela lei do resfriamento de Newton (RUFFIN, 2014):

$$
q_{c o v, w}=h_{g}\left(T_{a w}-T_{w}\right)
$$

Onde:

- $h_{g}$ : coeficiente de transferência de calor convectivo

- $T_{a w}$ : temperatura adiabática da parede

- $T_{w}$ : temperatura da parede 
BARTZ 1957 propôs uma estimativa preliminar rápida dos coeficientes de transferência convectivo na tubeiras de foguetes

$$
h_{g}=\left[\frac{0.026}{D^{*}}\left(\frac{\mu^{0.2} c_{p}}{P r^{0.6}}\right)\left(\frac{p_{e} g}{C^{*}}\right)^{0.8}\left(\frac{D^{*}}{r_{c}}\right)^{0.1}\right]\left(\frac{A^{*}}{A}\right)^{0.9} \sigma
$$

onde:

- $D^{*}$ : diâmetro da garganta

- $C^{*}$ : velocidade característica obtida através da seguinte expressão $\frac{P_{o} A^{*}}{\rho u A}$

- $r_{c}$ : raio de curvatura da garganta

- $A^{*}$ : área da seção da garganta

- $A$ : área transversal da seção analisada

O número de Prandtl é calculado usando a Equação 3.9 .

$$
\operatorname{Pr}=\frac{4 \gamma}{9 \gamma-5}
$$

O termo $\sigma$ é um fator de correção que normalmente próximo da unidade mas é dado como:

$$
\sigma=\left(\frac{\rho_{r e f}}{\rho}\right)^{0.8}\left(\frac{\mu_{r e f}}{\mu}\right) 0.2
$$

Observa - se que quando empregado um diâmetro da garganta pequeno, o fluxo de calor é maior. O fluxo de calor convectivo será máximo na garganta, essa consideração é importante para análise térmica da estrutura da garganta (BARTZ, 1957).

A temperatura adiabática da parede é dada pela seguinte expressão:

$$
T_{a w}=T_{e}+R\left(T^{o}-T_{e}\right)=T_{e}+R \frac{u_{e}^{2}}{2 c_{p}}
$$

onde $T^{o}$ é a temperatura de estagnação.

\subsubsection{Fluxo de calor por radiação}

O componente radiativo é a soma do fluxo do gás quente e a energia irradiada de volta da parede. Em $\mathrm{HRM}^{2}$, a emissividade do gás de escape pode variar significativamente. Como a emissividade da proteção térmica é alta e constante, o fluxo de calor 
irradiado depende mais da geometria da tubeira e da tendência da temperatura da parede (BIANCHI, 2013).. Mesmo se a emissividade de gás for alta, o fluxo de calor radiativo relativo é geralmente pequeno comparado ao calor convectivo, pelo menos na tubeira, portanto, pode ser negligenciado (KUO, 2012).

Como uma avaliação do fluxo de calor radiativo geral não é simples e sua contribuição é apenas uma fração do fluxo de calor convectivo, sua avaliação é geralmente considerada uma etapa avançada no projeto do tubeiras. Assim, neste trabalho, um único fluxo de calor convectivo é avaliado.

\subsubsection{Fluxo de calor químico}

As reações químicas são acompanhadas por transferências de energia. O fluxo de calor químico é a diferença de energia química total no volume de controle, essa energia é conhecida como calor de ablação, pois é o calor proveniente dos fenômenos de ablação.

O fluxo de calor é a diferença de entalpia entre os produtos gasosos das reações heterogêneas superficiais e a entalpia do material ablativo da tubeira. Este termo é frequentemente referido ao calor químico fluxo (BIANCHI, 2013).

$$
q_{q u i m}=\sum_{i} \dot{\omega}_{i} \cdot h_{i_{w}}-\dot{m} \cdot h_{s}
$$

\subsection{Balanço de Massa}

Considere a Fig 8 onde fluxos de elementos químicos estão entrando e deixando uma superfície de controle fixada à superfície de ablação e assumindo que nenhum material está sendo removido com os fluxos de massa entrando e saindo da superfície. O material da superfície da tubeira pode ser visualizado como se a superfície estivesse a uma taxa de $\dot{s}=\dot{m} / \rho_{c}$. O balanço de massa superficial (BMS) para cada espécie podem ser escritos como (BIANCHI, 2013; KUO, 2012):

$$
\left.\rho D_{i m} \frac{\partial y_{i}}{\partial \eta}\right|_{w}=\dot{\omega}_{i}+(\rho \nu)_{w} Y_{w_{i}}
$$

O termo do lado esquerdo descrevem, os fluxos de massa das espécies que entram na superfície devido à difusão da taxa de produção de espécies na fase gasosa $i$ na superfície da tubeira. Os termos do lado direito descrevem as reações heterogêneas entra a camada limite de gases e o carbono na superfície, e o fluxo de massa de espécies que deixa a superfície devido o processo erosão na parede . 


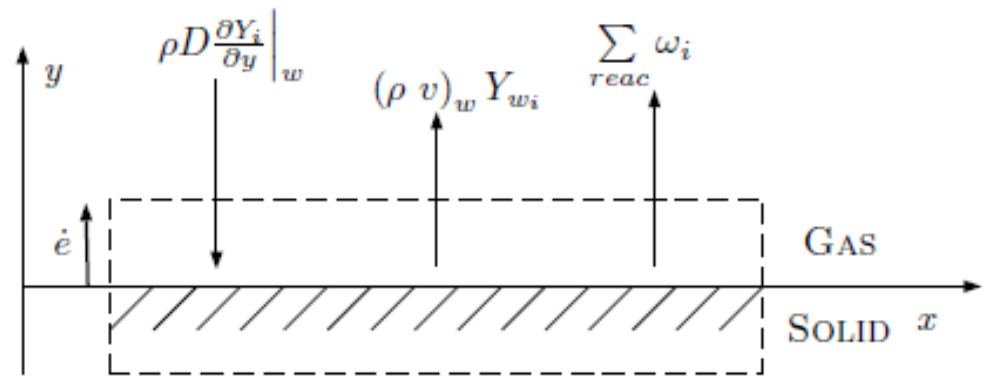

Figura 8 - Balanço de massa superficial (Fonte : RUFFIN 2014)

\subsubsection{Fluxo difusivo}

Os fluxos de difusão são determinados como fluxos relativos de diferentes componentes em uma mistura. O processo de difusão na camada limite regula a quantidade de reagente que atingem o material TPS. O primeiro termo da Eq. 3.13 contemplam esse fluxo difusivo que vai de regiões de alta concentração para regiões de baixa de concentração proporcional a um gradiente de concentração.

O fluxo de massa de difusão no volume de controle é dado pela Lei de Fick:

$$
\dot{m}_{d i f}=\rho D_{i} \frac{\partial Y_{i}}{\partial y}
$$

Onde $D_{i}$ é o coeficiente de difusão de espécies. A Eq. 3.14 também pode ser escrita como:

$$
\dot{m}_{d i f}=\rho u_{e} C_{M}\left(Y_{e_{i}}-Y_{w_{i}}\right)
$$

Onde $C_{M}$ é o coeficiente de transferência de massa, $Y_{e}$ e $Y_{w}$ é a concentração da espécie oxidante no fluxo livre e próximo a parede respectivamente. $C_{M}$ é proporcional ao produto do número Lewis com o número de Stanton. KUO (2012) supõem que o numero Le em seus modelos de ablação é próximo da unidade.

$$
C_{M}=L e^{\frac{2}{3}} \cdot C_{H}
$$

O número de Stanton $C_{H}$ é um número adimensional que relaciona o coeficiente de transferência de calor para a capacidade de calor de um fluido por unidade de área de seção transversal por unidade de tempo.

$$
C_{H}=\frac{h_{g}}{\dot{m} c_{p}}=\frac{h_{g}}{u_{e} \rho c_{p}}
$$




\subsubsection{Fluxo devido as reações heterogêneas}

No processo de combustão ocorrem reações químicas durante a qual um combustível é oxidado e uma grande quantidade de energia é liberada. Em um processo que envolve combustão, novos componentes são criados e outros são destruídos, portanto é importante levar em conta a energia necessária para criar novos produtos ou destruir esses componentes.

Para o equilíbrio durante uma reação, há uma conservação de massa e número de átomos, mas não uma conservação do número total de moles. Consideraremos uma combustão completa de $\mathrm{H}_{2} \mathrm{O}$ e $\mathrm{CO}_{2}$ para produtos de combustão da parafina (hidrocarboneto). Já para a combustão incompleta, resultará em produtos que contém $\mathrm{H}_{2}, \mathrm{CO}, \mathrm{C}$ e $\mathrm{OH}$. As causas da combustão incompleta são geralmente oxigênio ou mistura insuficiente (SATYAJIT, 2014).

Como já dito anteriormente, as reações químicas heterogêneas ocorrem entre o material da tubeira e as espécies oxidantes como $\mathrm{H}_{2} \mathrm{O}, \mathrm{OH}, \mathrm{CO}_{2}, \mathrm{O}, \mathrm{O}_{2}$ no fluxo de combustão que formam produtos como o monóxido de carbono $(\mathrm{CO})$ que causam a erosão química e consequentemente faz com a superfície da tubeira retroceda. Para THAKRE, um aumento de área da garganta de mais de $5 \%$ é geralmente inaceitável para a maioria das aplicações de foguetes sólidos e híbridos.

O material da tubeira do foguete híbrido testado no presente estudo é o grafite, que apresenta alta resistência e baixa densidade. As reações químicas heterogêneas da superfície do gás são descritas por um mecanismo de reação heterogêneo semi global para a oxidação de grafite, consistindo de cinco reações que formam primariamente monóxido de carbono (BIANCHI, 2013). . O termo semi global implica que, enquanto múltiplas reações são consideradas para a oxidação de grafite, cada reação é considerada independente e não afeta as reações entre grafite e outras espécies gasosas (KUO, 2012).

$$
\begin{gathered}
\mathrm{C}_{\mathrm{s}}+\mathrm{H}_{2} \mathrm{O} \rightarrow \mathrm{CO}+\mathrm{H}_{2} \\
\mathrm{C}_{\mathrm{s}}+\mathrm{CO}_{2} \rightarrow 2 \mathrm{CO} \\
\mathrm{C}_{\mathrm{s}}+\mathrm{OH} \rightarrow \mathrm{CO}+\mathrm{H} \\
\mathrm{C}_{\mathrm{s}}+\mathrm{O} \rightarrow \mathrm{CO} \\
\mathrm{C}_{\mathrm{s}}+\frac{1}{2} \mathrm{O}_{2} \rightarrow \mathrm{CO}
\end{gathered}
$$


A taxa de consumo de grafite por uma espécie oxidante $i$, ou seja sua contribuição por erosão é expresso por $\dot{m}_{i}$. O cálculo $\dot{m}_{i}$ para cada espécie encontra - se no Apêndice A.

A taxa de erosão do carbono devido as reações heterogêneas de superfície é dado pela soma de todos as taxas de consumo de cada espécie:

$$
\dot{m}=\dot{m}_{\mathrm{H}_{2} \mathrm{O}}+\dot{m}_{\mathrm{CO}_{2}}+\dot{m}_{\mathrm{OH}}+\dot{m}_{\mathrm{O}}+\dot{m}_{\mathrm{O}_{2}}=\rho_{s} \dot{s}
$$

Na Fig. 12 é mostrada um exemplo do comportamento da superfície de reação para as cinco espécies à uma pressão de $1 \mathrm{~atm}$. A taxa de produção de espécies genéricas na fase gasosa i na superfície do tubeira $\dot{w}_{i}$ na Eq. 3.13 pode ser derivada da taxa de erosão do carbono pelas espécies oxidantes e o balanço de massa disponível uma vez conhecidos os pesos moleculares da espécie e a estequiometria das reações de superfície. O cálculo de $\dot{w}_{i}$ é dado no Apêndice B.

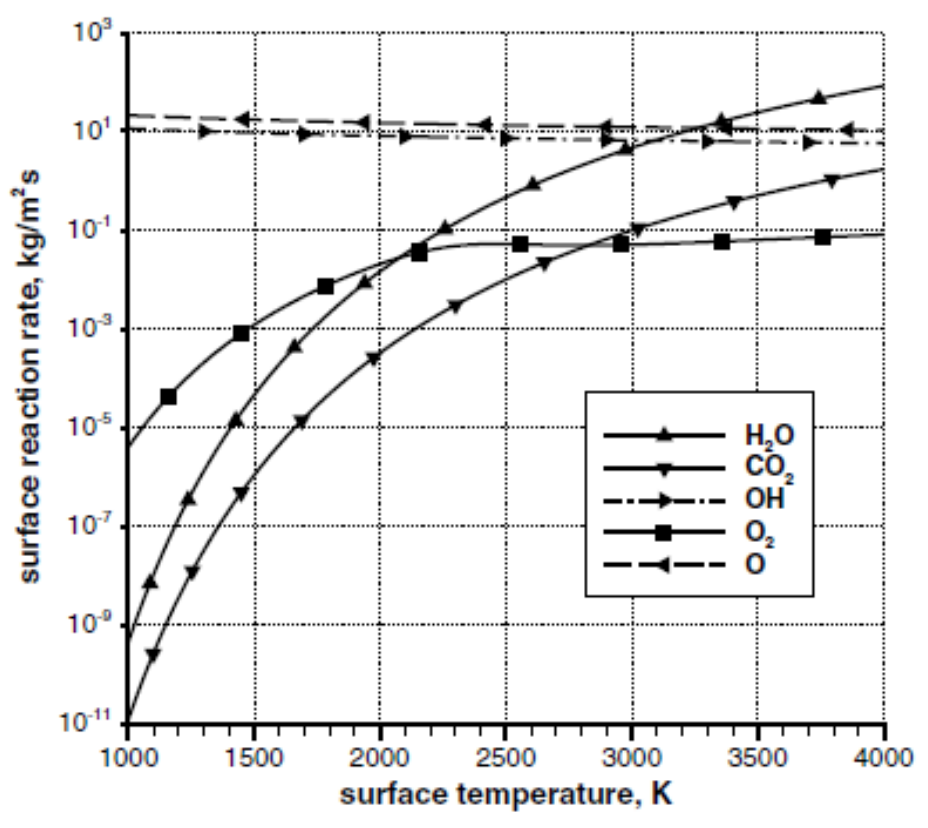

Figura 9 - Fluxo de massa (Fonte : BIANCHI 2013)

Observa-se pelas equações 3.18 a 3.22 que um mol de carbono é consumido com um mol de $\mathrm{H}_{2} \mathrm{O}, \mathrm{OH}, \mathrm{O}$ ou $\mathrm{CO}_{2}$, portanto a contribuição da taxa de erosão dessas espécies podem ser obtida pelo balanço de massa considerando que cada espécies oxidantes é completamente consumida na superfície expressada pela equação abaixo (BIANCHI, 2009):

$$
\dot{s}_{i}=\frac{1}{\rho_{s}} \frac{W_{s}}{W_{i}}\left(\left.\rho D_{i m} \frac{\partial y_{i}}{\partial \eta}\right|_{w}\right)
$$


Observa-se que quanto maior a fração de massa e o peso molecular da espécie oxidante, maior a taxa de erosão dessa espécie.

Reações heterogêneas consomem as espécies oxidantes na superfície da tubeira e, assim, criam gradientes de concentração de espécies na camada limite que resultam na difusão de espécies oxidantes para a superfície da tubeira. Assim, a taxa de erosão dependerá tanto da taxa de difusão de espécies oxidantes através da camada limite quanto da parede e das taxas cinéticas químicas de reação heterogênea na superfície. O processo de taxa mais baixa controla a taxa da erosão geral da tubeira: se as taxas cinéticas forem muito mais altas do que as taxas de difusão, a taxa de recessão é governada pelo mecanismo de difusão das espécies oxidantes. Por outro lado, se houver altas taxas de difusão e baixas taxas cinéticas, a recessão será determinada pela cinética (TURCHI, 2013),(BIANCHI, 2013).

Para propelentes não-metalizados, a taxa de recessão é ditada pela cinética química heterogênea porque a temperatura da superfície da tubeira é relativamente baixa, cerca de 2800 K. Para propelentes metalizados, o processo é controlado por difusão devido uma temperatura da superfície alta (maior que $2800 \mathrm{~K}$ )(THAKRE, 2008).

\subsubsection{Fluxo devido ao efeito de sopro (blowing effect)}

O efeito blowing é causado pela recessão da superfície. Assumindo que material de base se transforma em produtos de reação gasosos, de tal modo que não ocorre erosão mecânica, este termo $\rho \nu$ torna-se $\rho \dot{s}$ o que também é igual ao fluxo de massa do material do carbono $m_{c}$. Portanto o último termo da eq 3.13 torna-se:

$$
(\rho \nu)_{w} Y_{w_{i}}=(\rho \dot{s}) Y_{w_{i}}
$$

As equações de balanço de massa e energia podem ser rearranjadas e expressadas por meio do calor de ablação que representa a energia absorvida ou liberada pelas reações de superfície por unidade de massa do material consumido (BIANCHI, 2013).

$$
\Delta H_{a b l a}=\sum_{i}\left(\frac{\dot{\omega}_{i}}{\dot{m}}\right) \cdot h_{i_{w}}-h_{s}
$$

A taxa de produção / consumo das espécies genéricas da fase gasosa i na superfície da tubeira $\dot{\omega}_{i}$ na Eqs. 3.4 e 3.13 pode ser estimada com base no material da tubeira e a composição do gás de combustão. Ou seja, pode ser facilmente derivada da taxa de erosão do carbono pelas espécies oxidantes genéricas e o balanço de massa disponível uma vez conhecidos os pesos moleculares da espécie e a estequiometria das reações de superfície. 
A equação é fornecida abaixo:

$$
\dot{s}=\dot{s}_{\mathrm{H}_{2} \mathrm{O}}+\dot{s}_{\mathrm{CO}_{2}}+\dot{s}_{\mathrm{OH}}+\dot{s}_{\mathrm{O}}+\dot{s}_{\mathrm{O}_{2}}
$$



Parte II

Modelo Analítico 



\section{Parâmetros do Foguete}

Os testes estáticos foram realizados pelo CPL da Universidade de Brasília. Para realização dos testes, os motores são colocados em uma bancada fixa que permite o movimento horizontal do motor na direção de uma célula de carga para medição da força de empuxo. A temperatura é medida por sensores fixados sobre o motor. Abaixo temos alguns parâmetros do foguete.

\subsection{Condições na câmara de combustão}

Como já citado no capítulo anterior, o cálculo das concentrações de produtos de equilíbrio químico decorrentes da combustão dos propelentes serão fornecidos com base no programa CEA. Com isso podem ser determinados as propriedades de transporte e termodinâmica dos produtos de mistura.

\subsubsection{Propelentes}

O formato do grão da parafina no Sara é o cilíndrico com uma porta. A configuração de uma porta foi selecionada para simplificar o processo de design, pois além de ser simples é mais eficiente para câmara de combustão de pequenas dimensões (SHYNKARENKO O.; ANDRIANOV, 2015). O formato do núcleo influencia profundamente a forma do perfil de tempo e empuxo. Abaixo temos a curva para o formato de grão utilizado no Sara.

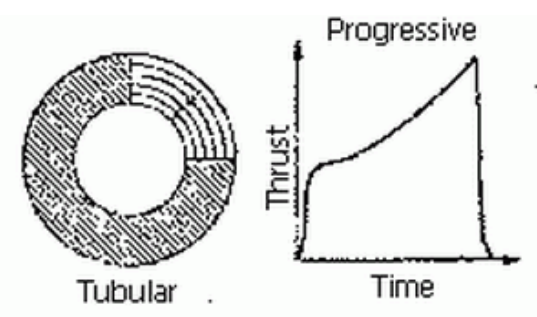

Figura 10 - Grão propelente do Sara (Fonte : SUTTON 2001)

O oxidante injetado na câmara de combustão é o óxido nitroso. Trata-se de um oxidante de fácil manuseio, límpido e incolor. À temperatura ambiente, o Óxido Nitroso é estável e inerte. Pode queimar a temperaturas superiores a $650^{\circ} \mathrm{C}$. Foi assumido uma razão $\mathrm{O} / \mathrm{F}=5.5^{1}$.

1 Informações fornecidas por um dos integrantes do CPL e acordada com outros integrantes. 


\subsubsection{Pressão}

A instabilidade de combustão em teste estáticos devido ao sistema de alimentação de oxidante e retenção de chama faz com que haja uma oscilação mais atenuante na curva pressão por tempo do que os foguete sólidos e líquidos. Nos testes experimentais e nas simulações foram assumidos uma pressão média efetiva de 30 bar.

\subsection{Tubeira}

Por se tratar de um motor híbrido que será exigido principalmente na reentrada atmosférica, a tubeira será submetida à uma pressão interna, força axial, erosão e altas temperaturas. Como já dito anteriormente, testes parciais mostraram a viabilidade de fabricar a tubeira com fibra de carbono pré-impregnado e matriz epóxi pelo processo de enrolamento filamentar (SHYNKARENKO, 2015)

A geometria inicial da tubeira utilizada nos testes experimentais do CPL é ilustrada na figura 13. O diâmetro da garganta é de 15,6 mm, com uma seção convergente assemelhada a uma curva parabólica e curva da seção divergente definida pela equação abaixo (SHYNKARENKO, 2015):

$$
y=17.9+0.480329 x-0.00226208 x^{2}+5.5731 \cdot 10^{-6} x^{3}
$$

Onde x é o comprimento e y é raio correspondente da seção transversal.

A parte divergente é facilmente encaixada na carcaça da tubeira (Fig 11) devido à superfície externa cilíndrica. Sua posição axial é ajustável devido à conexão roscada que é útil para a troca e utilização de várias tubeiras. A tubeira é isolada termicamente pelo composto laminado Celeron fabricado por tecido de algodão e prensagem a alta temperatura. A principal função do Celeron é prevenir que a superfície das paredes internas alcancem temperaturas que possam ser prejudicar a integridade estrutural e funcional do foguete.

O comprimento da parede é importante porque afeta a espessura da camada limite e, portanto, a taxa de transferência de calor e massa . A espessura indicada pela equação abaixo também foi determinada com uma análise estrutural.

$$
t=\frac{120}{d} \cdot 0.46
$$

Onde t é a espessura, d é o diâmetro, $120 \mathrm{~mm}$ é o diâmetro externo e 0,46 é a espessura de uma camada dupla (SHYNKARENKO, 2015).

Na parte do estrangulamento (região da garganta) foi utilizado as seguintes medições mostradas na Fig 12: 


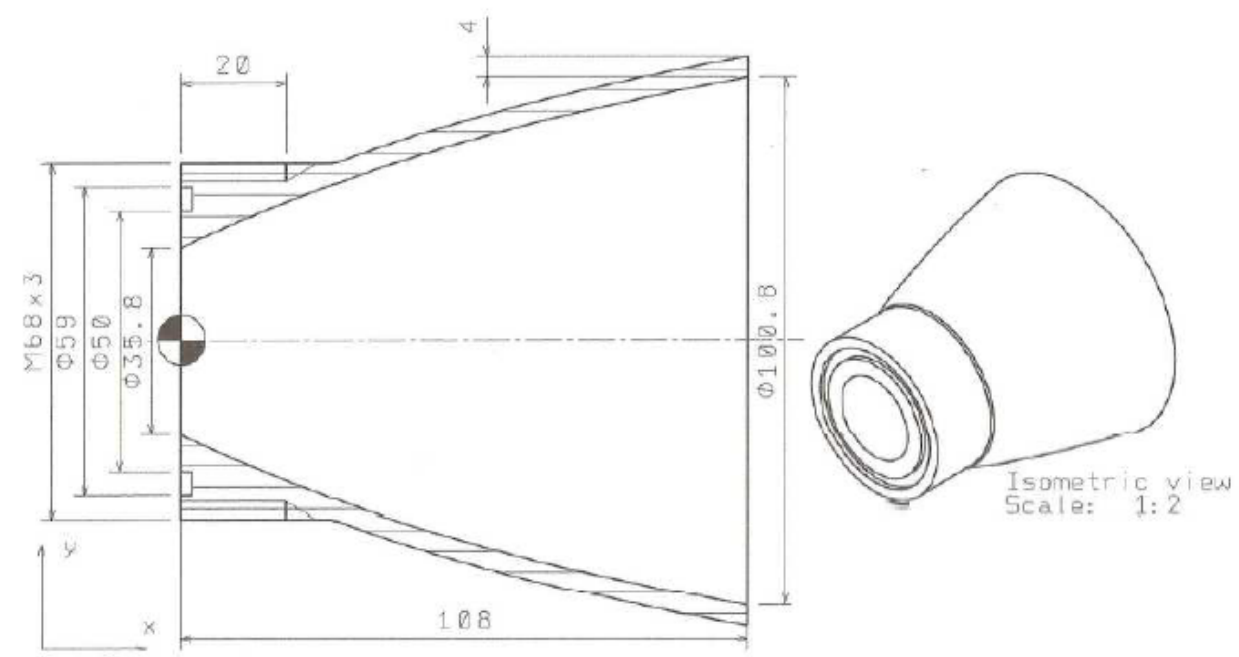

Figura 11 - Tubeira divergente (Fonte : SHYNKARENKO 2015)

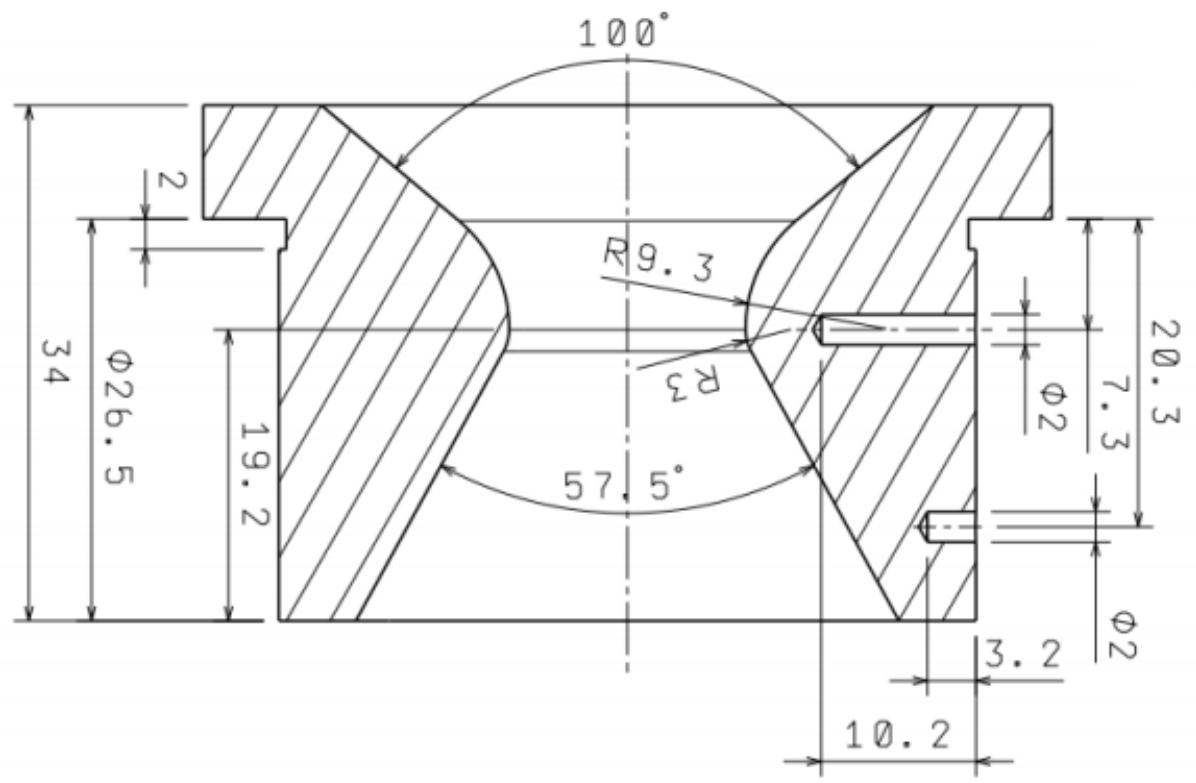

Figura 12 - Região da garganta (Fonte : SHYNKARENKO O.; ANDRIANOV 2015)

Com relação ao material, foi utilizado o grafite na garganta por ser considerado um material ablativo de alto desempenho e o compósito de carbono na seção divergente. Suas propriedades termodinâmicas são retiradas de (GORDON; MCBRIDE, 1994).

Abaixo temos uma vista longitudinal da tubeira completa (todas as unidades estão em $\mathrm{mm})$. 


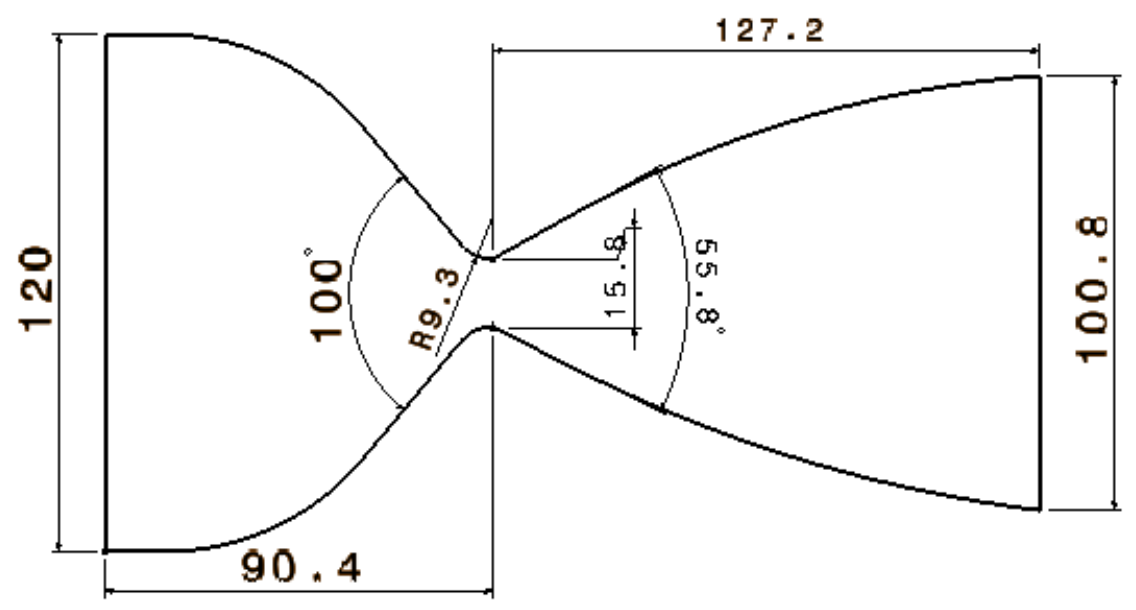

Figura 13 - Modelo da tubeira (Fonte : Elaborada pelo autor)

Abaixo estão resumidas as informações que foram utilizadas no modelo analítico e nas simulações:

- Oxidante: Óxido nitroso

- Combustível: Parafina

- Pressão tanque de combustível: 50,5 bar

- Pressão na câmara: 30 bar

- Comprimento do grão: $207 \mathrm{~mm}$

- Diâmetro da porta de combustão: $34 \mathrm{~mm}$

- Tempo de operação: $41 \mathrm{~s}$

- Vazão mássica do oxidante: $414,4 \mathrm{~g} / \mathrm{s}$

- Taxa de regressão do combustível: $0.9518 \mathrm{~mm} / \mathrm{s}$

- Densidade do combustível: $950 \mathrm{~kg} / \mathrm{m}^{3}$

- $\mathrm{O} / \mathrm{F}: 5.5$

- Diâmetro entrada da tubeira: $120 \mathrm{~mm}$

- Diâmetro de saída da tubeira: $108 \mathrm{~mm}$

- Diâmetro de garganta da tubeira: $15.7 \mathrm{~mm}$

- Temperatura ambiente antes da ignição : $298.15 \mathrm{~K}$ 


\section{Modelagem do Processo de Ablação Ter- moquímica}

Neste capítulo é apresentado o modelo analítico no Matlab para simular o comportamento do processo de erosão do foguete SARA especificado no capítulo anterior.

Existem na literatura diversos modelos para prever os fenômenos de ablação. Alguns métodos levam em consideração diversos fatores em sua composição mas ao mesmo tempo se tornam bastante complexos, outros são mais robustos porém podem ocorrer algumas divergências com o valor real (RUFFIN, 2014). Utilizaremos o modelo de ablação termoquímica que consiste na solução de um conjunto de equações compostas por balanços de massas de superfícies (BMS) e um balanço de energia superficial (BES).

O procedimento adotado para o modelo de ablação consiste nas seguintes etapas:

- Utilizar o código termoquímico CEA (descrito em 3.1.1) para obter a composição do fluxo livre em equilíbrio químico e suas propriedades na câmara de combustão e ao longo da tubeira. Consideraremos cinco espécies oxidantes nos cálculos.

- Obter o Número de Staton (Eq 3.17) e a temperatura adiabática da parede (Eq $3.11)$.

- Utilizar o procedimento iterativo aplicado no código Matlab para resolver as cinco equações de balanços de massa superficial e um balanço energia superficial ${ }^{1}$.

- Obter a contribuição de cada espécie para a taxa de erosão.

\subsection{Implementação}

A avaliação da taxa de erosão superficial requer o conhecimento do ambiente termoquímico de fluxo livre, a transferência de calor relacionada e as propriedades termo físicas do material ablativo e a maneira como ele interage com o fluxo (BIANCHI, 2013). Estes valores são a entrada da função desenvolvida no código.

O CEA Program fornece as seguintes propriedades :

- Propriedades avaliadas câmara de combustão como temperatura $T_{c c}$, pressão $p_{c c}$, velocidade característica $c *$.

$\overline{1 \text { Consideraremos cinco espécies oxidantes }}\left(\mathrm{H}_{2} \mathrm{O}, \mathrm{CO}_{2}, \mathrm{OH}, \mathrm{O}\right.$ e $\left.\mathrm{O}_{2}\right)$ resultando em cinco BSM 
- Composição das frações de massa das espécies oxidantes na câmara de combustão e ao longo de cada seção transversal da tubeira.

O BMS que permite calcular a temperatura da parede de equilíbrio, é composto por 5 equações, uma para cada espécie oxidante $\left(\mathrm{H}_{2} \mathrm{O}, \mathrm{CO}_{2}, \mathrm{OH}, \mathrm{O}\right.$ e $\mathrm{O}_{2}$. De acordo com cada equação BMS, é necessário conhecer a temperatura da parede para calcular a taxa global de reação de espécies devido as reações heterogêneas $(\dot{\omega})$. Conhecendo $\dot{\omega}$ é possível conhecer as concentrações de cada espécie na superfície próxima a parede. A temperatura da parede é obtida utilizando o BES através de um método de um método iterativo que será descrito abaixo.

\subsubsection{Código}

Foi usado o seguinte procedimento iterativo com base no método de convergência da bisseção ${ }^{2}$.

Passo 1 - Os valores obtidos do CEA para uma dada pressão e razão O/F é gerado um arquivo .txt com as seguintes saídas para cada secção transversal calculada:

- $\rho$

- $C_{p}$

- Viscosidade

- Velocidade característica

- Velocidade do som local

- Número de Mach

- Frações molares para as moléculas formadas proveniente dos produtos de combustão. Foram consideradas dez moléculas $\left(\mathrm{CO}, \mathrm{CO}_{2}, \mathrm{H}, \mathrm{HO}_{2}, \mathrm{H}_{2}, \mathrm{H}_{2} \mathrm{O}, \mathrm{N}, \mathrm{NO}, \mathrm{NO}_{2}, \mathrm{~N}_{2}, \mathrm{O}, \mathrm{OH}\right.$ e $\mathrm{O}_{2}$ ) que representam praticamente toda composição química em termos de massa na seção transversal analisada.

Passo 2 Cálculo do coeficiente de convecção (Com os parâmetros do dado 1), Número de Staton e o coeficiente de transferência de massa.

Passo 3 - Dois valores limites de temperatura da parede Tw são assumidos, e obtido um valor intermediário entre eles para o uso do método da bisseção.

Passo 4 - Para cada valor de temperatura é aplicado o solucionador BMS para concentração das espécies na parede.

\footnotetext{
2 O método da bisseção é explicado no apêndice 3
} 
Passo 5 - O solucionador BMS é avaliada da seguinte maneira:

- Assumimos um fluxo de massa inicial $\dot{m}_{c}$

- Dois valores limites de concentração na parede são assumidos (0 e a fração de massa da espécie) e um valor intermediário entre eles para o uso do método da bisseção.

- Com Tw e $\dot{m}_{c}$ assumidos, podemos achar a concentração das espécies oxidantes na parede pelo balanço de massa superficial (Eq. 3.13) para cada espécie oxidante.

- Com as concentrações da parede de convergência é calculado um valor de fluxo mais realista utilizando as Eq. em A.

- Quando o fluxo de massa do material ablativo $\dot{m}_{c}$ não muda dentro de uma tolerância assumida, o algoritmo convergiu e a concentração de espécies para uma dada temperatura da parede é obtida

Passo 6 Com as concentrações de parede, fluxo de massa do material ablativo e temperatura da parede é possível resolver o balanço de energia.

Passo 7 Quando a temperatura da parede não muda dentro de uma tolerância assumida, o algoritmo convergiu e a temperatura da parede é conhecida para uma dada seção transversal.

Passo 8 Conhecendo a concentração na parede das espécies para a temperatura da parede exata da seção, calcula-se a taxa de erosão para cada espécie através da equação 9.1.

O fluxograma do código é apresentado na próxima página e o modelo de erosão é validado no Anexo A 


\section{Inicio}

Dados : .txt (propriedades termoquímicas)

Obter: $h_{g}, C_{H}, C_{M}$

Como: Eq. 3.8, 3.16,3.17

Outro procedimento
interativo com uma
nova temperatura

Método da bisseção

$$
\mathrm{T}_{\text {sup }}=3300 \mathrm{~K}, \mathrm{~T}_{\text {inf }}=300 \mathrm{~K}, \mathrm{~T}_{\text {med }}
$$

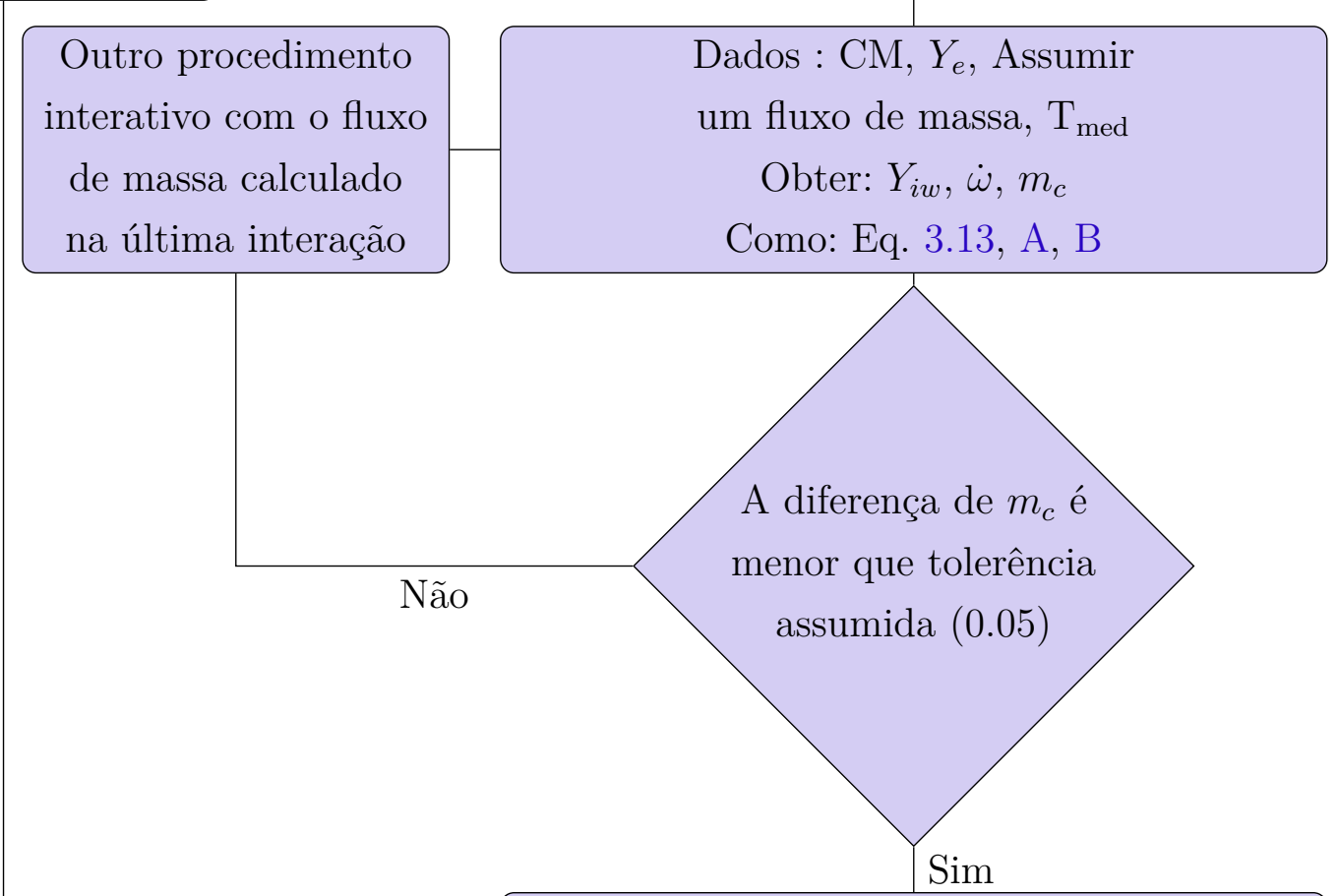

Obter :Balanço de energia

Como: 3.4

A temperatura da

Não

parede é aceitável para

o Método da bisseção?

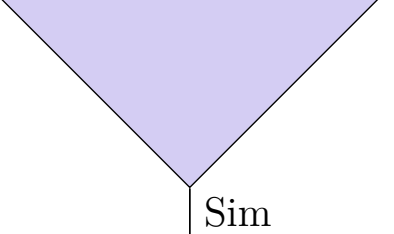

Obter : Taxa de erosão

Como: Eq.9.1 


\section{Análise de resultados}

O modelo de ablação termoquímica e o algoritmo descrito nas seções anteriores é conduzido para simular o processo de erosão da tubeira do SARA com uma análise extensiva associada. Foram consideradas diferentes composições químicas (relação O/F) utilizando os dados paramétricos do foguete explicado no capítulo 4 . Os resultados são comparados com o teste estático realizado pelo CPL da Universidade de Brasília.

Nos testes realizados foram feitas apenas cinco de medições de regressão na tubeira que estão colocadas na tabela $1 \mathrm{com}$ as respectivas taxas de erosão. O teste foi feito para um motor operado em $41 \mathrm{~s}$ supondo que esse tempo seja o suficiente para o que foguete opere em condições permanentes.

\begin{tabular}{|c|c|c|c|c|}
\hline Ponto & Posição, $\mathbf{m m}$ & $\mathbf{A} / \mathbf{A}^{*}$ & Diâmetro após 40.3 $\mathbf{~}$ & Taxa de erosão,mm/s \\
\hline 1 & 79.4 & 3.286 & 31.57 & 0.038 \\
\hline 2 & 82.6 & 3.202 & 29.49 & 0.075 \\
\hline 3 & 86.4 & 1.183 & 26.96 & 0.120 \\
\hline 4 & 96.4 & 1.858 & 24.72 & 0.040 \\
\hline 5 & 105.9 & 30.26 & 0.576 & 0.001 \\
\hline
\end{tabular}

Tabela 1 - Resultados experimentais

Os gases exaustão que fluem na tubeira consistem nos produtos de combustão da parafina com o óxido nitroso. As condições na câmara de combustão listadas na tabela 1 foram obtidas pelo CEA como já explicado anteriormente à uma pressão de 30 bar e uma razão $\mathrm{O} / \mathrm{F}=5.5$ que são os valores médio que mais se aproximam dos testes feitos. Com programa, encontrou -se uma temperatura da câmara de combustão de $3150.35 \mathrm{~K} \mathrm{e}$ foram consideradas 10 espécies oxidantes que representam $99.99 \%$ da massa dos gases de combustão.

\begin{tabular}{|c|c|c|c|c|c|c|c|c|c|}
\hline $\mathrm{CO}, \%$ & $\mathrm{CO}_{\mathbf{2}}, \boldsymbol{\%}$ & $\mathbf{H}, \%$ & $\mathbf{H}_{\mathbf{2}}, \boldsymbol{\%}$ & $\mathbf{H}_{\mathbf{2}} \mathrm{O}, \%$ & $\mathrm{NO}, \%$ & $\mathbf{N}_{\mathbf{2}}, \%$ & $\mathrm{O}, \%$ & $\mathrm{OH}, \%$ & $\mathrm{O}, \%$ \\
\hline 25.99 & 8.50 & 0.05 & 0.70 & 10.07 & 0.25 & 53.74 & 0.05 & 0.58 & 0.06 \\
\hline
\end{tabular}

Tabela 2 - Frações de massa na Câmara de Combustão

Observa-se que 95\% da massa dos produtos de combustão é constituída pelas cinco espécies oxidantes: $\mathrm{H}_{2} \mathrm{O}, \mathrm{CO}_{2}, \mathrm{OH}, \mathrm{O}, \mathrm{O}_{2}$.

A figura 14 mostra o resultado da erosão termoquímica ao longo do bocal com a contribuição de cada uma das 5 espécies oxidantes. Pela fórmula proposta na Eq 9.1, a taxa de erosão de uma espécie é altamente dependente de sua concentração química e inversamente proporcional ao seu peso molecular. Portanto espécies como o $\mathrm{CO}_{2}$ por 
exemplo mesmo tendo uma concentração na parede considerável terá uma contribuição para erosão menor por ter um peso molecular maior que em relação aos outros.

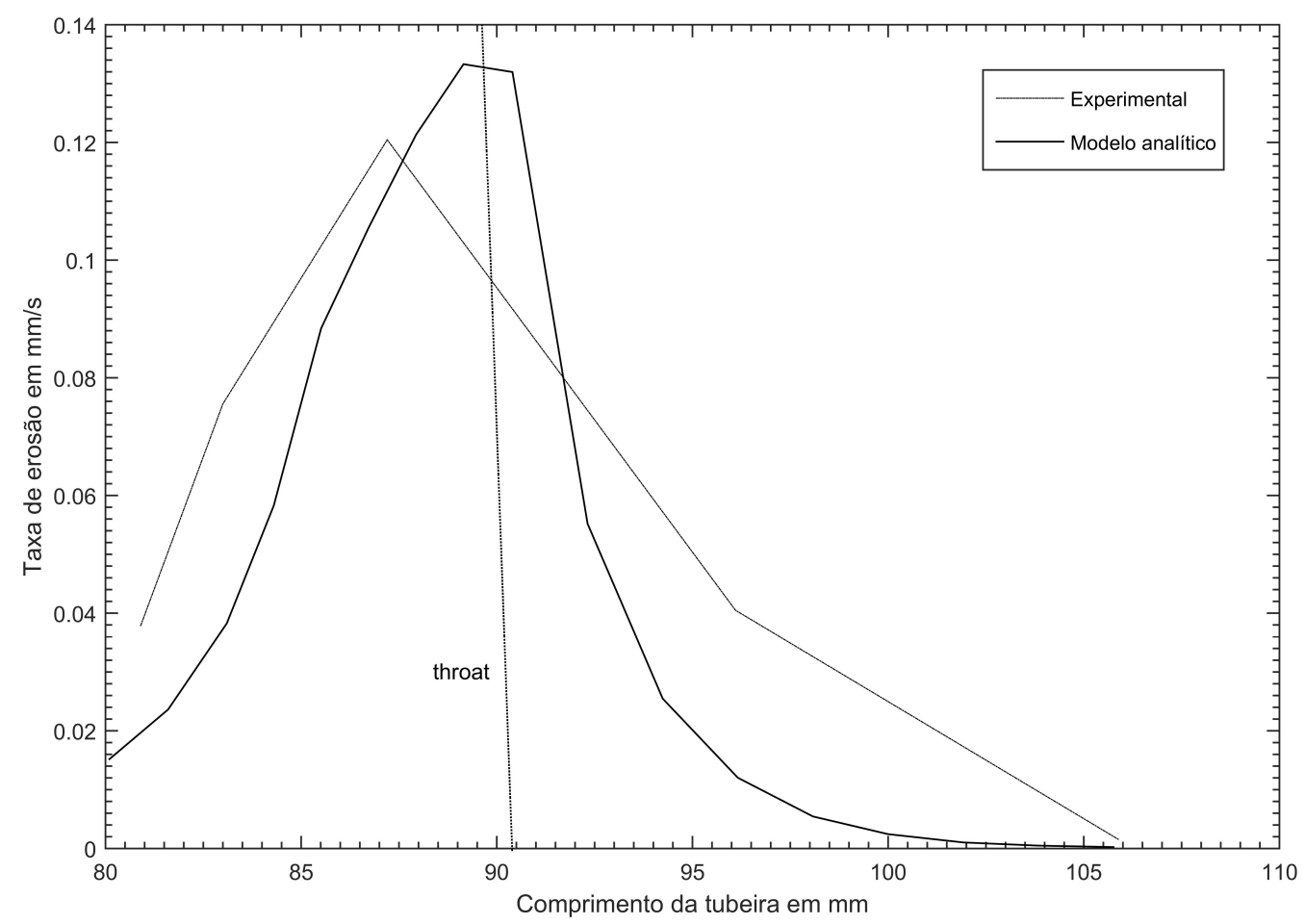

Figura 14 - Taxa de erosão do SARA (Fonte : Elaborada pelo autor)

A espécie oxidante com maior contribuição é o vapor de água. Logo em seguida são as moléculas de $\mathrm{OH}$ e $\mathrm{CO}_{2}$ que apresentam contribuições significativas também. As espécies $\mathrm{O}$ e $\mathrm{O}_{2}$ apresentam contribuição praticamente irrelevante, isso contraria o que foi dito acima a respeito de sua importância em foguetes híbridos, mas deve-se notar que isso é decorrente da baixa razão O/F utilizado, fazendo com que suas frações de massa mesmo em fluxo livre sejam insignificantes. Certamente se a razão O/F fosse alta, isso obviamente significaria uma mistura rica em oxidante e, portanto, as espécies $\mathrm{O}$ e $\mathrm{O}_{2}$ seriam fundamentais no cálculo da erosão.

A figura 14 é calculada para condições espaciais, abaixo são explicitados alguns fatores que contribuiram para a convergência de resultados entre o teste experimental e o modelo implementado.

- Como dito anteriormente, o teste foi feito em condições em solo e o modelo em condições espaciais. Com isso, no teste experimental ocorreram o aparecimento de onda de choque over -expanded devido a pressão atmosférica ambiente ser diferente da saída da tubeira. Com isso, há um crescimento da pressão e temperatura onde formou a onda de choque, o que contribui para a erosão. 
- Em casos reais a razão oxidante e combustível não constante ao longo da tubeira e no modelo consideramos constante ao longo de todo de comprimento.

- Ao longo do tempo de operação a pressão na câmara sofre oscilações e consideramos no modelo uma pressão constante.

- Não foram considerados o efeito da radiação e rugosidade de superfície.

- O modelo foi adotado para regime permanente.

BIANCHI explica que a taxa global das reações de superfície depende de sua cinética, bem como da taxa na qual as espécies oxidantes se difundem através da camada limite até a superfície da tubeira. Algumas reações podem ser limitadas cineticamente ou por difusão dependendo da composição próxima da parede. Na figura abaixo é explicitado as frações de massa de cada espécie na parede.

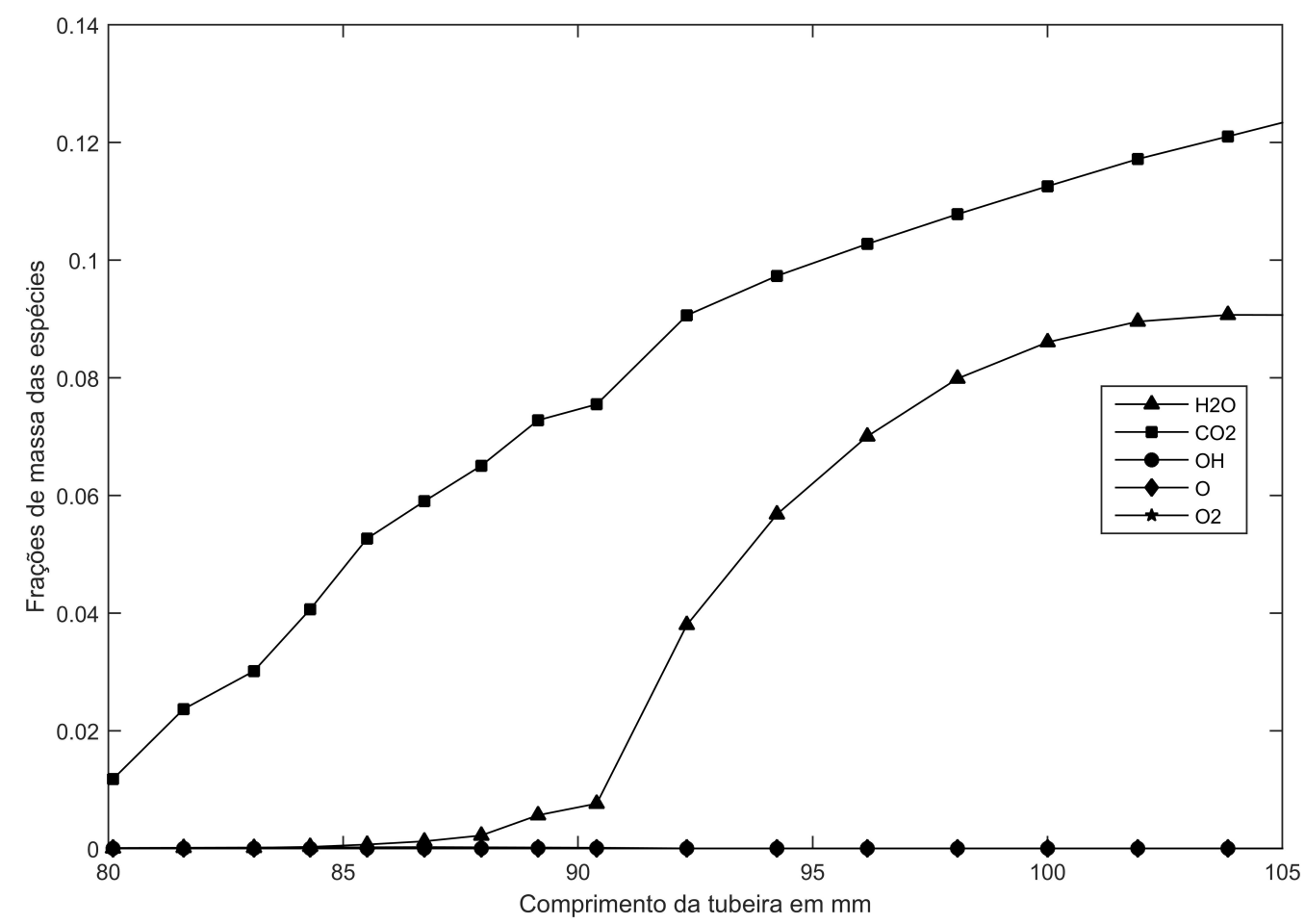

Figura 15 - Frações de massa das espécies (Fonte : Elaborada pelo autor)

Como as frações de massa das espécies $\mathrm{CO}_{2}$ e $\mathrm{H}_{2} \mathrm{O}$ são altas, isso significa menores taxas de reações. As espécies $\mathrm{OH}$ e principalmente $\mathrm{O}$ e $\mathrm{O}_{2}$ estão em baixíssima quantidade, portanto estão foram quase completamente consumidas na superfície da parede de ablação.

Como explicado já explicado no capítulo 3, o modelo foi utilizado cerca de três tipos de fluxo: convectivo, condução e químico. Considerado um fluxo positivo quando 

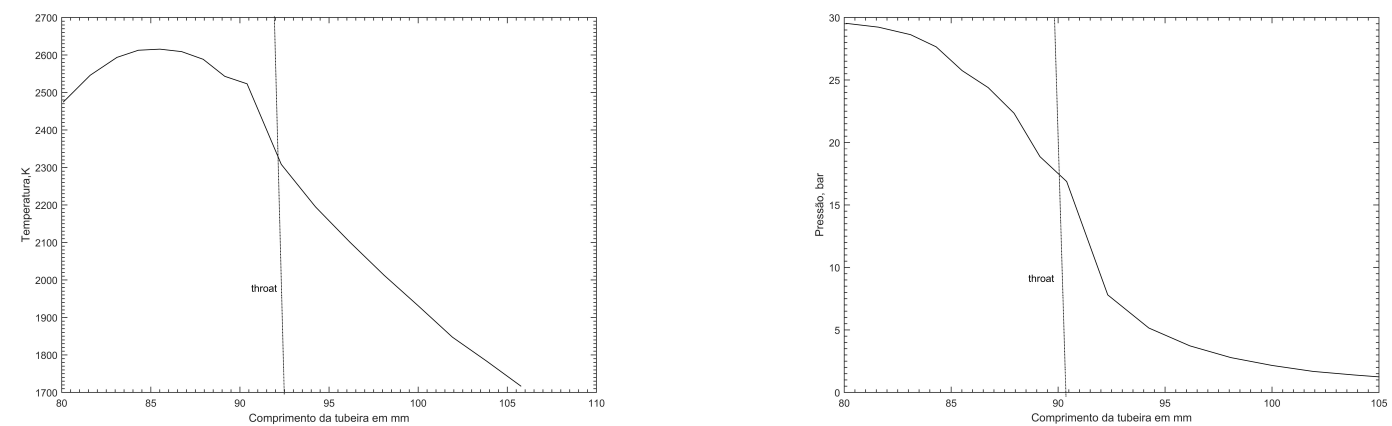

Figura 16 - Pressão e temperatura da parede (Fonte : Elaborada pelo autor)

adicionado ao volume controle, a proporção desses fluxos ao longo da seção transversal da tubeira é mostrada abaixo:

O fluxo de calor convectivo é absorvido pelas reações endotérmicas de superfície (fluxo de calor químico) e o restante é conduzido dentro do material da tubeira (fluxo de calor condutivo).

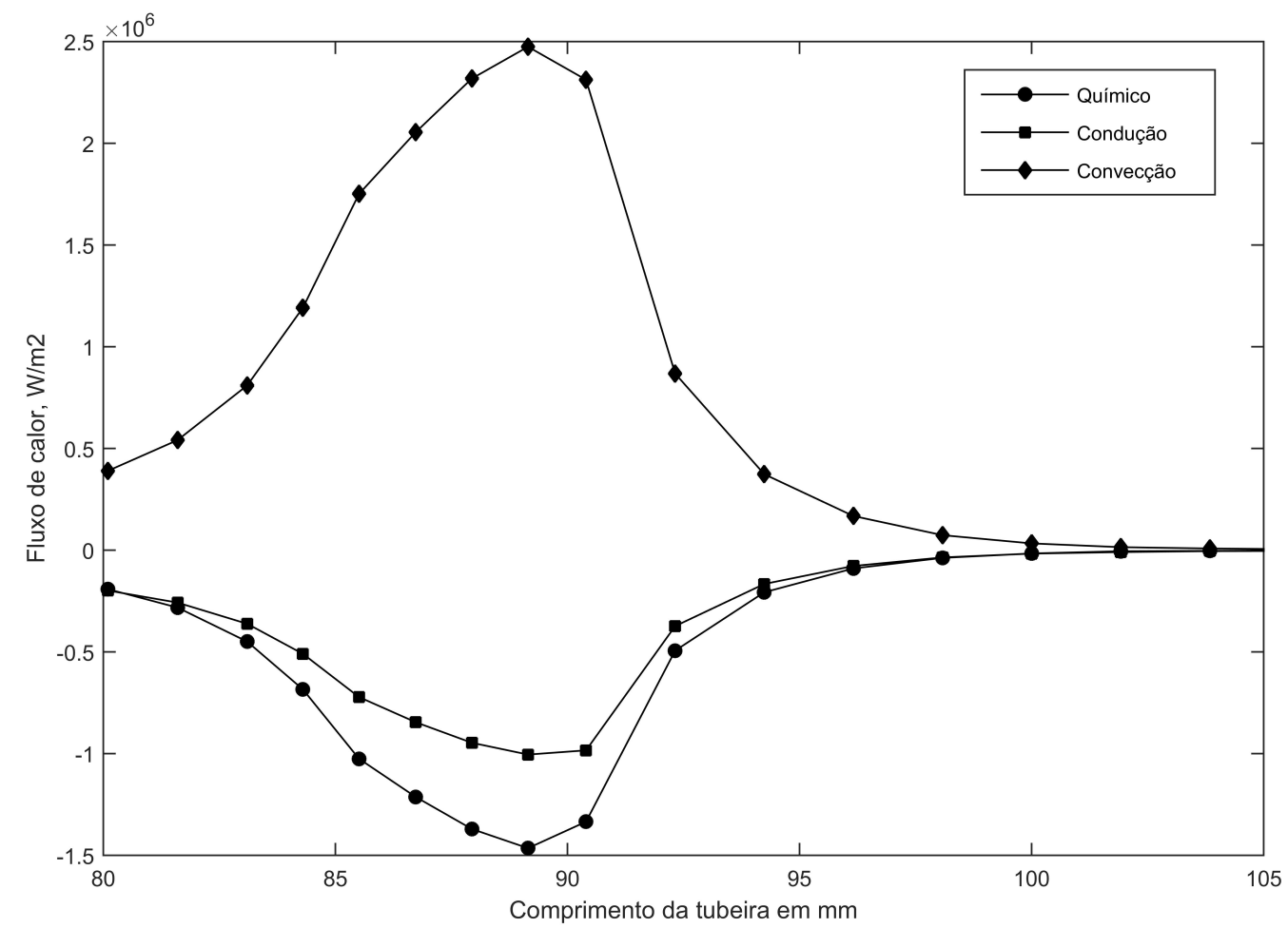

Figura 17 - Distribuição de fluxo na parede (Fonte : Elaborada pelo autor)

Pode -se concluir que diferentes combinações dos propulsores variam a temperatura da chama e a composição do gás de exaustão, que por sua vez podem afetar fortemente a resposta do material. O oxidante $\mathrm{N}_{2} \mathrm{O}$ é favorável a uma menor taxa de erosão devido ao seu reduzido teor de oxigênio. O calor da ablação é significativamente afetado pela escolha 
do oxidante, que altera a liberação de calor geral das reações superficiais heterogêneas. Outro fator interessante que contribui para e erosão é a temperatura da chama e da parede (BIANCHI, 2013).

\subsection{Efeito razão Oxidante/Combustível}

BIANCHI 2013 enfatiza que uma característica peculiar do HRM é um deslocamento intrínseco da razão de mistura durante a operação em estado estacionário. Esse parâmetro pode variar o comportamento do processo de erosão dependendo condições ricas em combustível ou oxidante. Portanto variar a proporção de mistura é de fundamental importância para prever a taxa de erosão e o estimar o material ablativo.

O código do modelo de ablação foi usado para o cálculo da erosão e a temperatura da parede para cerca de oito razões de mistura $(\mathrm{O} / \mathrm{F}): 3.5,5.5,7.5,9.5,11.5,13.5,15.5$ e 17.5. O diagrama de barra descrito na figura 18, descreve as contribuições percentuais das espécies oxidantes para as taxas de erosão total na garganta, que é a região mais importante de estudo. Foi utilizado um fator de recuperação igual a 0.9, que de acordo com (RUFFIN, 2014) é uma excelente aproximação na garganta.

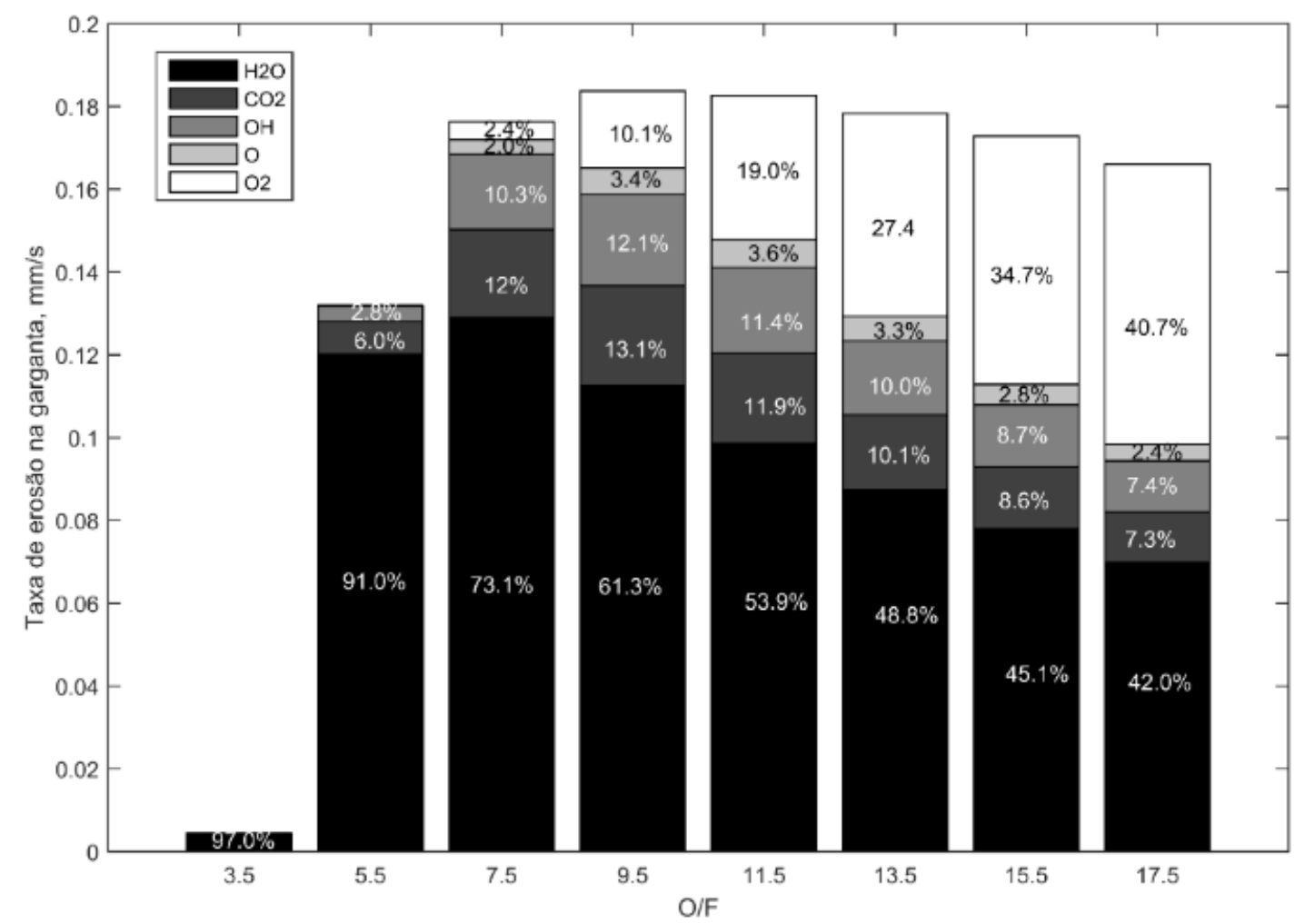

Figura 18 - Taxa de erosão para diferentes composições (Fonte : Elaborada pelo autor)

Observamos que a espécie com maior contribuição é o vapor de água que tende aumentar sua proporção em condições ricas em combustível pelo aumento do hidrogênio 
na mistura. Porém a espécie que teve a maior variação foi o gás oxigênio que aumenta sua quantidade à medida que a mistura fica cada vez mais rica em oxidante. Isso confirma a importância de considera o $\mathrm{O}_{2}$ na erosão.

Em condições que são mais ricas em combustível, nota - se que a taxa de erosão é altamente afetada, sofrendo grande variação com uma contribuição dominante de $\mathrm{H}_{2} \mathrm{O}$. Em contrapartida a taxa de erosão não sofre variações bruscas aumentando o $\mathrm{O} / \mathrm{F}$ em condições ricas em oxidante. BIANCHI explica que isso ocorre por que a presença de oxigênio molecular nos gases de combustão é grandemente aumentada para misturas ricas em oxidante, levando à liberação de calor pela reação de oxidação do grafite correspondente que por sua vez aumenta a temperatura da parede e a taxa de reação global

A figura 19 mostra a temperatura da parede para os diferentes $\mathrm{O} / \mathrm{F}$ aplicados:

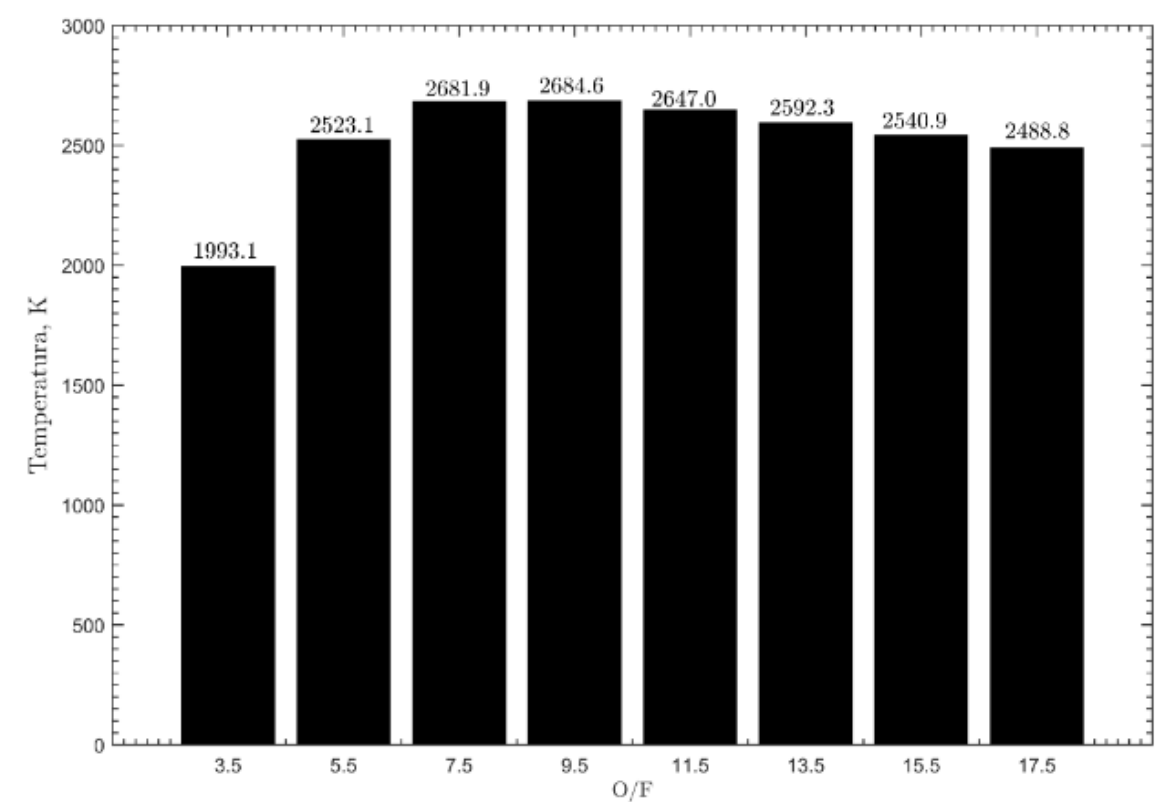

Figura 19 - Temperatura da parede para diferentes composições (Fonte :Elaborada pelo autor)

A temperatura da parede tende obter um máximo quando a razão equivalente $(\Phi)$ está próxima da unidade e depois tende a diminuir igualmente para condições ricas em combustível e oxidante. Isso é melhor explicado na figura abaixa expressa em termos de razão de equivalência $\Phi$ as oito $\mathrm{O} / \mathrm{F}$ relacionadas. Biachi considera condições rica em oxidante um $\Phi$ entre 0.67 e 0.5 e rica em combustível um $\Phi$ entre 1.5 e 2 . 


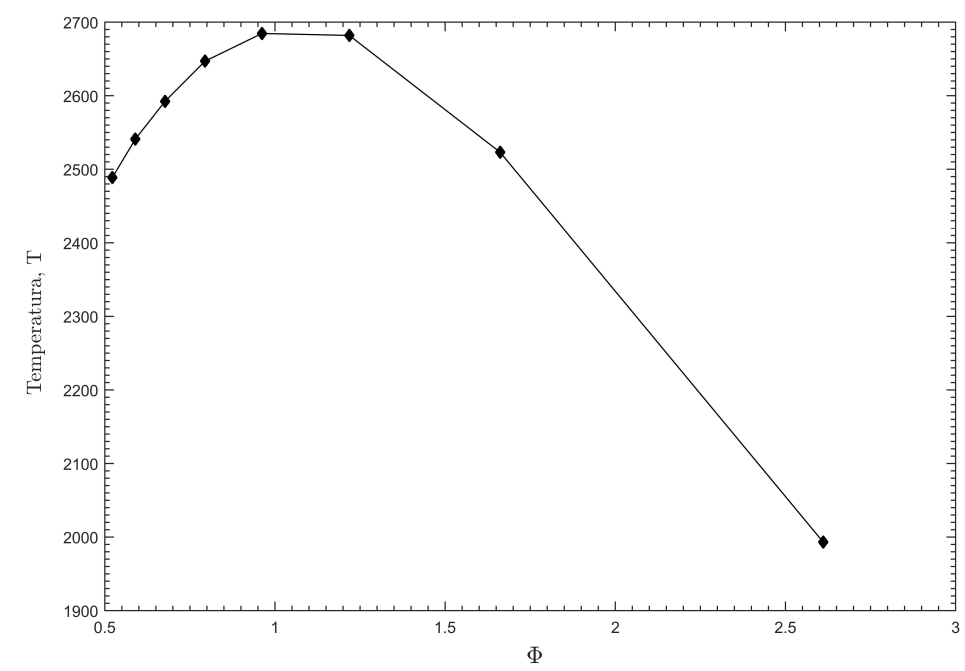

Figura 20 - Razão de equivalência e Temperatura da parede (Fonte : Elaborada pelo autor)

As frações de massa na parede também são expressadas abaixo. O resultado não é novidade, observa-se um aumento de $\mathrm{O}_{2}$ a medida que aumenta o $\mathrm{O} / \mathrm{F}$ pois sua fração de massa no fluxo livre é de uma alta ordem de grandeza.

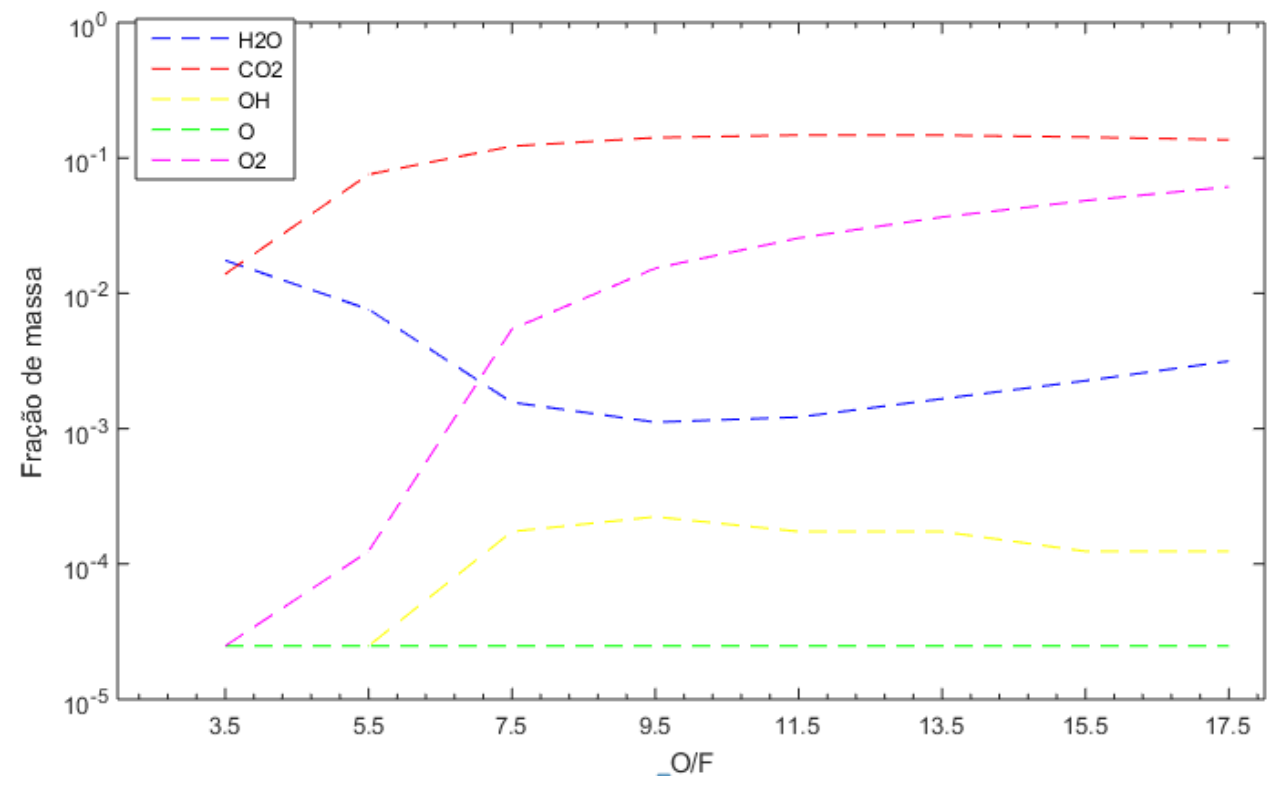

Figura 21 - Frações de massa das espécies oxidantes (Fonte : Elaborada pelo autor)

Conclui -se então que proporções ricas em oxigênio em erosões altas na garganta e proporções ricas em combustível gera erosões baixas. 



\section{Parte III}

\section{Simulação tridimensional}





\section{CFD - Modelo Numérico}

A dinâmica dos fluidos computacional é uma ferramenta poderosa para avaliar o comportamento de fluxo de fluidos em um sistema geral. O fluxo e fenômenos relacionados podem ser descritos por equações diferenciais parciais que são na maioria das vezes difíceis de serem resolvidos analiticamente. Para obter uma solução aproximada numericamente, é usado um método de discretização que aproxima as equações diferenciais por um sistema de equações algébricas, que podem ser resolvidas em um computador. As aproximações são aplicadas a pequenos domínios no espaço e / ou tempo, para que a solução numérica forneça resultados em locais distintos no espaço e no tempo. Essas equações discretizadas são resolvidas utilizando métodos iterativos (FERZIGER, 2002).

O diagrama abaixo esquematiza o procedimento geral para descrever o estudo de erosão da tubeira do motor de foguete SARA usado no CFD.

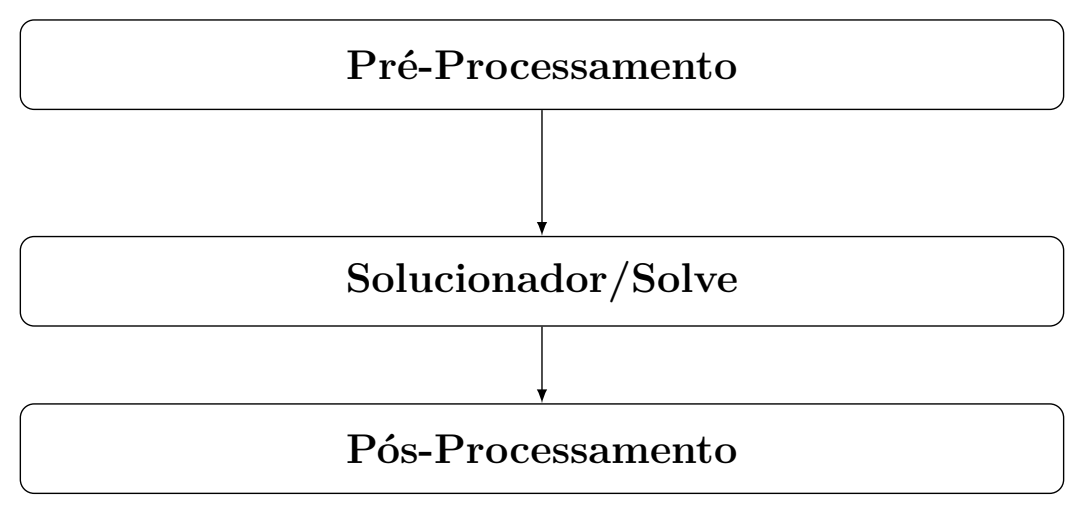

Figura 22 - Visão Geral da Modelagem CFD

Todos os códigos CFD são estruturados em torno de algoritmos numéricos que contém esses três elementos. Iremos ao longo deste capítulo examinar cada um deles e implementá-lo no modelo de simulação tridimensional.

\section{Pré-Processamento}

Após a identificação dos objetivos e o domínio do problema que consiste de posse das informações necessárias para o cálculo da taxa de erosão, as atividades no estágio de pré-processamento envolvem (VERSTEEG, 1995):

- Definição da geometria no domínio de interesse.

- Geração da malha. Uma malha divide uma geometria em muitos elementos. Eles são usados pelo solucionador CFD para construir volumes de controle (ANSYS, 2018).

- Seleção dos fenômenos físicos e químicos que precisam ser modelados. 
- Definição das propriedades do material.

- Especificação de condições de contorno apropriadas nas células nos limites dos domínios.

- Propriedades que podem ser especificadas pelo usuário utilizando UDF's ${ }^{1}$.

\section{Solucionador / Solve}

As equações discretas de conservação são resolvidas iterativamente até convergência. Os solucionadores ANSYS FLUENT são baseados no método de volume finito. Em resumo, o algoritmo numérico consiste nas seguintes etapas (VERSTEEG, 1995):

- Integração das equações que regem o fluxo de fluido em todos os volumes de controle (finitos) do domínio.

- Discretização.

- Solução das equações algébricas por um método iterativo.

As declarações resultantes expressam a conservação (exata) de propriedades relevantes para cada célula de tamanho finito. A conservação de uma variável de fluxo geral $\phi$, e um componente de velocidade ou entalpia, dentro de um volume de controle finito, pode ser expresso como um equilíbrio entre os vários processos que tendem a aumentá-lo ou diminuí-lo. Os códigos CFD devem conter técnicas de discretização adequadas para o tratamento dos principais fenômenos de transporte, convecção, os termos de fonte e de taxa de variação em relação ao tempo. Os fenômenos físicos subjacentes são complexos e não lineares, portanto, é necessária uma abordagem de solução iterativa (VERSTEEG, 1995).

\section{Pós-Processamento}

Por último, essa etapa consiste em examinar os resultados para revisar a solução e extrair dados úteis, principalmente os gráficos de linhas, contornos e plotagens de superfície 3D.

Por fim, será aplicado neste estudo uma simulação numérica tridimensional usando o software comercial CFD Fluent 18.1 correlacionado com uma função definida pelo usuário (UDF) para o cálculo da taxa de erosão da tubeira do foguete SARA. Detalhes sobre a malha computacional, condições de contorno implementadas e discussão sobre os solucionadores de fluxo são dadas nas próximas seções

1 User's Defined Function 


\subsection{Metodologia e implementação}

\subsubsection{Geometria}

O modelo descrito no capítulo 3 é agora implementado em uma simulação tridimensional para a análise de erosão do foguete híbrido SARA e comparação direta dos resultados obtidos numericamente com medições experimentais e do modelo analítico do capítulo 6.

O modelo geométrico tridimensional descrito na figura 23 foi feito no software Catia que possui a possibilidade de exportá-lo em um formato compatível para o Ansys Workbench (extensão .step).

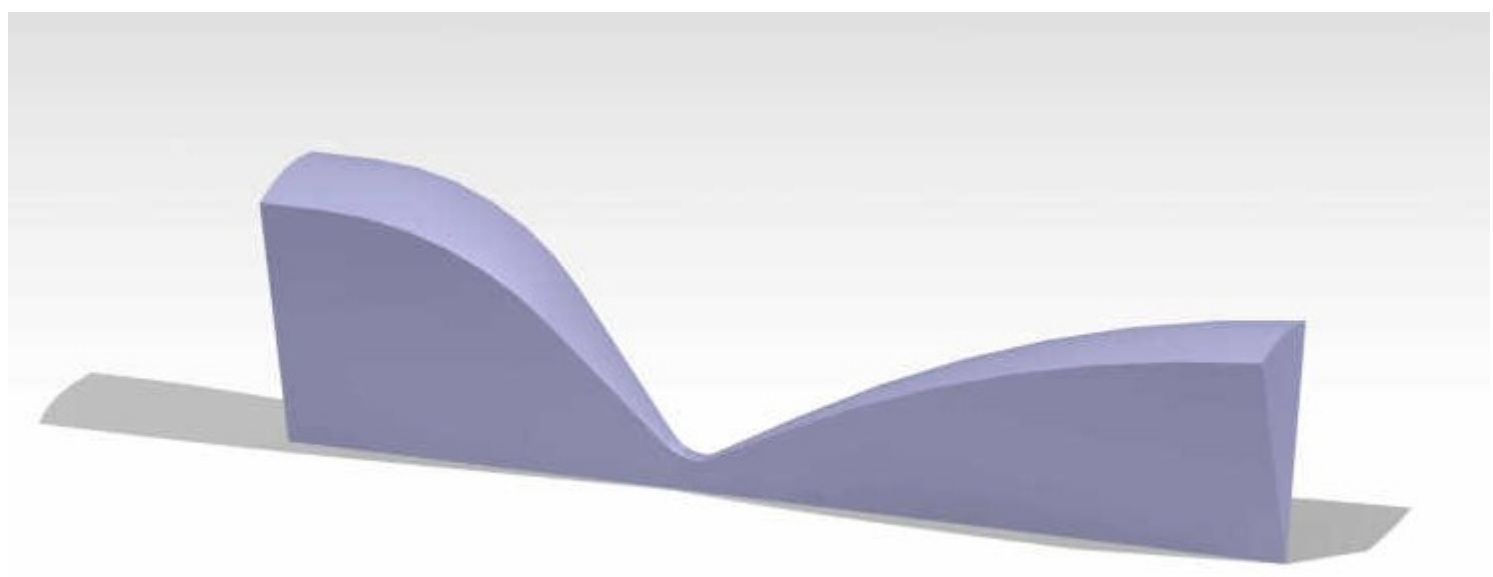

Figura 23 - Geometria do SARA (Fonte :Elaborada pelo autor)

A geometria da tubeira foi seccionada axialmente no plano de simetria e os planos laterais foram definidos para serem periódicos representados por um segmento de ângulo da tubeira de $30^{\circ}$ no plano radial. Com isso é possível reduzir o domínio computacional em $70 \%$ dado que as propriedades de fluxos são simétricas e ter a mesma precisão no cálculo da taxa de erosão.

\subsubsection{Malha}

Uma malha é uma discretização de um domínio geométrico em pequenas formas simples, como triângulos ou quadriláteros em geometrias bidimensionais e tetraedros ou hexaedros em tridimensionais (ANSYS, 2018). Com esses subdomínios menores e mais simples é possível a resolução das equações diferenciais que governam as propriedades de fluxo discretizando-a em cada um desses subdomínios (RUFFIN, 2014).

Portanto o próximo passo é a geração de malha, que é a divisão do domínio do fluido em elementos poligonais. Nesta simulação foi utilizada uma malha estruturada 
usando o Ansys Meshing feito em sua totalidade de elementos hexaédricos. Os geradores de malha estruturada são mais comumente usados no campo CFD, onde o alinhamento estrito dos elementos pode ser exigido pelo código de análise ou necessário para capturar algum fenômeno físico.

A malha estruturada hexaédrica escolhida é aquela em que todos os seus vértices são topologicamente iguais e regularmente conectados, oferecendo simplicidade e fácil acesso a dados. Isso será importante para a coleta de dados para a UDF. Esse tipo de malha se adapta ao contorno e é difícil controlar o refino local em geometrias complexas

Nesse tipo de malha, o usuário controla o posicionamento dos cantos do bloco e, em seguida, o gerador de malha projeta as arestas implícitas do bloco em curvas e superfícies de domínio automaticamente (ANSYS, 2018). A malha gerada é mostrada abaixo.

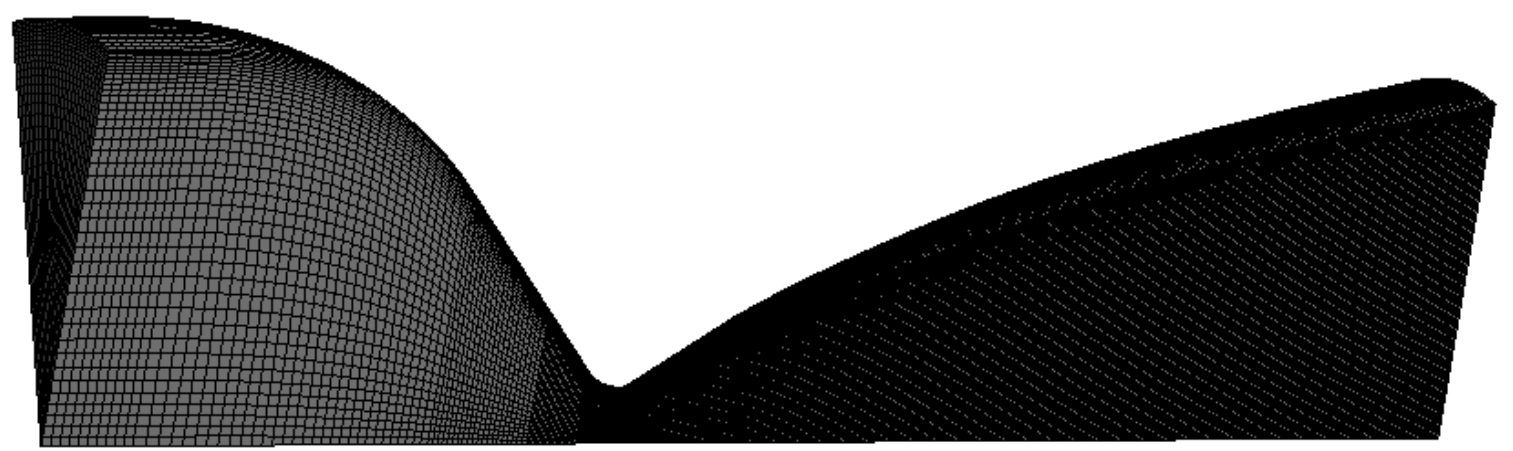

Figura 24 - Malha do SARA (Fonte :Elaborada pelo autor)

O domínio foi dividido em oito corpos e transferido para o Mechanical em uma parte usando a função New part. Ao agrupar corpos em uma parte multicorpos, ele permite o uso de Topologia Compartilhada entre os corpos.

Essa divisão em multicorpos é para facilitação da função Multizone e para que todas as regiões sejam mescladas com uma malha hexaédrica pura. Outra questão fundamental é para o refino nas regiões de interesse que será próximo da garganta.

Como a seção transversal consiste em uma arco de circunferência, deve -se organizar os elementos de tal forma que a topologia não distorça os elementos hexáedricos de um bloco. A topologia também determinará como as peças se encaixam, como os principais recursos serão capturados e como isso afetará outras regiões da malha. Portanto escolheu -se dividir as seções em três partes utilizando a comando face split como mostrado na 24

Observa - se que essa pré disposição faz com o número de elementos seja igual para cada seção transversal ao longo da tubeira. Abaixo estão os dados gerais da malha:

Utilizando o modelo de turbulência de BIANCHI, foi utilizado um modelo k- $\epsilon$ padrão com abordagem do modelo Reynolds baixo para as quantidades de turbulência 


\begin{tabular}{|c|c|}
\hline Nós & Elementos \\
\hline 435618 & 425136 \\
\hline
\end{tabular}

Tabela 3 - Frações de massa na Câmara de Combustão

próximas à parede.

Para resolver a camada limite, é necessário agrupar a grade na direção normal da superfície com o espaçamento do primeiro ponto da grade fora da parede para ficar bem dentro da subcamada laminar da camada limite.

Será observado que para simular o fluxo nos contornos e a transferência de calor, um espaçamento fino deve ser adotada perto da parede. Além disso, a função standard wall é usada para diminuir o número da grade no contorno.

É importante notar que parâmetros de qualidade da malha se não bem configurados podem resultar em falhas na simulação. Abaixo são listados alguns desses fatores de qualidade que foram baseados na geração de malha:

- Skewness: define o grau de afastamento do tipo ideal do mesmo elemento. De acordo com a definição, um valor de 0 indica uma célula equilateral (melhor) e o valor 1 indica uma célula completamente degenerada (pior).

- Ortogonalidade: mostra o grau afastamento do ângulo do elemento em relação ao hexaédro. O intervalo varia de $0-1$, onde o valor 0 é pior e o valor 1 é o melhor.

- Aspect ratio: razão entre os tamanhos das arestas de um mesmo elemento. Estima -se que um quadrilátero com uma proporção de 20 seja o máximo aceitável nas simulações.

Abaixo é dado os fatores de qualidade explicado acima na malha obtida.

\begin{tabular}{|c|c|c|}
\hline Orthogonal Quality & Skewness & Aspect ratio \\
\hline 0,81263 & 0,34694 & 2,7438 \\
\hline
\end{tabular}

Tabela 4 - Qualidade da malha 


\subsection{Configurações no Fluent}

\subsubsection{Setup}

O solucionador usado neste problema é o Ansys Fluent. O arquivo de malha da seção anterior é exportado e lido no Fluent. O Fluent é um programa escrito em linguagem C para modelar o fluxo de fluidos, transferência de calor e reações químicas em geometrias complexas. Sua técnica de solução é baseada em volume finito centralizado em célula. Nesse esquema, as variáveis de fluxo são armazenadas no centro dos elementos da malha. Por último, o Fluent oferece a capacidade de acessar funções adicionadas pelo usuário aplicando uma UDF(THIRUMURTHY, 2011).

O método numérico de solução consiste em resolver equações integrais que governam a conservação de massa, momento, energia, turbulência e espécies químicas (ANSYS, 2018). Para o solucionador de fluxo, o ANSYS FLUENT no uso de condições de contorno baseadas em pressão para altos números de Mach são recomendados para estabilidade numérica e convergência mais rápida (THIRUMURTHY, 2011). Portanto o solucionador baseado em pressão é usado no setup do Fluent. Na abordagem baseada em pressão, o campo de pressão é extraído através da resolução de uma equação de correção de pressão que é obtida através da manipulação de equações de continuidade e momento.

Foi escolhida a formulação de velocidade absoluta a partir de um referencial inercial para expressão das equações de momento e especificamos uma solução em estado estacionário

O modelo escolhido foi o de transporte de espécies para resolver as equações de conservação que descrevem as fontes de convecção, difusão e reação para cada espécie da mistura. Quanto as reações volumétricas, o Fluent prediz a fração de massa local de cada espécie, através da solução de uma equação de convecção- difusão. O fluxo de difusão de cada espécie também é parte do solucionador.

O fluxo e a transferência de calor não podem ser assumidos como laminares devido ao alto número de Reynolds, devendo ser considerado turbulento. Com isso, o modelo de turbulência Realizable $k-\epsilon$ foi empregado para simular as características de fluxo médio para condições de fluxo turbulento. Variações de temperatura e concentração de espécies estão relacionadas à estrutura de turbulência.

O modelo $k-\epsilon$ consiste de duas equações que fornece uma previsão geral da turbulência por meio de duas equações diferenciais parciais. A primeira variável transportada é a energia cinética turbulenta $k$ e a segunda variável é a dissipação turbulenta $\epsilon$.

Quanto ao modelo interação química-turbulência foi usado o Eddy dissipation. Nesse modelo presume-se que as taxas de reação sejam controladas pela turbulência, ignorando o efeito das escalas de tempo da química, o que evita cálculos cinéticos químicos 
dispendiosos de Arrhenius.

\subsubsection{Materiais}

Como o modelo de transporte de espécies foi empregado, se faz necessário selecionar o material de mistura. Um material de mistura pode ser pensado como um conjunto de espécies e uma lista de regras que governam sua interação.

Utilizando como parâmetros as frações de massa dos dados obtidos do CEA, foram escolhidas as 10 espécies $\left(\mathrm{CO}, \mathrm{CO}_{2}, \mathrm{H}, \mathrm{H}_{2}, \mathrm{H}_{2} \mathrm{O}\right.$, NO, $\mathrm{N}_{2}, \mathrm{O}, \mathrm{OH}$ e $\left.\mathrm{O}_{2}\right)$ mais abundantes para fazer parte do material de mistura do Fluent.

As propriedades de cada espécie tais como o calor específico, viscosidade e condutividade térmica são calculados em função da temperatura definida por meio de polinômios. Os polinômios seguem o seguinte o arranjo ${ }^{2}$ :

$$
\Phi(T)=A_{1}+A_{2} T+A_{3} T^{2}+\ldots
$$

As propriedades do fluido de escape são previstas usando a média ponderada da massa das espécies produzidas pelo sistema de combustão.

\subsubsection{Condições de contorno}

As especificações das zonas de condições de contorno foram feitas no Ansys Meshing. Foram nomeadas quatro zonas principais: entrada, saída, parede e periódico.

As faces longitudinais foram definidas de contorno periódico. Condições de contorno periódicas são usadas quando os fluxos através de dois planos opostos no seu modelo computacional são idênticos. Por padrão aplica-se uma condição periódica sem queda de pressão nos planos, e selecionaremos a opção rotacional no qual formam um ângulo incluído sobre a linha central de uma geometria rotacionalmente simétrica.

\subsection{Entrada e Saída}

Para especificação do tipo de zona de contorno usaremos a opção pressure inlet e pressure outlet para as especificações de entrada e saída de fluxo.

A opção pressure inlet são usadas quando a pressão de entrada é conhecida, mas a taxa de fluxo e / ou a velocidade não são. Portanto quando aplicamos as condições entrada de pressão o solucionador calcula todas as outras propriedades escalares de fluxo. As seguintes informações necessárias para pressure inlet são listadas abaixo.

- Pressão total

$\overline{2}$ Os coeficientes $A_{n}$ são encontrados no FLUENT Database Materials Dialog Box. 
- Pressão estática

- Temperatura total

- Frações de massa ou molar de espécies químicas

As condições de contorno de pressure outlet requerem a especificação de uma pressão estática. O valor da pressão estática especificada é usado apenas enquanto o fluxo é subsônico. Se o fluxo se tornar localmente supersônico, a pressão especificada não será mais usada, sendo a pressão extrapolada do fluxo no interior (ANSYS, 2018). As seguintes informações necessárias para pressure outlet são listadas abaixo:

- Pressão estática

- Temperatura total

- Frações de massa ou molar de espécies químicas

A tabela 5 é dada os valores inseridos no setup do programa:

\begin{tabular}{|c|c|c|}
\multicolumn{1}{c|}{} & Inlet & Outlet \\
\hline $\mathrm{CO}, \%$ & 25.99 & 16.092 \\
\hline $\mathrm{CO}_{2}, \%$ & 8.501 & 24.047 \\
\hline $\mathrm{H}, \%$ & 0.054 & 0 \\
\hline $\mathrm{H}_{2}, \%$ & 0.704 & 1.404 \\
\hline $\mathrm{H}_{2} \mathrm{O}, \%$ & 10.076 & 4.597 \\
\hline $\mathrm{NO}, \%$ & 0.248 & 0 \\
\hline $\mathrm{O}, \%$ & 0.046 & 0 \\
\hline $\mathrm{OH}, \%$ & 0.581 & 0 \\
\hline $\mathrm{O}_{2}, \%$ & 0.0581 & 0 \\
\hline Temperatura, $\mathrm{K}$ & 3150.34 & 877.65 \\
\hline Pressão total, $\mathrm{Pa}$ & 3000000 & 4638 \\
\hline Pressão estática, $\mathrm{Pa}$ & 2999912 & $\mathrm{X}$ \\
\hline
\end{tabular}

Tabela 5 - Pressure inlet e pressure outlet

O nitrogênio molecular é a espécie mais abundante da mistura (bulk specie) devendo ser a última espécie inserida na lista de espécie do Fluent por razões de precisão numérica. Nas condições de contorno pressure inlet e outlet não se faz colocar a fração da última espécie pois é calculada subtraindo a unidade pelas frações das outras espécies.

\subsection{Reações de Superfície}

A taxa geral das reações da superfície depende de sua cinética, bem como da taxa na qual as espécies oxidantes se difundem através da camada limite até a superfície da 
tubeira (BIANCHI, 2013). Com isso, para as reações de superfície, o Fluent trata as taxas de absorção e dissorção de espécies químicas por meio da cinética química e pela difusão de e para a superfície. As reações da superfície da parede, portanto, criam fontes e sumidouros de espécies químicas na fase gasosa, bem como na superfície reagente.

A taxa líquida de produção ou consumo de cada espécie na superfície de reação é dada pela contribuição das espécies da fase gasosa, espécies na fase sólida e as espécies adsorvidas na superfície (ou local).

A taxa de reação que representa o tempo que um produto é formado à medida que o reagente é consumido é computada usando a expressão de Arrhenius que permite associar a velocidade de reação com a temperatura. Com base nisso foi definido três reações heterogêneas (Eq. 7.2,7.3,7.4) na superfície da parede que são as principais para produção de monóxido de carbono.

$$
\begin{gathered}
\mathrm{C}_{\mathrm{s}}+\mathrm{H}_{2} \mathrm{O} \rightarrow \mathrm{CO}+\mathrm{H}_{2} \\
\mathrm{C}_{\mathrm{s}}+\mathrm{CO}_{2} \rightarrow 2 \mathrm{CO} \\
\mathrm{C}_{\mathrm{s}}+\mathrm{OH} \rightarrow \mathrm{CO}+\mathrm{H}
\end{gathered}
$$

Como a razão O/F do problema proposto é rica em combustível, as contribuições de $\mathrm{O}$ e $\mathrm{O}_{2}$ como mostrado na figura 18 são irrelevantes quando comparadas as outras espécies ${ }^{3}$. Portanto consideraremos apenas as espécies $\mathrm{H}_{2} \mathrm{O}, \mathrm{CO}_{2}$ e $\mathrm{OH}$.

Os parâmetros da expressão Arrhenius (fator pré exponencial, energia de ativação e expoente de temperatura) são inseridos com base no apresentado na tabela A. Consideraremos as reações como direta global (sem reação reversa) e elementares para simplificação dos cálculos ${ }^{4}$.

\subsubsection{Solution}

O primeiro consiste em definir os valores de sub-relaxamento das equações, que é usado no solucionador baseado em pressão para estabilizar o comportamento de convergência das iterações não lineares externas. O Ansys define os parâmetros de sub relaxamento ideal para todas as variáveis, porém em casos que os resíduos aumentam muito é prudente reduzir esses fatores.

3 Isso é verificado na figura 18

4 O procedimento utilizado para definir taxa de consumo e produção de espécies é encontrado em (ANSYS, 2018) 
Para a solução, foram feitos alguns testes e a solução obteve bons resultados usando valores de sub relaxamento de 0.8 para energia cinética turbulenta, 0.3 para pressão, 0.8 para taxa de dissipação específica e 1.0 para a viscosidade turbulenta. Foram também utilizados 1.0 para todas as espécies no fluxo.

A convergência foi monitorada usando os resíduos das variáveis de fluxo, fatores $k$ e $\epsilon$ e as espécies químicas utilizando um critério absoluto de 0.001 e $10^{-6}$ para equação de energia. A solução é convergida com uma média de 1100 iterações, com as reações de superfície e UDF já acoplada ${ }^{5}$.

Durante as iterações também foram monitoradas duas propriedades além das que estiveram no resíduo: pressão média estática e temperatura da parede. 


\section{Validação}

Como já dito, a simulação computacional tem vantagens em economizar tempo e custos em relação a experimento. Com isso, para toda simulação se faz necessário saber se os resultados obtidos estão corretos ou não. A validação do modelo é geralmente definida como a comprovação de que um modelo computadorizado dentro de seu domínio de aplicabilidade possui uma faixa de precisão satisfatória consistente com a aplicação pretendida ao modelo (SARGENT, 2011).

Sabe- se que o gás de alta temperatura na tubeira é uma mistura dos produtos de combustão WAX- $\mathrm{N}_{2} \mathrm{O}$ e portanto, tendo conhecimento dos parâmetros na entrada e saída da tubeira é possível calcular as propriedades termodinâmicas e químicas ao longo de cada seção usando o modelo de transporte de espécies fornecido no Fluent. As propriedades de mistura são calculadas com base na média ponderada das espécies provenientes do fluxo.

Tendo posse do que foi dito acima, a validação será feita comparando os dados obtidos de algumas propriedades termodinâmicas obtidas pelo CEA e o que foi obtido no Fluent. Seu objetivo consiste somente em comparar essas propriedades a partir da composição de equilíbrio químico obtida após a convergência, considerando um fluxo sem reações de superfície com as mesmas características que o CEA utiliza.

Utilizaremos três seções localizadas: na entrada, na garganta e na saída da tubeira para a comparação dos resultados. As propriedades que foram listadas abaixo são as principais que influenciam no modelo de ablação termoquímica em que é necessária boa aproximação com os valores analíticos.

- Frações de massa das três principais espécies oxidantes.

- Temperatura do fluxo livre.

- Pressão do fluxo livre.

- Velocidade do fluxo livre

Os valores são obtidos através de uma superfície criada utilizando o Area-Weighted Average na aba Surface Integrals. 

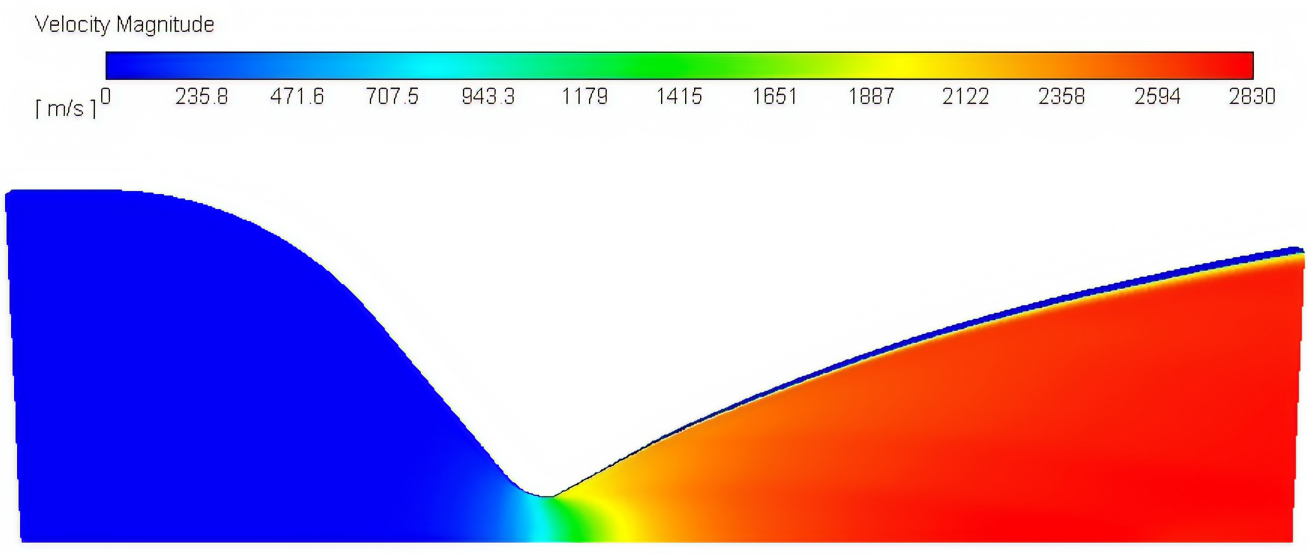

Figura 25 - Velocidade global [m/s] (Fonte : Elaborada pelo autor)

\begin{tabular}{l|c|c|}
\multirow{2}{*}{} & \multicolumn{2}{|c|}{ Velocidade $(\mathrm{m} / \mathrm{s})$} \\
& CFD & CEA \\
\cline { 2 - 3 } Entrada & 11.33 & 7.88 \\
\cline { 2 - 3 } Garganta & 1103.34 & 1079.0 \\
\cline { 2 - 3 } Saída & 2690.27 & 2805.99 \\
\hline
\end{tabular}

Tabela 6 - Velocidade

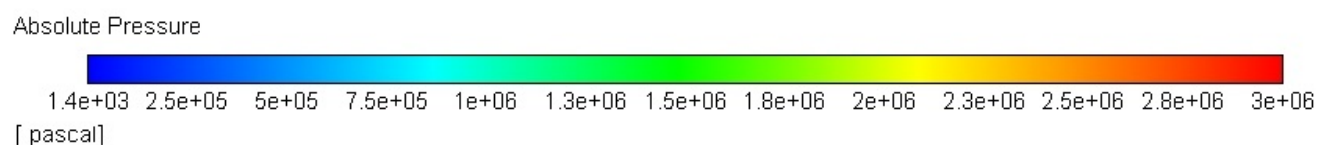
「pascal]

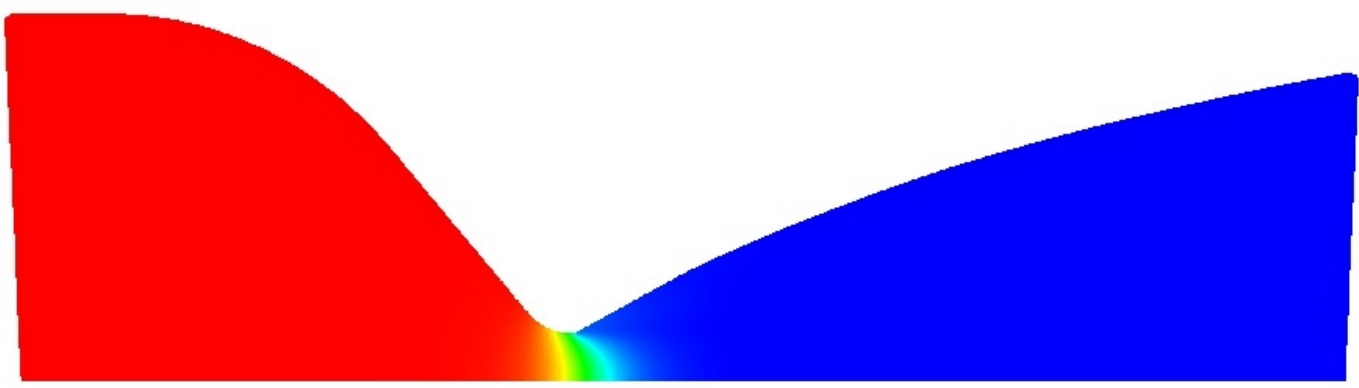

Figura 26 - Pressão absoluta [Pa] (Fonte : Elaborada pelo autor)

\begin{tabular}{|l|c|c|}
\multicolumn{1}{c|}{} & \multicolumn{2}{|c|}{ Pressão (Pa) } \\
\multicolumn{1}{c|}{} & CFD & CEA \\
\cline { 2 - 3 } Entrada & 2999816.9 & 2999999.9 \\
\cline { 2 - 3 } Garganta & 1627088.9 & 1687500.0 \\
\cline { 2 - 3 } Saída & 5460.11 & 4779 \\
\hline
\end{tabular}

Tabela 7 - Temperatura 
Static Temperature

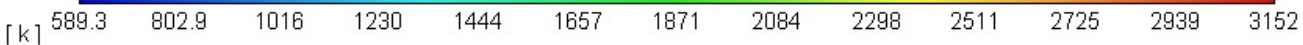

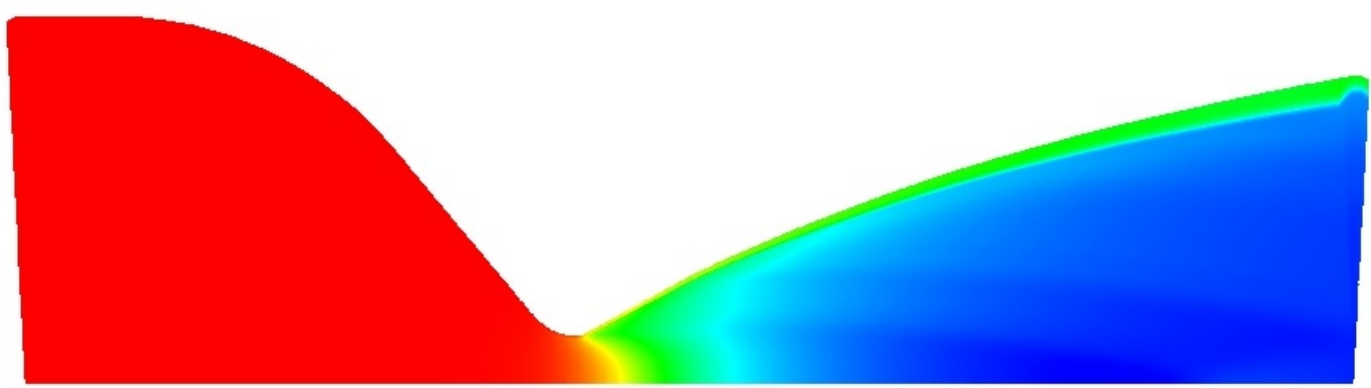

Figura 27 - Temperatura estática [K] (Fonte : Elaborada pelo autor)

\begin{tabular}{|l|c|c|}
\multicolumn{1}{c|}{} & \multicolumn{2}{|c|}{ Temperatura (K) } \\
\multicolumn{1}{c|}{} & CFD & CEA \\
\cline { 2 - 3 } Entrada & 3150.30 & 3150.34 \\
\cline { 2 - 3 } Garganta & 2785.65 & 2881.03 \\
\cline { 2 - 3 } Saída & 935.51 & 877.65 \\
\hline
\end{tabular}

Tabela 8 - Pressão

\begin{tabular}{|l|c|c|c|c|c|c|}
\hline \multirow{1}{*}{} & \multicolumn{4}{|c}{ Frações de Massa } & \multicolumn{2}{c|}{ OH } \\
& CFD & CEA & CFD & CEA & CFD & CEA \\
\hline Entrada & 0.10076 & 0.10076 & 0.08501 & 0.08501 & 0.00581 & 0.00581 \\
\hline Garganta & 0.09989 & 0.103 & 0.08548 & 0.09 & 0.00539 & 0.00283 \\
\hline Saída & 0.064 & 0.0495 & 0.1753 & 0.2 & 0.00091 & 0 \\
\hline
\end{tabular}

Tabela 9 - Frações de massa do CFD e do CEA 


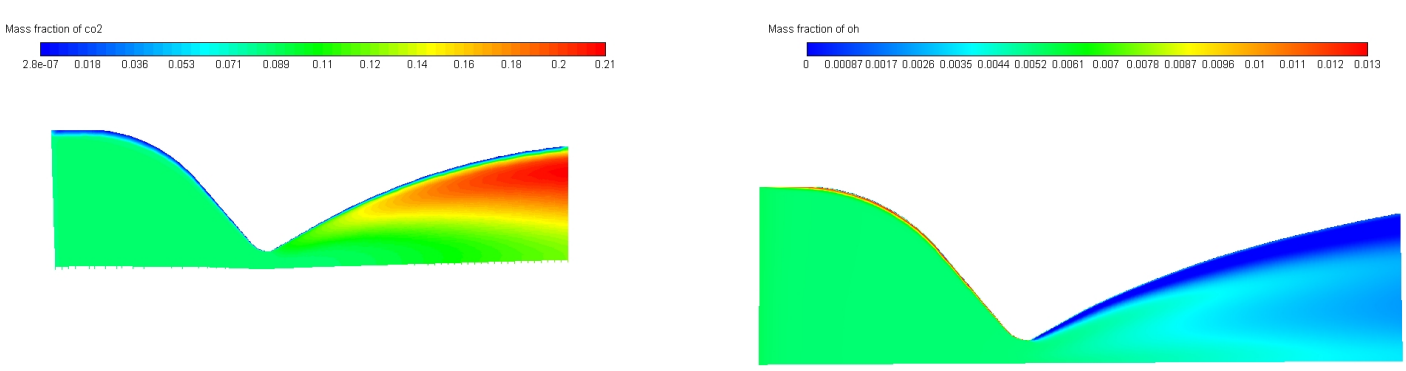

Figura $28-Y_{\mathrm{CO}_{2}}$ e $Y_{\mathrm{OH}}$ respectivamente

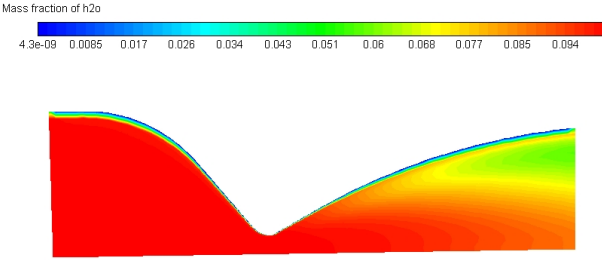

Figura $29-Y_{\mathrm{H}_{2} \mathrm{O}}$

Os resultados do Fluent concordaram bem (principalmente $\mathrm{H}_{2} \mathrm{O}$ e $\mathrm{CO}_{2}$ com os resultados com os resultados do CEA principalmente na faixa da região da garganta. É interessante notar que a faixa de interesse para erosão se encontra entre os 80 a $110 \mathrm{~mm}$ do comprimento axial da tubeira. Consequentemente, é possível a utilização dos resultados obtidos do Fluent e apresentaram uma boa aproximação com os valores de referência para o coeficiente de transferência de calor e taxa de erosão que serão tratados na próxima seção.

Outras propriedades importantes constam no Anexo B caso seja de interesse de consulta. 


\section{User-Defined Function}

O User's Defined Function, ou UDF, é uma função em linguagem de programação C que pode ser utilizada como ferramenta para personalizar condições de contorno, definir propriedades de material, especificar taxas de reação volumétrica e de superfície, modelo de turbulência e entre outras. A UDF é carregada dinamicamente com o solucionador Ansys Fluent e chamadas em horários predeterminados pelo no processo de solução.

A maneira pela qual o código fonte é compilado e o código resultante do processo de compilação será utilizado pelo modo de UDF compilada. Em resumo é criado um arquivo de biblioteca a partir do programa em $\mathrm{C}$ e depois carregado a biblioteca no Fluent como se fosse parte dele (ANSYS, 2018).

A UDF será utilizada para definir a taxa de erosão do carbono devido as reações heterogêneas de superfície alocada em uma variável de memória (UDM). A UDF será implementada para ser executada no final de cada iteração utilizando a macro DEFINE_ EXECUTE_AT_END. Assim é possível calcular as quantidades de fluxo nesses momentos específicos.

Como já dito nas seções anteriores, a taxa de erosão de cada espécie é explicitada pela equação abaixo:

$$
\dot{s}_{i}=\frac{1}{\rho_{s}} \frac{W_{s}}{W_{i}}\left(\left.\rho D_{i m} \frac{\partial y_{i}}{\partial \eta}\right|_{w}\right)
$$

Portanto as equações inseridas na UDF devem definir principalmente o fluxo de massa por difusão já que os outros termos (peso molecular da espécie e propriedades do carbono de superfície) são propriedades constantes.

Como a parede é a região de interesse para taxa de erosão, utilizaremos no código um laço de repetição que percorre apenas as faces da parede e consequentemente as células adjacente a ela, otimizando o tempo computacional. As células na parede explicitadas por um thread ${ }^{1}$ e um ID correspondente que será colocado na UDF.

Por características do Fluent, cada célula possui um conjunto de valores de propriedades tais como temperatura, pressão, velocidade aliadas a ela Esses valores são acessados por meio de macros que capturam os valores fornecidos no Fluent para que depois possam ser na UDF. Com base nisso, a sequência das equações dispostas na UDF calculadas para cada célula na parede são dadas no diagrama abaixo:

A sequência das equações na UDF são dadas no diagrama abaxo:

\footnotetext{
$\overline{1}$ Tipo de estrutura de dados que armazena um grupo de células ou face que as representam
} 


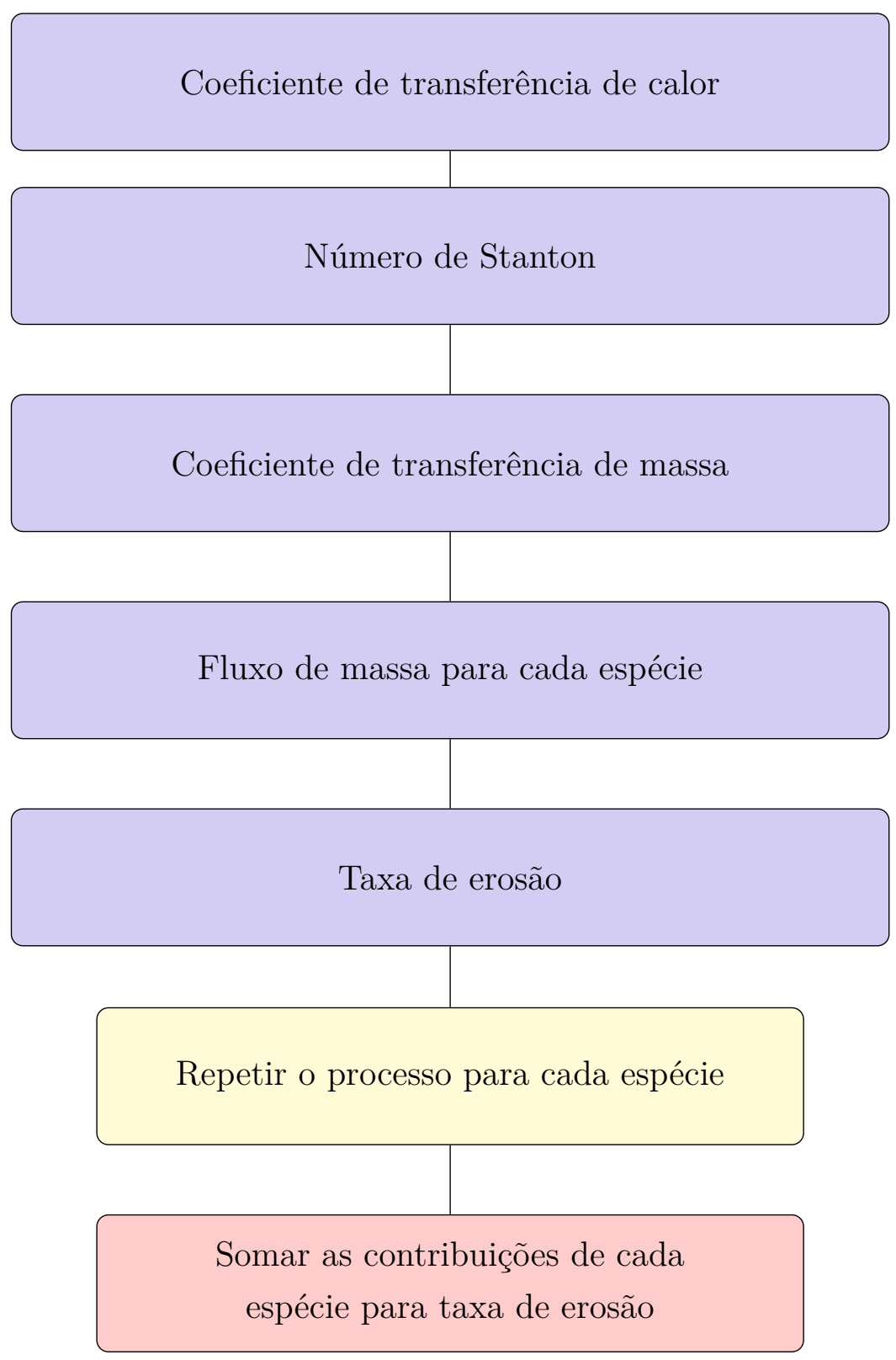

Com isso é possível obter a taxa de erosão e o deslocamento de cada célula da parede ao longo de cada iteração.

É importante notar que as propriedades termofísicas que possuem índice $e$ significam que os valores são baseados no fluxo médio da seção. Portanto para isso é usado uma função polinomial de interpolação para cada propriedade que necessite do fluxo médio ao longo da posição. As outras propriedades podem ser obtidas usando o valor disposto em cada célula ou por conta que seu valor de variação é insignificante ao longo da seção ou porque é realmente necessário usar (como por exemplo a fração de massa das espécies na parede). 


\section{Análise de resultados}

De acordo com RUFFIN(2014) e BIANCHI(2013), o modelo de ablação implementado fornece informações suficientes para:

- Estudo da variação de desempenho devido a regressão na parede principalmente na garganta.

- Dimensionamento dos materiais TPS.

Nesta seção os resultados do CFD serão comparados com os encontrados no teste experimental e no modelo analítico (Fig. 14) em relação ao transporte de espécies, distribuição de temperatura da superfície da parede, fluxo de calor e a taxa final de erosão ao longo de todo comprimento da tubeira.

O modelo de ablação termoquímica é diretamente usado em um código onde alguns parâmetros são calculados e outros fornecidos pelo Fluent. Serão utilizados e comparados o coeficiente de transferência de calor (HTC) fornecido pelo CFD através da equação de Bartz ( Eq. 3.8) e a taxa de erosão.

A equação de Bartz utiliza o conhecimento do método da camada limite turbulenta para correlacionar a transferência de calor com o fluxo de massa por unidade de área de seção transversal da tubeira. Para (SMITH,1970) essa equação pode ser usada para obter uma estimativa rápida da distribuição de transferência de calor e que apresenta bons resultados, exceto na região de entrada da tubeira com espessura fina de camada limite

Na figura 30 é apresentado o contorno do HTC obtido. Como já dito na seção 9, os valores que necessitam das propriedades de fluxo médio na seção foram obtidos através de polinômios de interpolação.

Observa-se que o HTC máximo ocorre na garganta com o valor de $4995 \mathrm{~W} / \mathrm{m}^{2} K$. Utilizou-se um fator de recuperação de 0.9 que é uma boa aproximação especialmente na garganta. 


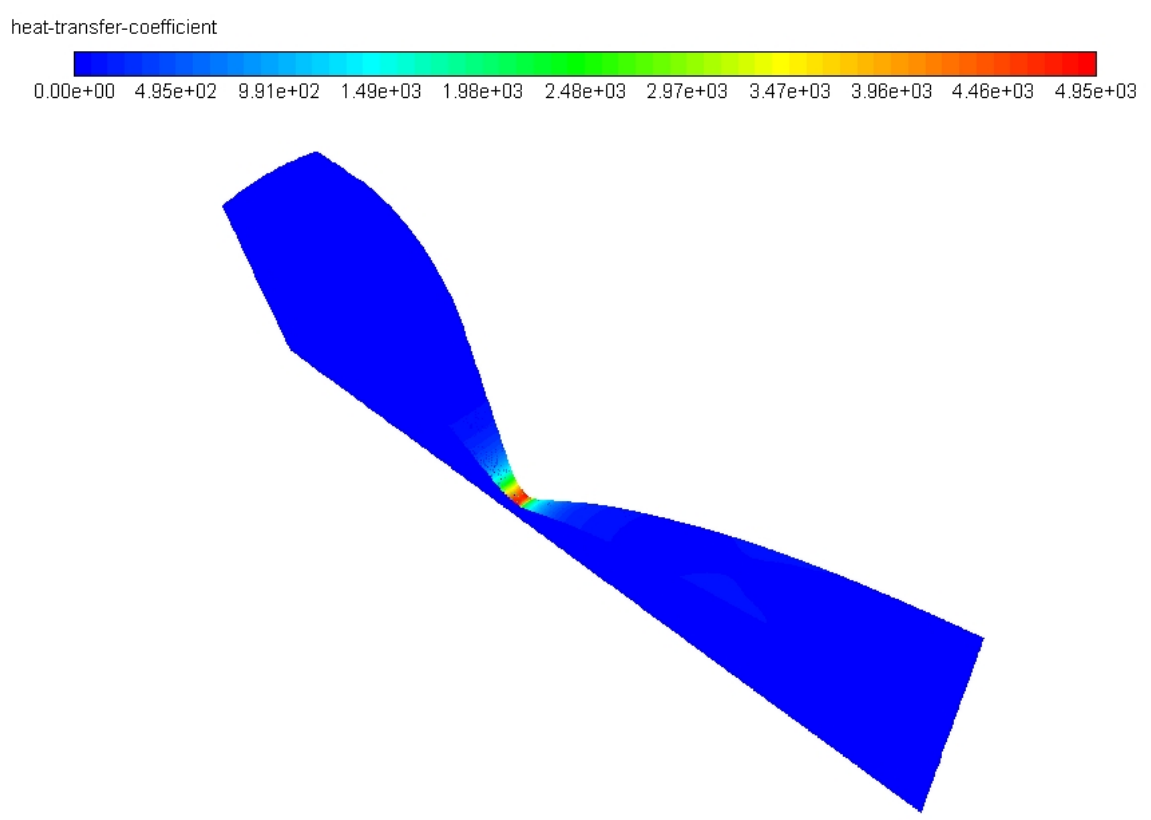

Figura 30 - Coeficiente de transferência de calor $\left[\mathrm{W} / m^{2} k\right]$ (Fonte : Elaborada pelo autor)

Como dito anteriormente, observa-se que o HTC é dominante na região da garganta. Na figura abaixo tem-se uma visualização melhor.

heat-transfer-coefficient

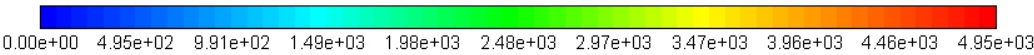

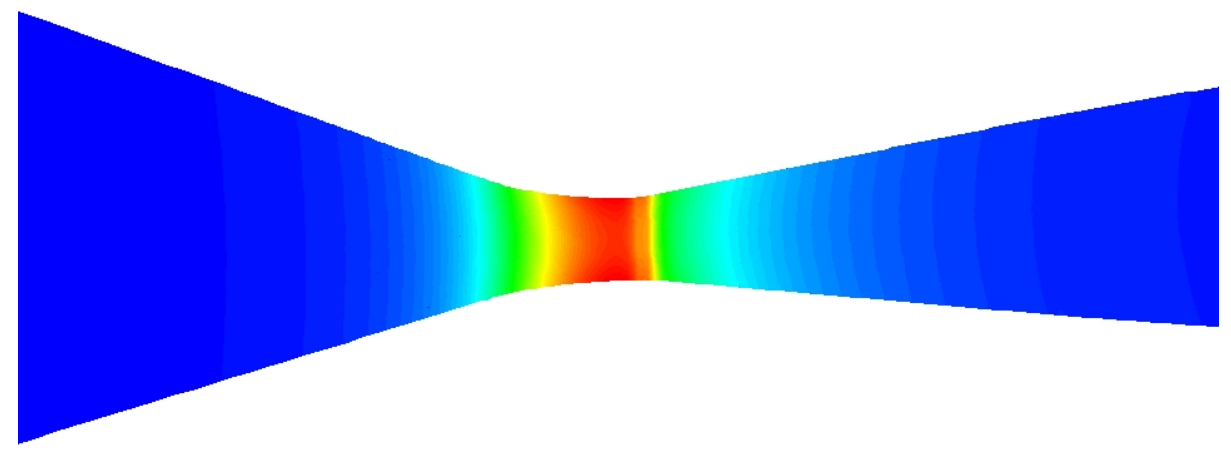

Figura 31 - Coeficiente de transferência de calor ampliado $\left[\mathrm{W} / \mathrm{m}^{2} k\right]$ (Fonte : Elaborada pelo autor)

O gráfico plotado ao longo da posição também é mostrado: 


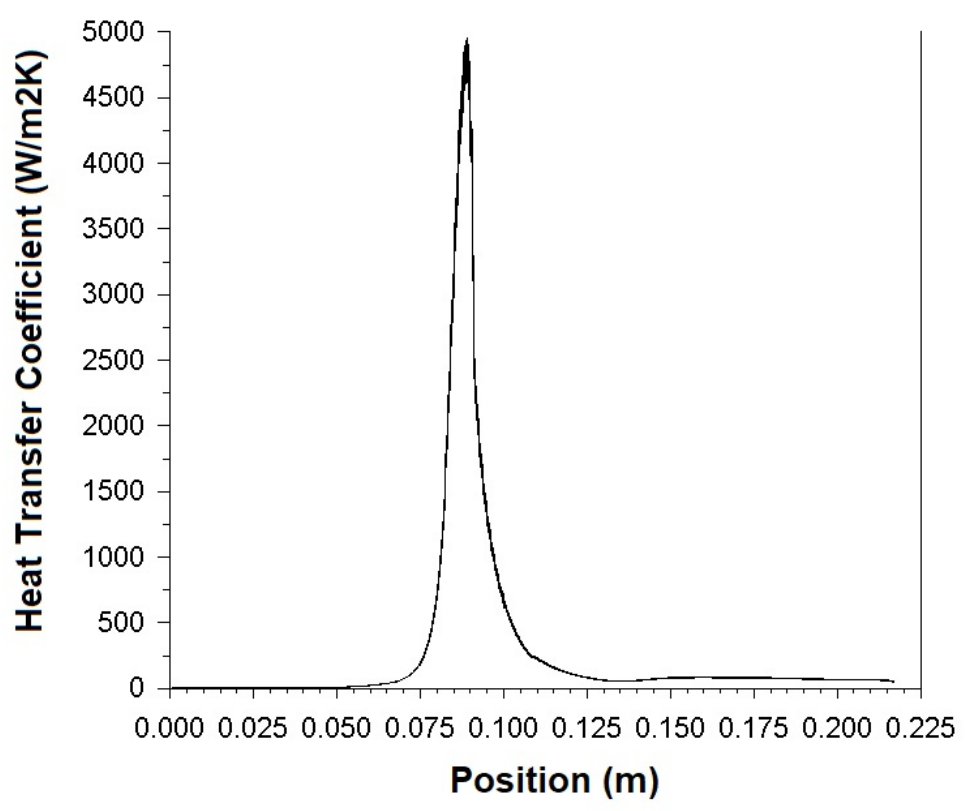

Figura 32 - Gráfico do Coeficiente de transferência de calor (Fonte : Elaborada pelo autor)

Observamos na uma linha oblíqua na figura 29 logo após a região da garganta que gera uma descontinuidade na curva, esse é um efeito de choque oblíquo. Com HTC da figura 30, foi possível observar ao longo das iterações essa mudança de inclinação na mesma coordenada e que foi suavizando até a convergência. Observa-se também que o pico ocorre na região um pouco depois da garganta com o valor $4995 \mathrm{~W} / \mathrm{m}^{2} K$. Na tabela 10 é apresentado um comparativo entre esses valores com o que foi obtido no modelo analítico implementado no código do Matlab.

\begin{tabular}{|c|c|}
\hline Método & Na garganta $\left(\mathbf{W} / \mathrm{m}^{2} \mathbf{K}\right)$ \\
\hline Analítico & $5.88 \cdot 10^{3}$ \\
\hline Bartz via UDF & $4.95 \cdot 10^{3}$ \\
\hline
\end{tabular}

Tabela 10 - Comparativo entre os HTC

A diferença relativa entre os picos é de $15 \%$. Outra maneira utilizada, é que o Fluent pode calcula diretamente o fluxo de calor nos contornos. Sabe-se que o HTC é uma quantidade derivada usando uma temperatura de referência que consiste na temperatura da célula próxima à parede, a temperatura do fluido adjacente e o fluxo de calor. Nota-se que o modelo de turbulência impacta na espessura da camada limite térmica e, portanto, no valor HTC do Fluent. Uma alternativa usada é obter um pequeno y+ de modo a obter uma melhor performance do HTC. 
Os resultados para taxa de erosão são apresentados abaixo. Primeiramente é apresentado os contornos dos valores de erosão que são armazenados em uma unidade de memória (User Memory 0) representados em m/s.

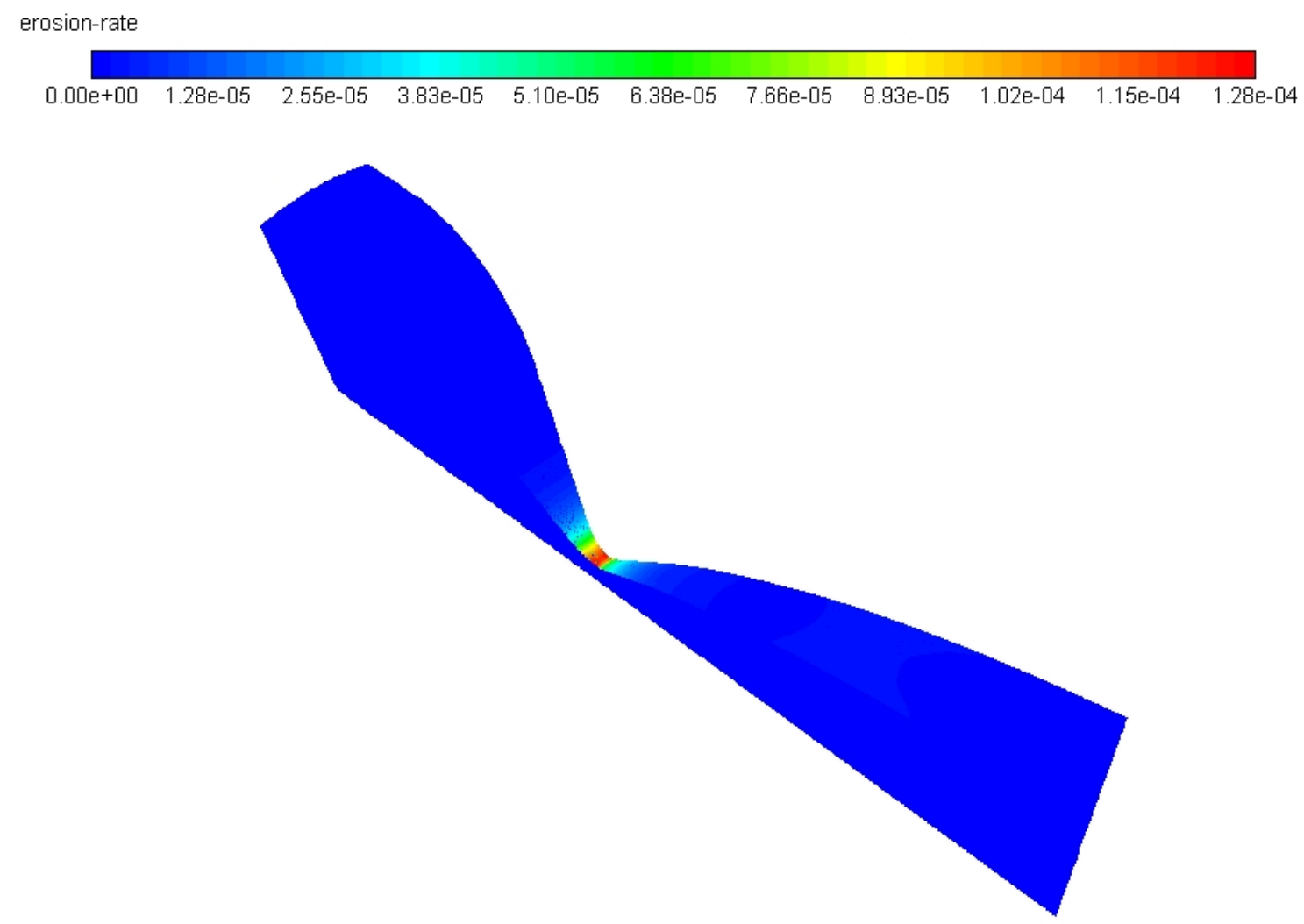

Figura 33 - Taxa de erosão [m/s] (Fonte : Elaborada pelo autor)

A distribuição da taxa de erosão termoquímica utilizando o HTC do CFD é mostrada na figura 33. Observamos que a taxa de erosão imita a do HTC na parede e consequentemente o fluxo de calor na superfície ao longo de todo o comprimento, indicando uma correlação direta entre as duas quantidades. Isso também é notado por THAKRE(2008) e BIANCHI(2009).

Assim como acontece com o modelo analítico, a taxa de erosão máxima se encontra um pouco atrás da garganta. Não é mostrado na figura, mas importante frisar que o $\mathrm{H}_{2} \mathrm{O}$ é a espécie oxidante mais importante para a erosão. A molécula de $\mathrm{CO}_{2}$ apresenta uma quantidade de frações de massa na parede razoável na parede, mas sua contribuição é reduzida devido seu alto peso molecular quando comparado ao $\mathrm{H}_{2} \mathrm{O}$. A molécula de $\mathrm{OH}$ apesar do baixo molecular apresenta uma contribuição pequena devida ao reduzida $Y_{w}$. O contorno ampliado é mostrado na Fig. 34 


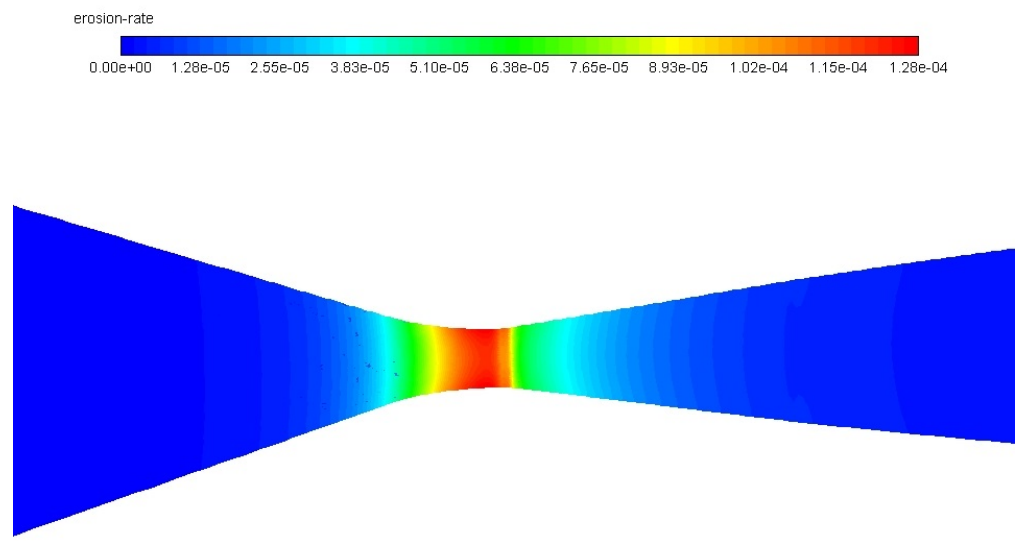

Figura 34 - Taxa de erosão ampliada [m/s] (Fonte : Elaborada pelo autor)

O gráfico da taxa de erosão utilizando a equação de Bartz é dada na figura 35.

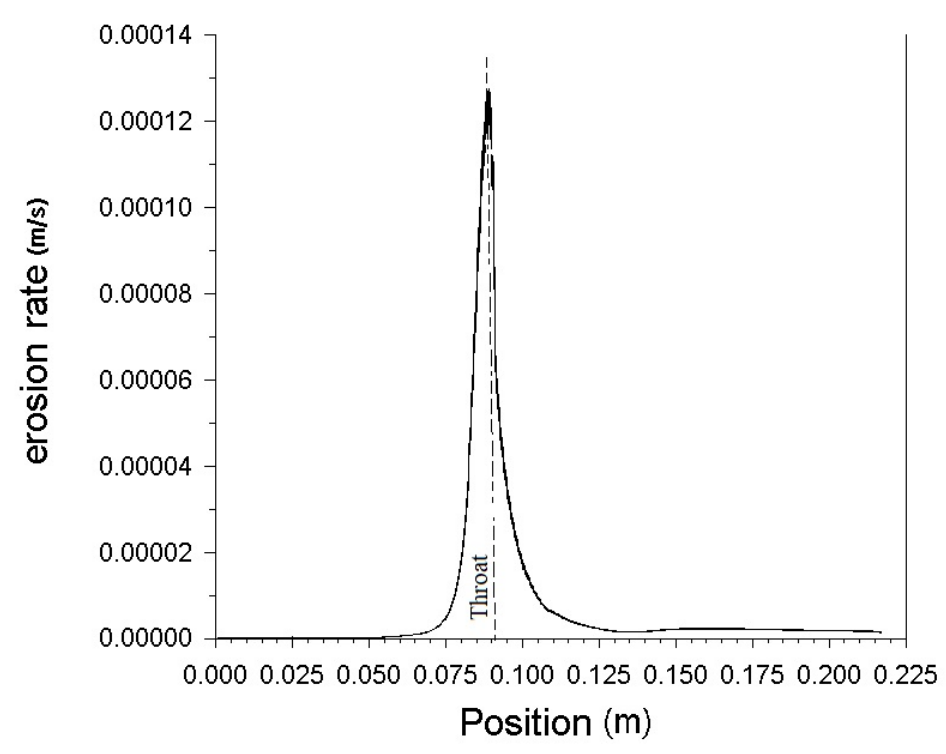

Figura 35 - Gráfico da taxa de erosão ao longo da posição (Fonte : Elaborada pelo autor)

É apresentado uma tabela com as taxas de erosão obtida pelos dois modelos de código CFD e o modelo analítico.

\begin{tabular}{|c|c|}
\hline Método & Na garganta $(\mathrm{mm} / \mathbf{s})$ \\
\hline Analítico & 0.135 \\
\hline CFD & 0.128 \\
\hline
\end{tabular}

Tabela 11 - Comparativo da taxa de erosão 
É importante ressaltar que no teste de bancada experimental não ouve medição da regressão na garganta, apenas $86.4 \mathrm{~mm}$ da tubeira que resultou em um $\dot{s}$ de aproximadamente $0.12 \mathrm{~mm} / \mathrm{s}$. As taxas de erosão resultaram em valores com boa precisão (em torno de 5.1\%). Para todas as formulações de propulsores, os erros relativos avaliados resultam em excesso de previsão e menor que $15 \%$. Assim como já explicado no capítulo 6 , o erros associados podem ser decorrentes (RUFFIN, 2014), (BIANCHI, 2009):

- Erros relacionados ao método usado para estimar o HTC.

- Os parâmetros utilizados na reações de superfície.

- O modelo implementando consiste para situações de voo. No teste experimental observou-se a ocorrência de uma onda de choque no interior da tubeira devido a diferença de pressão na saída da tubeira e a pressão ambiente.

- O modelo implementado simplificou para um material de superfície non charring, o material de fato utilizado possuem é em parte de sua composição cerâmico.

- Dados termoquímicos referente a composição da mistura nos propelentes

- Considerou-se uma pressão média efetiva de 30 bar e uma razão de mistura de 5.5. Os dois são parâmetros influenciam altamente na taxa de erosão e nos dados de entrada do setup do fluent.

- Considerou-se apenas três reações volumétricas na parede que geram o monóxido de carbono

- O modelo de turbulência impacta diretamente no fluxo de calor por convecção. 
Parte IV

\section{Conclusões}





\subsection{Considerações Finais}

Foi implementado um método para prever a taxa de erosão do foguete híbrido SARA, por um modelo de ablação termoquímica limitados a materiais ablativos não carbonizados. Para o seu desenvolvimento, foram considerados diferentes fenômenos físicos e químicos envolvendo: composição química de equilíbrio, propriedades termodinâmicas e de transporte, transferência de calor convectivo e condutor, difusividade da fase gasosa através da camada limite, reação heterogênea na superfície e massa e balanços de energia. Como resultado obteve - se como previsto uma taxa de erosão nas regiões próximas a garganta e taxas praticamente nula em seções longe da garganta, o que foi confirmado com as medições experimentais.

Quando analisado o comportamento para diferentes razões de mistura, mostrou -se uma dependência cada vez maior do oxigênio molecular na taxa de erosão a medida que era aumentada a razão $\mathrm{O} / \mathrm{F}$. O vapor de água é a espécie oxidante com maior contribuição com mais de $40 \%$ em todas as variações testadas. Como dito no capítulo 6 observou-se que algumas espécies foram limitadas cineticamente e outras limitadas por difusão.

A simulação tridimensional foi modelada seguindo os mesmo critérios do modelo do analítico. Foi implementado o modelo de transporte de espécies com as propriedades termodinâmicas e de composição química. Obteve-se uma boa aproximação com os valores do CEA. O tratamento dado a parede requeriu uma malha suficientemente refinada para as reações heterogêneas de superfície. E por fim foi aplicado juntamente uma UDF para o cálculo da taxa de erosão ao longo das iterações. Observou-se que os valores do coeficiente de transferência de calor ao longo da seção apresentaram boa aproximação com a equação de Bartz devido ao modelo de turbulência empregado. A taxa de erosão foi calculada somando a contribuição das três espécies oxidantes que mais reagem com o carbono de superfície para a produção de monóxido de carbono. Os resultados apresentaram boa aproximação com o teste de bancada variando em menos $0.017 \mathrm{~mm} / \mathrm{s}$ com os modelos aplicados neste trabalho.

O que interessa é a partir das condições de operação impostas em um foguete, determinar uma faixa de valor aceitável de regressão ou corrosão na parede que não necessariamente precise ser tão precisa, mas que possa ajudar no dimensionamento da taxa de erosão para previsão da resposta ablativa do material TPS e no projeto desses materiais em tubeiras

\subsection{Trabalhos Futuros}

Para a continuação do trabalho pode ser interesse de estudo:

- Adicionar mais espécies oxidantes nas reações heterogêneas. 
- Aplicar uma UDF para descrição das reações de superfície.

- Estudar os efeitos e impactos do aumento de pressão na câmara de combustão.

- Aplicar os efeitos de radiação no balanço de energia.

- Considerar a erosão mecânica devido ao impacto das partículas na superfície da parede.

- Pode-se estudar a variação das frações de massa na parede em uma seção ao longo do tempo de operação.

- Pode-se estudar a variação das frações de massa na parede em uma seção ao longo do tempo de operação. 


\section{Referências}

ANSYS FLUENT TUTORIAL GUIDE. Canonsburg, PA 15317, 2018. Citado 7 vezes nas páginas $77,79,80,82,84,85$ e 91 .

BARTZ, D. A Simple Equation for Rapid Estimation of Rocket Nozzle Convective Heat Transfer Coefficients. Jet Propulsion Laboratory California Institute of Technology, Pasadena, Cal: NASA RP-1311, 1957. Disponível em: <DOI:10.2514/8.12572>. Citado na página 49.

BIANCHI. Modeling of ablation phenomena in space applications (ph.d. thesis). 2006. Citado na página 42.

BIANCHI. Coupled analysis of flow and surface ablation in carbon-carbon rocket nozzles. p. 9, 2009. Citado 3 vezes nas páginas 53, 96 e 98.

BIANCHI. Numerical analysis of nozzle material thermochemical erosion in hybrid rocket engines. p. 12, 2013. Citado 20 vezes nas páginas 15, 27, 28, 34, 38, 44, 45, 47, $50,52,53,54,63,69,71,72,80,85,93$ e 117.

CANTWELL, B. J. AIRCRAFT AND ROCKET PROPULSION. [S.l.]: Willey, 2010. Citado na página 34.

CHARRING. Disponível em: < https://howlingpixel.com/i-en/Charring > . Acesso em: junho 2019. Citado na página 37.

DELENEY, L. A semiquantitative prediction of the erosion of graphite nozzle inserts. AIAA, 1964. Disponível em: <https://doi.org/10.2514/3.2570>. Citado na página 43.

FAROKHI, S. Aircraft Propulsion. [S.l.]: John Wiley Son, 2014. v. 2. 821-897 p. Citado na página 35.

FERZIGER, M. P. J. H. Computational Methods for Fluids Dynamics. [S.l.]: Springer, 2002. v. 3. 23-89 p. Citado na página 77.

GEISLER, R. L.; BECKMAN, C. W. The history of the bates motors at the air force rocket propulsion laboratories. 1998. Disponível em: < https://arc.aiaa.org/doi/10.2514/ 6.1998-3981>. Citado na página 117.

GORDON, S.; MCBRIDE, B. J. Computer Program for Calculation of Complex Chemical Equilibrium Compositions and Applications. [S.l.]: NASA RP-1311, 1994. Citado 5 vezes nas páginas 35, 41, 44, 45 e 61 .

HOW Do Hybrid Rocket Motors Work. 2019. Disponível em: < https://sites.google. $\mathrm{com} /$ site/pennhybridrocket/how-do-hybrid-rocket-motors-work $>$. Citado 2 vezes nas páginas 33 e 34.

IAE lançará o SARA Suborbital I até novembro. 2019. Disponível em: < http: //www.ita.br/noticias/iaelanarosarasuborbitaliatnovembro $>$. Citado na página 38. 
JACOB, E. The effect of oxidizer laced hybrid rocket regression rates and performance. 2007. Citado na página 34.

KUO, K. K. Applications of Turbulent and Multiphase Combustion. [S.l.]: Willey, 2012. Citado 5 vezes nas páginas 27, 43, 50, 51 e 52.

MARTELLI, E. Studio della uidodinamica interna di ugelli propulsivi di tipo dual bell. 2006. Citado 2 vezes nas páginas 41 e 42.

NIST Chemistry WebBook. [s.n.], 2011. Disponível em: <http://webbook.nist.gov/ chemistry/>. Citado na página 46.

PANELLI, M. Numerical prediction of nozzle ablation in hybrid rocket engine. AIAA, 2015. Disponível em: <https://doi.org/10.2514/1.B34813>. Citado 2 vezes nas páginas 27 e 28.

RUFFIN, A. Numerical investigation of nozzle thermochemical behaviour in hybrid rocket motors. 2014. Citado 13 vezes nas páginas 15, 37, 38, 44, 46, 47, 48, 51, 63, 71, 79,93 e 98.

SARGENT, R. Verification and validation of simulation models. p. 17, 2011. Citado na página 87.

SATYAJIT, C. A Textbook of Engineering Thermodynamics. [S.l.]: Vikas, 2014. Citado na página 52.

SHAH, A. Design and prototyping of a solid fuel/liquid oxidizer hybrid rocket engine. 2016. Disponível em: <https://www.researchgate.net/publication/313798269_Design_ and_Prototyping_of_a_Solid_FuelGaseous_Oxidizer_Hybrid_Rocket_Engine $>$. Citado 2 vezes nas páginas 15 e 33.

SHYNKARENKO, O. Design of a composite nozzle manufactured by filament winding. In: MACMS. [S.l.: s.n.], 2015. Citado 3 vezes nas páginas 15, 60 e 61.

SHYNKARENKO O.; ANDRIANOV, A. Concept and design of the hybrid test-motor for the development of a propulsive decelerator of sara reentry capsule. AIAA, 2015.

Disponível em: < https://doi.org/10.2514/6.2015-3941>. Citado 7 vezes nas páginas 15, $28,29,38,39,59$ e 61 .

SMITH, D. M. A comparison of experimental heat transfer coefficients in a nozzle with analytical predictions from bartz's methods for various combustion chamber pressures in a solid propellant rocket motor. p. 99, 1970. Disponível em: <https://ntrs.nasa.gov/search.jsp?R=19710011726>. Citado na página 93.

SUTTON, G. P. Rocket propulsion elements. 2001. Citado 7 vezes nas páginas 15, 27, $33,34,35,36$ e 59 .

THAKRE, P. Chemical erosion of carbon-carbon/graphite nozzles in solid-propellant rocket motors. p. 12, 2008. Disponível em: <DOI:10.2514/1.34946>. Citado 6 vezes nas páginas 37, 38, 43, 52, 54 e 96 .

THIRUMURTHY, D. Preliminary design and computational analysis of an ejector nozzle with chevrons. p. $1-17,2011$. Citado na página 82. 
TRANSFERÊNCIA DE CALOR POR CONVECÇÃO. Disponível em: < http: //professor.unisinos.br/jcopetti/transcal_ppg/conveccao_introd.pdf $>$. Acesso em: maio 2019. Citado na página 48.

TURCHI, A. Radiation and roughness effects on the thermochemical erosion of ablative materials in rocket nozzles. AIAA, 2013. Disponível em: < https: //doi.org/10.2514/6.2013-186>. Citado 2 vezes nas páginas 28 e 54.

VERSTEEG, W. M. H. K. An Introduction to Computational Fluid Dynamics. [S.1.]: Pearson Education, 1995. v. 2. 1 - 10 p. Citado 2 vezes nas páginas 77 e 78.

ÇENGEL, M. A. B. Y. A. Termodinâmica. [S.l.]: Bookman, 2013. v. 7. Citado na página 46. 

Apêndices 



\section{APÊNDICE A - Primeiro Apêndice}

$$
\begin{gathered}
\dot{m}_{i}=k_{j} p_{i}^{n_{j}} \\
\dot{k}_{j}=A_{j} T_{\omega}^{{ }^{b_{j}}} \exp \left(-E_{j} / R T_{\omega}\right) \\
\dot{m}_{\mathrm{O}_{2}}=\frac{k_{5} p_{\mathrm{O}_{2}} Y}{1+k_{6} Y}+k_{7} p_{\mathrm{O}_{2}}(1-Y) \\
Y=\left(1+\frac{k_{8}}{k_{7} p_{\mathrm{O}_{2}}}\right)
\end{gathered}
$$

- $T_{w}$ : Temperatura da parede em $\mathrm{K}$

- $p_{i}$ : Pressão parcial da espécie i. É calculada como $X_{i} \cdot p$

- $k_{j}$ : Constante de taxa específica

- $A_{j}$ : Fator pré exponencial

\begin{tabular}{|c|c|c|c|c|c|}
\hline Reação de superfície & $\mathbf{j}$ & $A_{j}$ & $E_{j}, \mathrm{kJmol}$ & $b_{j}$ & $n_{j}$ \\
\hline $\mathrm{Cs}+\mathrm{H}_{2} \mathrm{O} \rightarrow \mathrm{CO}+\mathrm{H}_{2}$ & 1 & $4.8 \times 10^{5}$ & 288 & 0 & 0.5 \\
\hline $\mathrm{Cs}+\mathrm{CO}_{2} \rightarrow 2 \mathrm{CO}$ & 2 & 9000 & 285 & 0 & 0.5 \\
\hline $\mathrm{Cs}+\mathrm{OH} \rightarrow \mathrm{CO}+\mathrm{H}$ & 3 & 361 & 0 & -0.5 & 1 \\
\hline $\mathrm{Cs}+\mathrm{O} \rightarrow \mathrm{CO}$ & 4 & 665.5 & 0 & -0.5 & 1 \\
\hline \multirow{4}{*}{$\mathrm{Cs}+\frac{1}{2} \mathrm{O}_{2} \rightarrow \mathrm{CO}$} & 5 & 2400 & 125.6 & 0 & \\
\hline & 6 & 23.1 & -17.17 & 0 & \\
\hline & 7 & 0.535 & 63.64 & 0 & \\
\hline & 8 & $1.87 \times 10^{7}$ & 406.1 & 0 & \\
\hline
\end{tabular}

- $E_{j}$ : Energia de ativação

- $b_{j}$ : Expoente de temperatura

- $R$ : Constante universal dos gases : $8.31 \mathrm{~J} / \mathrm{mol} . \mathrm{K}$

Tabela 12 - Constantes heterogêneas e reações do grafite com $\mathrm{H}_{2} \mathrm{O}, \mathrm{CO}_{2}, \mathrm{OH}, \mathrm{O}$ e $\mathrm{O}_{2}$ 



\section{APÊNDICE B - Segundo Apêndice}

Os termos de taxa de produção das espécies $i$ na fase gasosa devido os produtos injeção na equação 3.13 em função do fluxo de massa é definido como:

$$
\begin{gathered}
\dot{\omega}_{\mathrm{CO}}=\dot{m}_{\mathrm{H}_{2} \mathrm{O}}\left(W_{\mathrm{CO}} / W_{\mathrm{C}}\right)+\dot{m}_{\mathrm{CO}_{2}}\left(2 W_{\mathrm{CO}} / W_{\mathrm{C}}\right)+\dot{m}_{\mathrm{OH}}\left(W_{\mathrm{CO}} / W_{\mathrm{C}}\right) \\
\dot{\omega}_{\mathrm{CO}_{2}}=-\dot{m}_{\mathrm{CO}_{2}}\left(W_{\mathrm{CO}_{2}} / W_{\mathrm{C}}\right) \\
\dot{\omega}_{\mathrm{H}_{2} \mathrm{O}}=-\dot{m}_{\mathrm{CO}_{2}}\left(W_{\mathrm{H}_{2} \mathrm{O}} / W_{\mathrm{C}}\right) \\
\dot{\omega}_{\mathrm{OH}}=-\dot{m}_{\mathrm{OH}}\left(W_{\mathrm{OH}} / W_{\mathrm{C}}\right) \\
\dot{\omega}_{\mathrm{H}_{2}}=\dot{m}_{\mathrm{H}_{2} \mathrm{O}}\left(W_{\mathrm{H}_{2}} / W_{\mathrm{C}}\right) \\
\dot{\omega}_{\mathrm{H}}=-\dot{m}_{\mathrm{OH}}\left(W_{\mathrm{H}} / W_{\mathrm{C}}\right) \\
\dot{\omega}_{\mathrm{HCl}}=\dot{\omega}_{\mathrm{N}_{2}}=0
\end{gathered}
$$





\section{APÊNDICE C - Terceiro Apêndice}

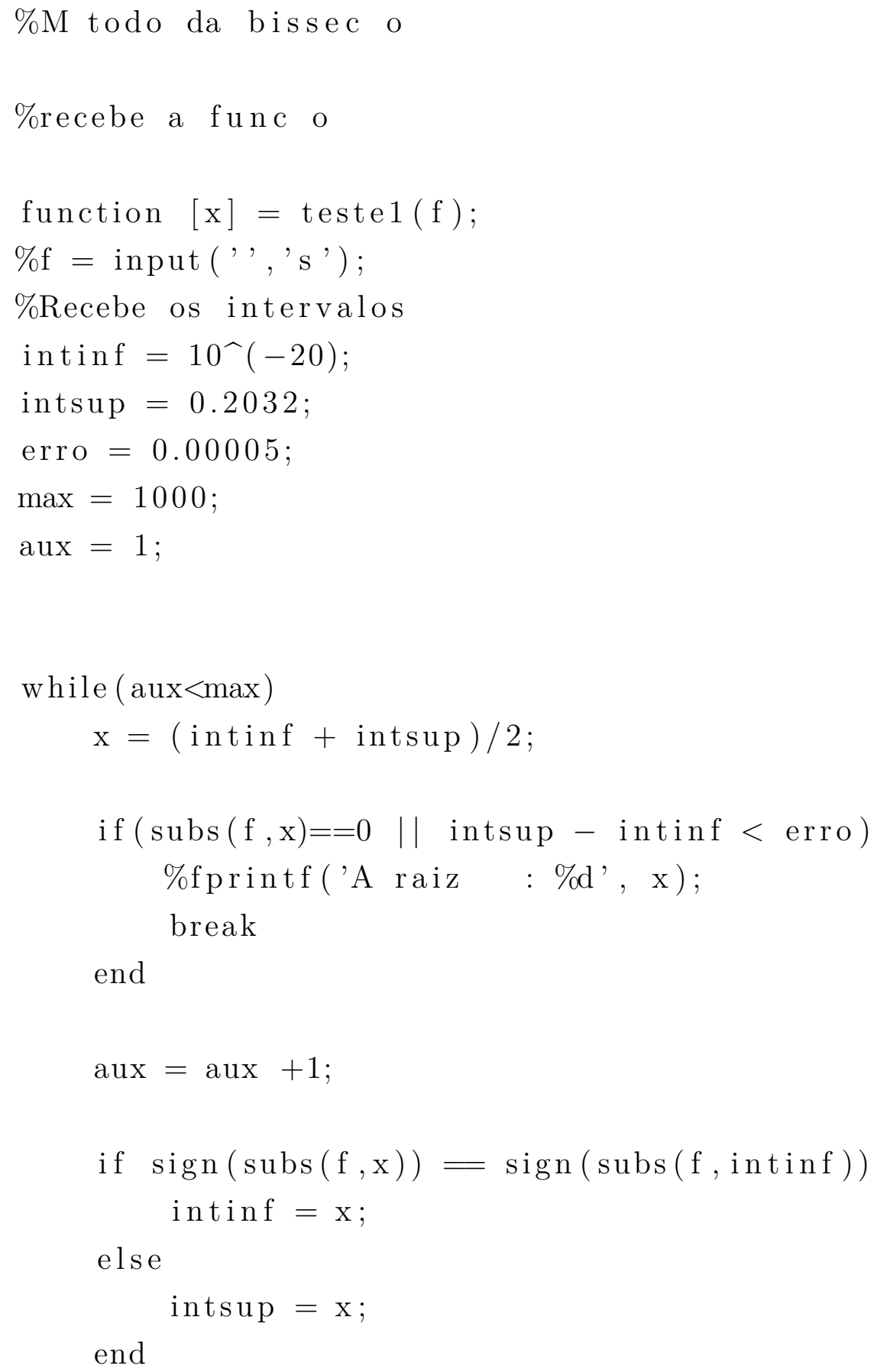

end

end 

Anexos 



\section{ANEXO A - Validação do Modelo}

A validação consistiu em utilizar o modelo de ablação termoquímica para determinar a taxa de erosão para a formulação de propelentes e geometria da tubeira utilizada no BATES ${ }^{1}$ e resultados fornecidos em (BIANCHI, 2013). Em resumo a tubeira possui um raio da garganta de $2,54 \mathrm{~cm}$, com um seção convergente de $45^{\circ}$ e uma seção divergente cônica de $15^{\circ}$.

Foi escolhido cerca de três tipos combinações de propelentes : WAX - $\mathrm{N}_{2} \mathrm{O}$, WAX - $\mathrm{O}_{2}$, WAX - $\mathrm{N}_{2} \mathrm{O}_{4}$, utilizando um $\phi=1$ e pressão na câmara de 10 bar. As composições químicas e temperatura da câmara de combustão que estão dadas em BIANCHI estão expressas abaixo:

\begin{tabular}{|c|c|c|c|}
\multicolumn{1}{l|}{} & WAX $-\mathbf{N}_{\mathbf{2}} \mathbf{O}$ & WAX $-\mathbf{O}_{\mathbf{2}}$ & WAX $-\mathbf{N}_{\mathbf{2}} \mathbf{O}_{\mathbf{4}}$ \\
\hline$T_{c}, \mathrm{~K}$ & 3230.59 & 3468.71 & 3295.53 \\
\hline $\mathrm{CO}_{2}, \%$ & 13.54 & 28.70 & 25.04 \\
\hline $\mathrm{H}_{2} \mathrm{O}, \%$ & 9.37 & 20.66 & 16.80 \\
\hline $\mathrm{OH}, \%$ & 2.47 & 7.45 & 4.37 \\
\hline $\mathrm{O}_{2}, \%$ & 4.33 & 13.12 & 7.99 \\
\hline $\mathrm{O}, \%$ & 0.85 & 3.00 & 1.42 \\
\hline
\end{tabular}

Tabela 13 - BATES Motor

Com esses dados, foi aplicado o modelo de ablação desenvolvido no capítulo 5 e comparado os dados da referência. Após implementação do método, obteve-se as seguintes taxas de erosão.

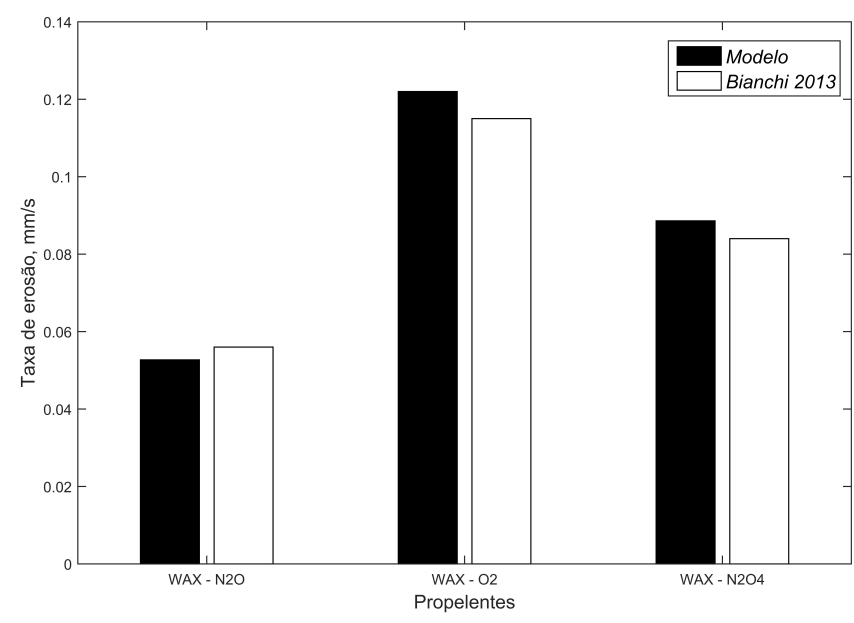

Figura 36 - Resultados calculados e obtidos pela referência (Fonte : Elaborada pelo autor)

$\overline{1}$ Os principais parâmetros geométricos relatados em (GEISLER; BECKMAN, 1998) 



\title{
B ANEXO B - Resultados do fluxo
}

\author{
Wall Temperature

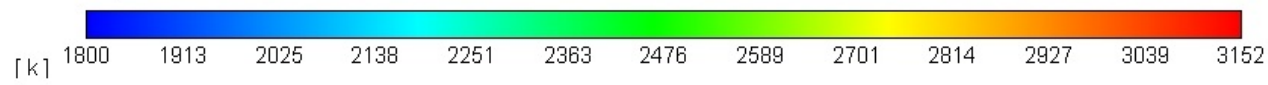

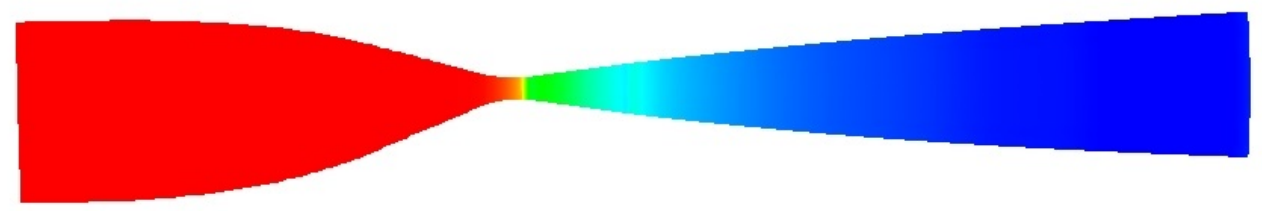

Figura 37 - Temperatura da parede $[\mathrm{K}]$
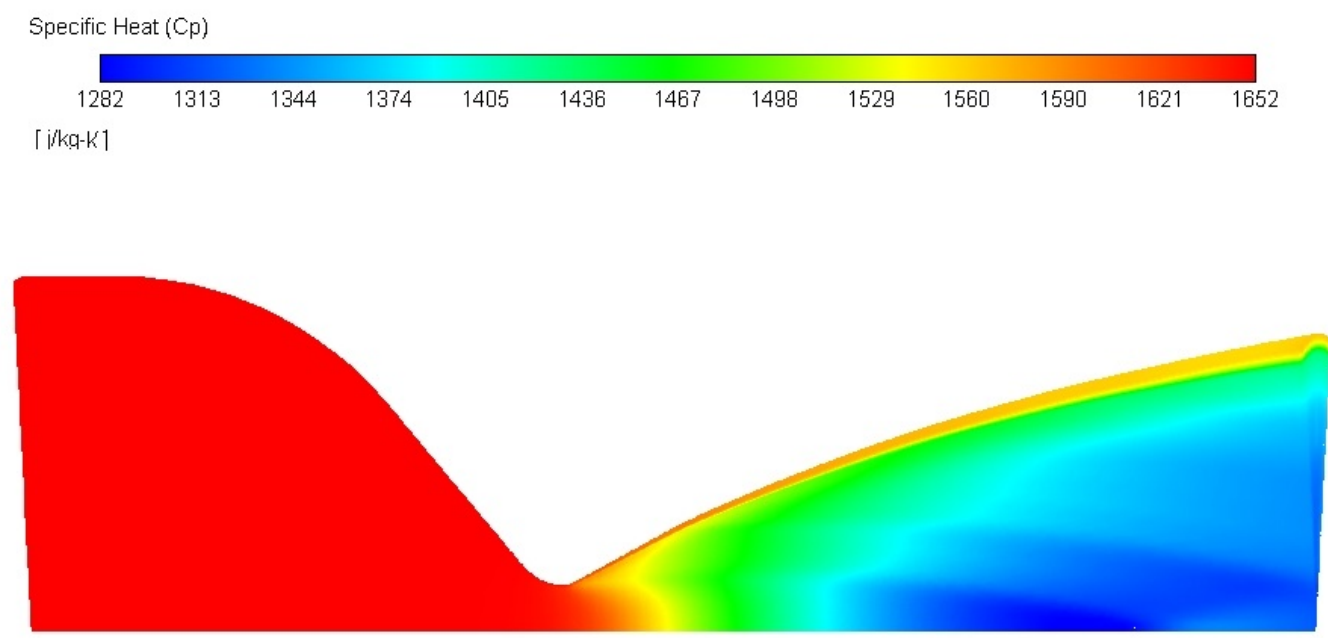

Figura 38 - Calor específico $[\mathrm{J} / \mathrm{kg}-\mathrm{K}]$ 

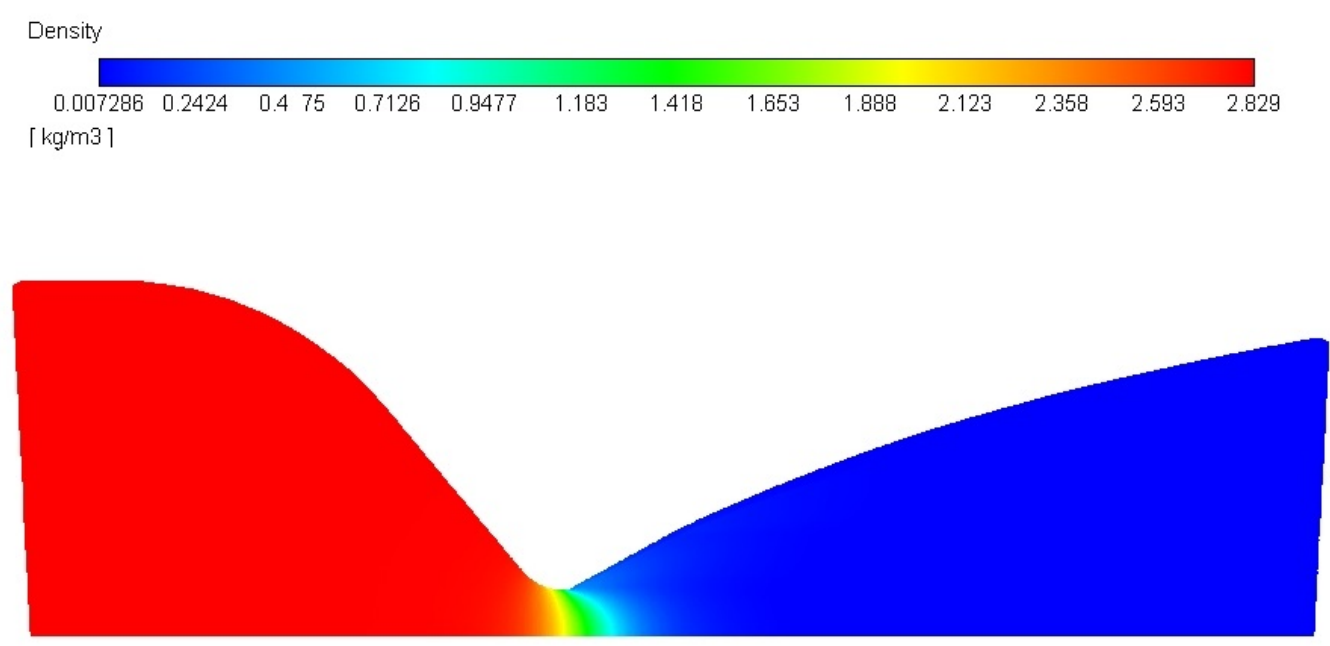

Figura 39 - Densidade $\left[\mathrm{kg} / \mathrm{m}^{3}\right]$

Molecular Prandtl Number
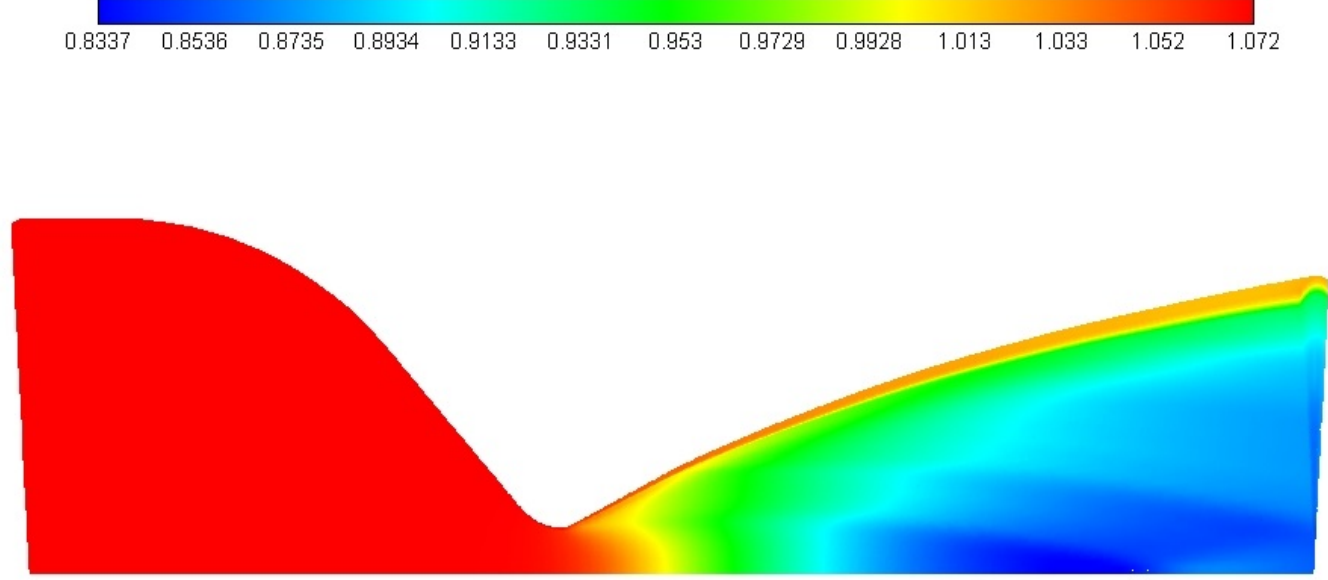

Figura 40 - Número de Pradtl 


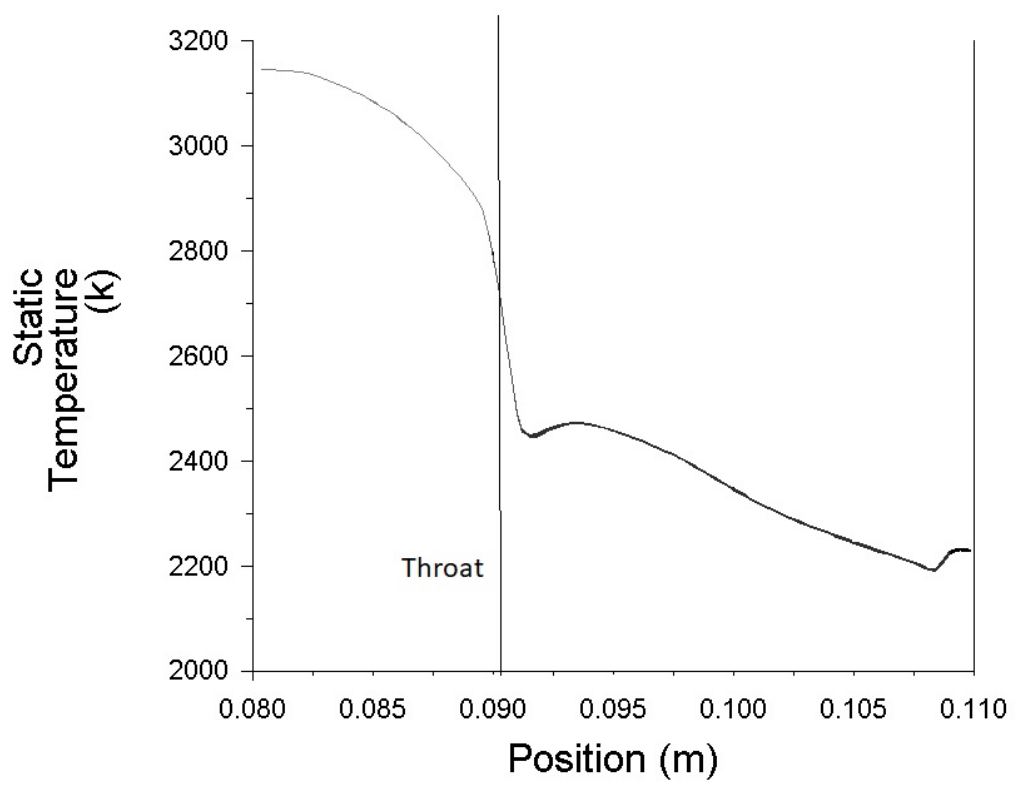

Figura 41 - Temperatura da parede ao longo do comprimento axial

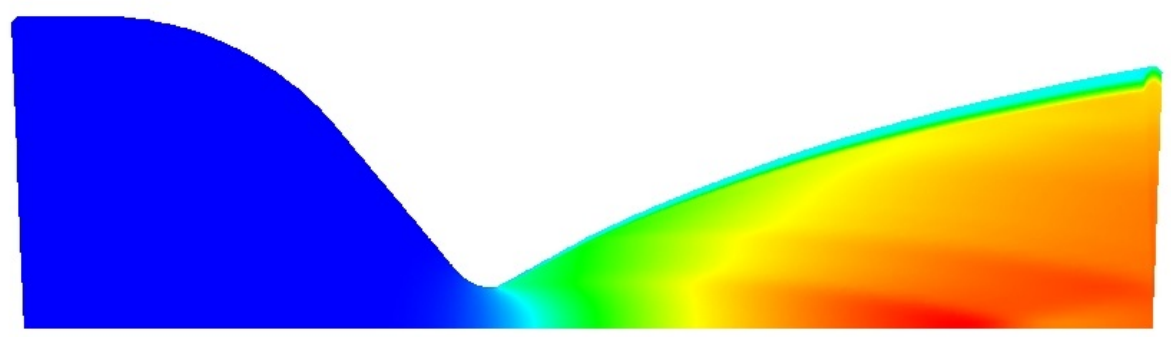

Figura 42 - Número de Mach 